\title{
Revision of Oligo-Miocene kangaroos, Ganawamaya and Nambaroo (Marsupialia: Macropodiformes, Balbaridae)
}

\author{
Kaylene Butler, Kenny J. Travouillon, Gilbert J. Price, \\ Michael Archer, and Suzanne J. Hand
}

\begin{abstract}
The generic and specific status of fossil kangaroo specimens attributed to Nambaroo and Ganawamaya from the Riversleigh World Heritage Area, Australia, are revised and new material is described. Results indicate that the previously proposed 12 species (eight of Nambaroo and four of Ganawamaya) represent four species from a single genus (Ganawamaya). Previous studies distinguished species of Ganawamaya from Nambaroo in lacking a protostylid on the lower first molar. However, our analyses indicate that the apparent presence/absence of the protostylid is related to the degree of dental wear, being totally worn in older individuals. Unworn specimens from Riversleigh were previously typically attributed to Nambaroo, while worn specimens were most commonly attributed to Ganawamaya. With support from phylogenetic analyses, we refer Riversleigh's N. couperi and N. gillespieae to Ganawamaya. The diagnoses of both genera are revised. We also assign undescribed specimens from the Ngapakaldi Quarry and Leaf Locality, South Australia, to Gan. couperi comb. nov. and Gan. acris, respectively, and describe new material of Gan. acris and Gan. aediculis.
\end{abstract}

Kaylene Butler. School of Earth Sciences, University of Queensland, St Lucia, Queensland 4072, Australia. kaylene.butler@uqconnect.edu.au

Kenny J. Travouillon. School of Earth Sciences, University of Queensland, St Lucia, Queensland 4072, Australia; Western Australian Museum, Locked Bag 49, Welshpool DC, Western Australia 6986, Australia. k.travouillon@uq.edu.au; Kenny.Travouillon@museum.wa.gov.au

Gilbert J. Price. School of Earth Sciences, University of Queensland, St Lucia, Queensland 4072, Australia. g.price1@uq.edu.au

Michael Archer. PANGEA Research Centre, School of Biological, Earth and Environmental Sciences, University of New South Wales Australia, New South Wales 2052, Australia. m.archer@unsw.edu.au Suzanne J. Hand. PANGEA Research Centre, School of Biological, Earth and Environmental Sciences, University of New South Wales Australia, New South Wales 2052, Australia. s.hand@unsw.edu.au

Butler, Kaylene, Travouillon, Kenny J., Price, Gilbert J., Archer, Michael, and Hand, Suzanne J. 2018. Revision of Oligo-Miocene kangaroos, Ganawamaya and Nambaroo (Marsupialia: Macropodiformes, Balbaridae). Palaeontologia Electronica 21.1.8A 1-58. https://doi.org/10.26879/747

palaeo-electronica.org/content/2018/2095-revision-of-oligo-miocene-kangaroos

Copyright: March 2018 Palaeontological Association

This is an open access article distributed under the terms of Attribution-NonCommercial-ShareAlike 4.0 International (CC BY-NC-SA 4.0 ), which permits users to copy and redistribute the material in any medium or format, provided it is not used for commercial purposes and the original author and source are credited, with indications if any changes are made.

creativecommons.org/licenses/by-nc-sa/4.0/ 
Keywords: Macropodiformes; Riversleigh; taxonomy; marsupials; phylogeny

\section{INTRODUCTION}

The Riversleigh World Heritage Area (WHA), located in northwestern Queensland, Australia, contains numerous macropodiform-bearing fossil deposits dating from the late Oligocene through to the late Miocene (Travouillon et al., 2006; Arena et al., 2015). A biostratigraphic study by Cooke (1997a) found that during the late Oligocene, Balbaridae, an extinct family of kangaroos with hypertrophied canines, was the most diverse macropodiform (kangaroos and allies) family represented in the Riversleigh WHA deposits. Cooke (1997a) suggested that in the middle Miocene, macropodids were the most diverse, and that only a single balbarid species, 'Balbaroo sp. 4' (now $B$. nalima; Black et al., 2014), was present. Subsequent to publication of Cooke (1997a), several new Riversleigh fossil macropodiform specimens have been recovered, and many additional species have been described (e.g., Kear et al., 2007; Bates et al., 2014; Travouillon et al., 2014; Cooke et al., 2015; Travouillon et al., 2015; Butler et al., 2016).

In order to understand the temporal range, evolution, and extinction of Australia's earliest macropodiforms, it is necessary to have a robust understanding of alpha-level taxonomic diversity throughout the Cenozoic. One group that requires taxonomic revision is the Balbaridae. First erected as a subfamily by Flannery et al. (1982) who proposed that the group was ancestral to Macropodidae, Balbaridae was elevated to family level following a morphology-based phylogenetic analysis by Kear and Cooke (2001). More recent studies suggest that Balbaridae is most closely related to the hypsiprymnodontid subfamily Propleopinae (Wroe et al., 1998; Kear et al., 2007; Kear and Pledge, 2007). Several balbarid genera have been described including Balbaroo (Flannery et al., 1982), Galanarla (Flannery et al., 1982), Nambaroo (Flannery and Rich, 1986), Ganawamaya (Cooke, 1992), and Wururoo (Cooke, 1997b).

Nambaroo was described to include three species (N. tarrinyeri, N. Saltavus, and N. novus) from the Namba Formation, South Australia (Flannery and Rich, 1986). Two additional species, $N$. couperi Cooke 1997 and N. gillespieae Kear et al., 2007, were described from the Riversleigh WHA. Nambaroo bullockensis, from the Bullock Creek Local Fauna from the Camfield Beds, Northern Ter- ritory, was later described by Schwartz and Megirian (2004). Black et al. (2014) identified $N$. bullockensis as a junior synonym of Balbaroo camfieldensis Flannery et al., 1982. Ganawamaya was described from Riversleigh by Cooke (1992) to include the three species Gan. acris, Gan. ornata and Gan. aediculis. Cooke (1997a) listed eight morphospecies of Nambaroo and four of Ganawamaya, all from Riversleigh, although several of these species (six of Nambaroo and one of Ganawamaya) were not formally described therein. Those species were informally described in a thesis by Cooke (1996).

Black et al. (2014) demonstrated that a remnant protostylid is evident in unworn juvenile molars (those specimens without a fully erupted fourth premolar) of some Balbaroo taxa (e.g., $B$. fangaroo and $B$. nalima) and suggested that the lack of a protostylid in adult specimens is most likely the results of a greater degree of dental wear. This suggests that the apparent lack of a protostylid in other balbarid species may similarly be the result of dental wear. Ganawamaya was previously distinguished from Nambaroo by the lack of a protostylid on $\mathrm{m} 1$ (Cooke, 1992). The present study aims to revise the taxonomic status of species attributed to Ganawamaya and Nambaroo and to assess whether the lack of a protostylid in species of Ganawamaya is related to dental wear. Our study is based on a re-examination of previously known material, as well as new specimens that have been recovered since Cooke's (1997a) biostratigraphic study. As part of this revision, we describe new material for Gan. acris, N. couperi and Gan. aediculis and revise the generic classification of $N$. couperi based on new material. The phylogenetic relationships of Nambaroo and Ganawamaya within Macropodiformes are also reassessed.

\section{MATERIALS AND METHODS}

\section{Terminology}

Terminology for dental anatomy follows Archer (1984), Cooke (1997b), and Cooke (1997c). Higher systematic nomenclature follows Prideaux and Warburton (2010) except for subordinal classification (Macropodiformes) which follows Meredith et al. (2009). 


\section{Materials and Mensuration}

Specimens used in this study were collected from several fossil sites in the Riversleigh WHA and from Ngapakaldi Quarry (Ngapakaldi Local Fauna) and Leaf Locality (Kutjamarpu Local Fauna), Tirari Desert, South Australia. Ganawamaya and Nambaroo specimens from Riversleigh are housed in the Queensland Museum fossil collection (prefix QM F), Brisbane, Australia. Specimens from South Australia were measured from casts of original specimens made by the University of California Museum of Paleontology (prefix UCMP) at Berkeley USA. These casts are currently stored in the Queensland Museum and the School of Biological, Earth, and Environmental Sciences at the University of New South Wales (UNSW).

Several specimens examined in this study were previously listed as undescribed morphospecies by Cooke (1996). Specimens attributed to Ganawamaya sp. 4 by Cooke (1996) include: QM F20365, right dentary with i1, p3, m1-m4. Specimens for Nambaroo sp. 2 include: QM F20563, right dentary with m1; QM F57790, right dentary with i1, p3, m1-m4. Specimens attributed to Nambaroo sp. 4 include: QM F19899, right dentary with i1, dp3, unerupted p3, m1, m3. Specimens attributed to Nambaroo sp. 5 include: QM F13099, right dentary with i1, p3, m1-m4; QM F20036, left dentary with m1-m3; QM F24185, left maxilla with P3, M1; QM F24186, left dentary with p3, m1; QM F57788, left m4; QM F58648, left maxilla with P3, M1-M4; QM F57791, left maxilla with P3, M1-M2. Specimens attributed to Nambaroo sp. 6 include: QM F19639, right dentary with p3, m1; QM F19661, right dentary with m1-m2; QM F20292, right dentary with $\mathrm{m} 1-\mathrm{m} 2 ; \mathrm{QM} \mathrm{F} 24222$, left dentary with m1-m3; QM F57789, right dentary with i1, m1-m3. Specimens attributed to Nambaroo sp. 8 include: QM F19878, left dentary with dp3, unerupted $\mathrm{p} 3, \mathrm{~m} 1$.

Maximum tooth length and width of the third premolar were measured for each specimen using digital callipers. In addition, maximum tooth length, anterior and posterior widths were measured for all molars. Length measurements were taken at the base of the crown while widths were measured across the base of the anterior and posterior lophs. All dental measurements are presented in Tables 1-7.

\section{Metric Analysis}

Metric analyses were conducted using PAST Version 3.01 (Hammer et al., 2001). In order to determine whether the amount of variation within each species is consistent with that expected for a mixed sex mammalian population, coefficients of variation (CVs) were calculated for dental measurements from the revised Ganawamaya species (see Systematic Palaeontology). Expected ranges of variation for dental measurements within macropodiforms are from Travouillon et al. (2014) in which ranges of $\mathrm{CVs}$ for the extant macropodids Thylogale stigmatica (3.54-12.5) and $T$. thetis (4.98-11.16) were calculated. Bivariate plots (length vs. anterior, or posterior, width of all molars and length vs. width of the third premolar) were made. For each molar, either the anterior or posterior width was used for bivariate plots depending on which measurement best distinguished between species. We also conducted Kruskal-Wallis and Mann-Whitney $U$ tests for each dental measurement to determine whether dental measurements differ for each species. Ganawamaya couperi comb. nov. could not be included in statistical analysis for the lower fourth molar or upper third and fourth molars as only one specimen for each of these molars was available. A Principal Component Analysis (PCA) using log transformed dental measurements for all molars and premolars was conducted for both upper and lower tooth rows.

\section{Phylogenetic Analysis}

A phylogenetic analysis was conducted using a combination of the taxon-character matrices by Kear and Pledge (2007) and Prideaux and Warburton (2010), as integrated in Butler et al. (2016). Characters for Ganawamaya were then rescored with specimens classified as outlined in our study (i.e., four species; Ganawamaya acris, Gan. aediculis, Gan. gillespieae comb. nov., and Gan. couperi comb. nov.). The total matrix consists of 120 characters (Appendix 1). An additional character (120), not included in previous matrices, was included in the matrix to account for the presence or absence of the interparietal bone. Parsimony analysis was completed using PAUP 4.0b10 (Swofford, 2002). The analysis used a two-stage heuristic search in which the initial search involved 1,000 replicates, saving 10 trees per replicate, followed by a second search within the saved trees. Bootstrap values were then calculated using 1000 replicates. Decay indices were calculated using TreeRot v3.

\section{SYSTEMATIC PALAEONTOLOGY}

Class MAMMALIA, Linnaeus, 1758

Infraclass MARSUPIALIA Illiger, 1811 
Order DIPROTODONTIA Owen, 1866

Suborder MACROPODIFORMES Kirsch, Lapointe and Springer, 1997

Family BALBARIDAE Flannery, Archer and Plane, 1982 sensu Cooke and Kear, 1999

Genus GANAWAMAYA Cooke, 1992

Type Species. Ganawamaya acris Cooke, 1992, by original description.

Emended Generic Diagnosis. Species of Ganawamaya differ from all other balbarids in having the following unique combination of features: a poorly developed hypocingulid; a lack of a neometaconule and postlink; a short buccally flexed p3 with five cuspids along the occlusal margin; pronounced lingual cingulum on P3; a welldeveloped posterobuccal transcrista on $\mathrm{P} 3$; a rectilinear P3; a poorly developed preprotocrista; a postprotocrista that extends into the interloph valley; a pronounced nuchal crest; and well-developed postorbital processes.

Remarks. While species of Ganawamaya and Balbaroo all have a pronounced nuchal crest, it is less developed in Ganawamaya. However, it is better developed than in several macropodiform groups (e.g., macropodines). Species of Ganawamaya also have a more gracile cranium and smaller molars than those of Balbaroo. Species of Ganawamaya differ from species of Nambaroo in having a rectilinear $\mathrm{p} 3$ as opposed to a more plagiaulacoid form, a less developed preprotocrista, and a postprotocrista on the M1 that extends into the interloph valley and in lacking a neometaconule and postlink. Herein 'plagiaulacoid' is used in this study to refer to a shorter tooth with a recurved crown and many cuspids and transcristae, while 'rectilinear' refers to a tooth with a straight crown and less cuspids and transcristae than premolars with a plagiaulacoid form. For example, the p3 of NMV P157559, referred to $N$. tarrinyeri by Flannery and Rich (1986), has a recurved crown with seven cuspids with associated transcristae anterior to the large posterior cuspid.

In this study, we also examined the holotype and sole specimen of Galanarla tessellata, QM F10644. The distinguishing features of Gal. tessellata proposed by Flannery et al. (1982) are shared with species of Nambaroo and Ganawamaya. Those include: lophodont molars, a convex ventral margin of the dentary, a small buccal opening for the masseteric canal, a p3 flexed buccally out of alignment with the molar row. The holotype of $\mathrm{Gal}$. tessellata is a heavily damaged jaw with two very worn molars. It is closest to Gan. aediculis in size and morphology. However, because most diagnos- tic features distinguishing balbarids (those of $\mathrm{p} 3$ and $\mathrm{m} 1$ ) are not preserved, its relationship to other balbarid taxa cannot, at present, be determined. However, the type locality for Gal. tessellata, Riversleigh's $D$ Site, is no longer accessible for fossil collection. Additionally, more informative specimens may in the future be recovered from other Depositional Phase 1 deposits such as Hiatus and White Hunter Sites (e.g., Arena et al., 2015). We suggest $\mathrm{Gal}$. tesselata might be considered as a nomen dubium as the holotype specimen cannot be confidently ascribed to a single taxon.

\section{Ganawamaya acris Cooke, 1992}

Figures 1-2

V*1992 Ganawamaya ornata Cooke, p. 202, figs. 1, 3.

Holotype. QM F16840, right dentary with i1, p3 and m1-m4 from RSO Site, Riversleigh WHA, northwestern Queensland, Australia (Cooke, 1992).

Referred Specimens. Boid Site: QM F24693, right dentary with p3, m1-m2, broken m3-m4. Camel Sputum Site: QM F58648, left maxilla with P3, M1M4; QM F16841, right maxilla with P3, M1-M4; QM F19677, left maxilla with M2-M3; QM F19693, right maxilla with broken M1, M2-M4; QM F19862, left maxilla with P3, M1; QM F19901, right dentary with p3, m2-m4; QM F19969, right dentary with m3; QM F19970, left dentary with m2-m4; QM F19981, left maxilla with M2-M3; QM F20161, left maxilla with M1-M4; QM F20286, right maxilla with M3M4; QM F20523, left maxilla with P3, M1-M4; QM F20617, left maxilla with P3, M1; QM F20618, left maxilla with M1-M4; QM F23476, right maxilla with P3, M1; QM F23485, right maxilla with M2-M3; QM F23485, right maxilla with M2-M3; QM F24189, right maxilla with broken $M 1, M 2$, broken M3. Creaser's Ramparts Site: QM F20365, right dentary with i1, p3, m1-m4; QM F30870, left dentary with i1, p2, dp3, m1; QM F23820, right maxilla with M2-M4; QM F30274, right maxilla with P3, M1-4. Gag Site: QM F58649, partial left dentary with m1-m2. Inabeyance Site: QM F58650, right p3; QM F24514, left dentary with i1, p3, broken $\mathrm{m} 1-\mathrm{m} 2, \mathrm{~m} 3-\mathrm{m} 4$. Judith's Horizontalis Site: QM F58651, left maxilla with P3, M1-M4. Neville's Garden Site: QM F13090, right maxilla with M2-M4; QM F19879, right dentary with $\mathrm{m} 1-\mathrm{m} 4 ; \mathrm{QM}$ F19880, left dentary with $\mathrm{m} 3, \mathrm{~m} 4$ in crypt; $\mathrm{QM}$ F24186, left dentary with p3, m1; QM F24222, left dentary with $\mathrm{m} 1-\mathrm{m} 3$. Price is Right Site: $\mathrm{QM}$ F58652, left dentary with i1, p3, m1-m2, m4; QM F58653, left dentary with p3, m1-m4; QM F58654, right dentary with p3, m1-m3; QM F58655, left p3 
TABLE 1. Measurements ( $\mathrm{mm}$; rounded to one decimal place) of the lower dentition of the type and referred material of Ganawamaya acris. $L=$ tooth length, $A W=$ anterior width, $P W=$ posterior width, $p=$ lower premolar, $m=$ lower molar.

\begin{tabular}{|c|c|c|c|c|c|c|c|c|c|c|c|c|c|c|c|}
\hline Specimen & Locality & p3L & p3w & m1L & $\underset{W}{\mathbf{m 1 A}}$ & $\underset{\mathbf{W}}{\mathbf{m} 1 \mathbf{P}}$ & $\mathrm{m} 2 \mathrm{~L}$ & $\begin{array}{c}\mathrm{m} 2 \mathrm{~A} \\
\mathrm{~W}\end{array}$ & $\underset{W}{\mathrm{~m} 2 \mathrm{P}}$ & $\mathrm{m} 3 \mathrm{~L}$ & $\begin{array}{c}\mathbf{m} 3 \mathrm{~A} \\
\mathrm{~W}\end{array}$ & $\begin{array}{c}\mathrm{m} 3 P \\
\mathbf{W}\end{array}$ & $\mathrm{m} 4 \mathrm{~L}$ & $\begin{array}{c}\mathrm{m} 4 \mathrm{~A} \\
\mathrm{~W}\end{array}$ & $\begin{array}{c}\mathrm{m} 4 \mathrm{P} \\
\mathrm{W}\end{array}$ \\
\hline QMF24693 & Boid Site & 6.0 & 3.6 & 6.2 & 3.7 & 4.4 & 7.0 & 4.6 & 5.0 & & & & & & \\
\hline QMF19901 & Camel Sputum Site & 6.8 & 4.1 & & & & 6.3 & 4.4 & 4.7 & 7.0 & 4.8 & 4.9 & 6.8 & 4.9 & 4.5 \\
\hline QMF19969 & Camel Sputum Site & & & & & & & & & 7.1 & 4.6 & 4.6 & & & \\
\hline QMF19970 & Camel Sputum Site & & & & & & 6.6 & 4.3 & 4.5 & 6.8 & 4.8 & 4.8 & 7.1 & 4.7 & 4.4 \\
\hline QMF20365 & Creaser's Ramparts & 6.2 & 4.4 & 5.8 & 3.5 & 4.2 & 6.4 & 4.0 & 4.7 & 6.7 & 4.8 & 4.5 & 7.2 & 4.5 & 4.1 \\
\hline QMF30870 & Creaser's Ramparts & & & 5.0 & 3.1 & 3.8 & & & & & & & & & \\
\hline QMF58649 & Gag Site & & & 6.1 & 3.9 & 4.0 & 6.0 & 4.2 & 4.2 & & & & & & \\
\hline QMF24514 & Inabeyance Site & 6.7 & 3.7 & 6.5 & & & & & & 6.8 & 4.6 & 4.6 & 6.8 & 4.5 & 4.3 \\
\hline QMF58658 & Inabeyance Site & 7.2 & 3.9 & & & & & & & & & & & & \\
\hline QMF19879 & Neville's Garden Site & & & 6.6 & 3.6 & 4.2 & 6.7 & 4.4 & 4.4 & 6.8 & 4.7 & 4.7 & 7.5 & 4.8 & 4.4 \\
\hline QMF19880 & Neville's Garden Site & & & & & & & & & 7.9 & 5.1 & 5.2 & & & \\
\hline QMF24186 & Neville's Garden Site & 7.0 & 4.3 & 7.0 & 4.0 & 4.7 & & & & & & & & & \\
\hline QMF24222 & Neville's Garden Site & & & 6.6 & 3.7 & 4.4 & 7.1 & 4.5 & 4.9 & 7.5 & 5.0 & 4.9 & & & \\
\hline QMF58652 & Price is Right Site & 6.7 & 4.0 & 5.9 & 3.6 & 4.4 & 6.0 & 4.4 & 4.6 & & & & 6.7 & 4.6 & 4.0 \\
\hline QMF58653 & Price is Right Site & 5.8 & 3.5 & 5.8 & 3.4 & 3.9 & 6.1 & 4.4 & 4.5 & 6.7 & 4.7 & 4.5 & 7.2 & 4.5 & 4.2 \\
\hline QMF58654 & Price Is Right Site & 7.3 & 4.1 & 5.7 & 3.6 & 4.3 & 6.0 & 4.4 & 4.8 & 6.9 & 4.7 & 4.9 & & & \\
\hline QMF58655 & Price is Right Site & 5.7 & 2.9 & & & & & & & & & & & & \\
\hline QMF16840 & RSO Site & 6.7 & 3.9 & 5.9 & 3.4 & 4.1 & 6.3 & 4.0 & 4.3 & 6.6 & 4.6 & 4.6 & 6.8 & 4.7 & 4.4 \\
\hline QMF20033 & RSO Site & 6.6 & & & & & & & & 7.4 & 5.3 & 5.1 & & & \\
\hline QMF19625 & Upper Site & & & & & & 7.0 & 4.2 & 4.4 & & & & & & \\
\hline QMF19639 & Upper Site & & & 6.5 & 2.9 & 4.1 & & & & & & & & & \\
\hline QMF19661 & Upper Site & & & 6.2 & 3.3 & 4.1 & 6.0 & 4.2 & 4.4 & & & & & & \\
\hline QMF19665 & Upper Site & & & & & & & & & 6.9 & 4.5 & 4.8 & 6.9 & 4.7 & \\
\hline QMF19944 & Upper Site & & & 6.2 & 3.8 & 4.5 & 7.1 & 4.6 & 4.8 & 7.3 & 5.0 & 5.0 & & & \\
\hline QMF20192 & Upper Site & & & & & & 7.2 & 4.7 & 4.9 & 7.4 & 5.1 & 5.1 & & & \\
\hline QMF20292 & Upper Site & & & 6.6 & 3.4 & 4.1 & & & & & & & & & \\
\hline QMF16839 & Wayne's Wok Site & 6.7 & 3.9 & 6.5 & 3.8 & 4.4 & 6.3 & 4.2 & 4.8 & 6.8 & 4.7 & 5.0 & & & \\
\hline QMF16842 & Wayne's Wok Site & 6.1 & 3.4 & & & & & & & & & & & & \\
\hline QMF19596 & Wayne's Wok Site & 6.1 & & & & & & & & & & & & & \\
\hline QMF19846 & Wayne's Wok Site & & & & & & & & & & & & 7.7 & 4.9 & 4.6 \\
\hline QMF19899 & Wayne's Wok Site & 6.6 & & 5.7 & 3.5 & 4.3 & & & & 7.1 & 4.7 & 4.9 & & & \\
\hline QMF20563 & Wayne's Wok Site & & & 6.1 & 3.4 & 4.0 & & & & & & & & & \\
\hline QMF57788 & Wayne's Wok Site & & & & & & & & & & & & 7.3 & 4.6 & 4.3 \\
\hline QMF57789 & Wayne's Wok Site & & & 6.5 & 3.6 & 4.3 & 6.8 & 4.3 & 4.7 & 7.1 & 4.9 & 4.8 & & & \\
\hline QMF57790 & Wayne's Wok Site & 6.4 & 3.6 & 6.1 & 3.3 & 4.1 & 6.5 & 4.3 & 4.8 & 7.3 & 4.8 & 4.8 & 7.3 & 5.0 & 4.6 \\
\hline QMF58657 & Wayne's Wok Site & 6.0 & 3.5 & & & & & & & & & & & & \\
\hline QMF58659 & Wayne's Wok Site & 6.2 & & & & & & & & 6.8 & 4.8 & 4.6 & & & \\
\hline UCMP88204 & $\begin{array}{l}\text { Kutjamarpu Local } \\
\text { Fauna, South } \\
\text { Australia }\end{array}$ & 7.0 & 4.1 & 6.9 & 3.8 & 4.7 & 7.6 & 5.1 & 5.2 & 7.8 & 5.4 & 5.2 & & & \\
\hline
\end{tabular}


TABLE 2. Measurements ( $\mathrm{mm}$; rounded to one decimal place) of the upper dentition of the type and referred material of Ganawamaya acris. $\mathrm{L}=$ tooth length, $\mathrm{AW}=$ anterior width, $\mathrm{PW}=$ posterior width, $\mathrm{P}=$ upper premolar, $\mathrm{M}=$ upper molar.

\begin{tabular}{|c|c|c|c|c|c|c|c|c|c|c|c|c|c|c|c|}
\hline Specimen & Locality & P3L & P3W & M1L & M1AW & M1PW & M2L & M2AW & M2PW & M3L & M3AW & M3PW & M4L & M4AW & M4PW \\
\hline QMF16841 & $\begin{array}{l}\text { Camel Sputum } \\
\text { Site }\end{array}$ & 6.8 & 4.3 & 6.0 & 5.4 & 4.9 & 6.6 & 6.1 & 5.2 & 7.5 & 6.0 & 5.2 & 6.2 & 5.6 & 4.2 \\
\hline QMF19677 & $\begin{array}{l}\text { Camel Sputum } \\
\text { Site }\end{array}$ & & & & & & 6.7 & 7.0 & 5.7 & 7.4 & 6.5 & 5.5 & & & \\
\hline QMF19693 & $\begin{array}{l}\text { Camel Sputum } \\
\text { Site }\end{array}$ & & & & & & 6.0 & 5.7 & 5.2 & 5.7 & 5.6 & 4.6 & 5.9 & 5.2 & 3.7 \\
\hline QMF19862 & $\begin{array}{l}\text { Camel Sputum } \\
\text { Site }\end{array}$ & 6.7 & 4.9 & 6.7 & 5.4 & 4.8 & & & & & & & & & \\
\hline QMF19981 & $\begin{array}{l}\text { Camel Sputum } \\
\text { Site }\end{array}$ & & & & & & 6.9 & 6.1 & 5.2 & 7.4 & 6.2 & 5.3 & & & \\
\hline QMF20161 & $\begin{array}{l}\text { Camel Sputum } \\
\text { Site }\end{array}$ & & & 6.3 & 5.7 & 5.2 & 6.6 & 6.0 & 4.9 & 6.7 & 5.6 & 4.9 & 7.2 & 5.7 & 4.4 \\
\hline QMF20286 & $\begin{array}{l}\text { Camel Sputum } \\
\text { Site }\end{array}$ & & & & & & & & & 8.1 & 6.7 & 5.7 & 7.1 & 5.8 & 4.6 \\
\hline QMF20523 & $\begin{array}{l}\text { Camel Sputum } \\
\text { Site }\end{array}$ & 7.4 & 5.0 & 6.8 & 6.0 & 5.4 & 7.3 & 6.4 & 5.7 & 7.9 & 6.1 & 5.5 & 7.3 & 5.4 & 4.5 \\
\hline QMF20617 & $\begin{array}{l}\text { Camel Sputum } \\
\text { Site }\end{array}$ & 6.9 & 4.1 & 6.7 & 5.7 & 5.3 & & & & & & & & & \\
\hline QMF20618 & $\begin{array}{l}\text { Camel Sputum } \\
\text { Site }\end{array}$ & & & 6.8 & 5.7 & 5.2 & 6.9 & 6.2 & 5.3 & 7.4 & 6.0 & 5.2 & 7.2 & 5.4 & 4.4 \\
\hline QMF23476 & $\begin{array}{l}\text { Camel Sputum } \\
\text { Site }\end{array}$ & 8.0 & 5.6 & 7.4 & 6.1 & 5.6 & & & & & & & & & \\
\hline QMF23485 & $\begin{array}{l}\text { Camel Sputum } \\
\text { Site }\end{array}$ & & & & & & 6.9 & 6.5 & 5.3 & 8.1 & 6.1 & 5.1 & & & \\
\hline QMF24189 & $\begin{array}{l}\text { Camel Sputum } \\
\text { Site }\end{array}$ & & & & & 5.6 & 6.7 & 6.4 & 5.3 & 6.6 & & & & & \\
\hline QMF58648 & $\begin{array}{l}\text { Camel Sputum } \\
\text { Site }\end{array}$ & 6.7 & 4.2 & 5.9 & 5.3 & 4.8 & 6.4 & 5.5 & 4.8 & 6.7 & 5.5 & 4.6 & 7.3 & 5.5 & 3.7 \\
\hline QMF23820 & $\begin{array}{l}\text { Creaser's } \\
\text { Ramparts Site }\end{array}$ & & & & & & 6.8 & 5.9 & 5.3 & 7.1 & 6.1 & 5.4 & 7.4 & 5.7 & \\
\hline QMF30274 & $\begin{array}{l}\text { Creaser's } \\
\text { Ramparts Site }\end{array}$ & 7.4 & 4.8 & 6.8 & 5.6 & 5.4 & 6.5 & 6.2 & 5.4 & 7.3 & 6.4 & 5.2 & 7.2 & 5.6 & 4.3 \\
\hline QMF58651 & $\begin{array}{l}\text { Judith's } \\
\text { Horizontalis } \\
\text { Site }\end{array}$ & 7.5 & 4.5 & 6.8 & 5.8 & 5.2 & 6.6 & 6.0 & 5.3 & 7.3 & 6.1 & 4.9 & 7.2 & 5.3 & 4.5 \\
\hline QMF13090 & $\begin{array}{l}\text { Neville's } \\
\text { Garden Site }\end{array}$ & & & & & & 7.3 & 6.6 & 5.4 & 7.2 & 6.3 & 4.9 & 7.9 & 5.7 & 4.5 \\
\hline
\end{tabular}

cap. RSO: QM F20033, left dentary with dp3, unerupted p3, m3. Upper Site: QM F58656, left maxilla with P3, M1-M4; QM F19618, left maxilla with M2; QM F19625, right m2; QM F19639, right dentary with $\mathrm{m} 1$ and unerupted $\mathrm{p} 3$; QM F19661, right $\mathrm{m} 1$ and $\mathrm{m} 2$; QM F19665, right dentary with m3-m4; QM F19684, right maxilla with P3, M1; QM F19686, right maxilla with dP3, unerupted P3, M1M2; QM F19840, palate with left M1-M4 and right M2-M4; QM F19884, right maxilla with M1, QM F19927, left maxilla with M3; QM F19944, right dentary with m1-m3; QM F19946, right M2,;QM F20192, right dentary with m2-m3; QM F20280, right maxilla with M1; QM F20292, right dentary with m1; QM F20296, right maxilla with M2-M4. Wayne's Wok Site: QM F58657, right dentary with p3; QM F57789, right dentary with m1-m3; QM F58659, right dentary with $\mathrm{p} 2$, dp3, unerupted p3, m3; QM F16839, right dentary with p3, m1-m3; QM F16842, left dentary with i1, p3; QM F19577, cranium with left P3, M1-M3; QM F19596; right dentary with p2, dp3, unerupted p3; QM F19821, right maxilla with M1-M4; QM F19846, left dentary with m4; QM F19899, right dentary with i1, dp3, unerupted p3, m1, m3; QM F19920, right maxilla with partial M1-M4; QM F19935, right maxilla with M1-M2; QM F20563, right dentary with m1; QM F24192, right maxilla with M2-M4; QM F31461, cranium with left P3, M1-M4 and right M1-M4; QM F36412, right maxilla with P3, M1-M3; QM F57788, left m4; QM F57790, right dentary with i1, p3, m1-m4. 
TABLE 2 (continued).

\begin{tabular}{|c|c|c|c|c|c|c|c|c|c|c|c|c|c|c|c|}
\hline Specimen & Locality & P3L & P3W & M1L & M1AW & M1PW & M2L & M2AW & M2PW & M3L & M3AW & M3PW & M4L & M4AW & M4PW \\
\hline QMF19618 & Upper Site & & & & & & 7.4 & 5.7 & 5.0 & & & & & & \\
\hline QMF19684 & Upper Site & 7.6 & 4.8 & 7.0 & 5.7 & 5.4 & & & & & & & & & \\
\hline QMF19686 & Upper Site & 7.1 & 4.2 & 6.8 & 5.6 & 5.4 & 7.4 & 6.0 & 5.5 & & & & & & \\
\hline QMF19840 & Upper Site & & & 6.0 & 5.4 & 5.2 & 6.8 & 5.9 & 5.1 & 6.9 & 5.6 & 5.1 & 6.5 & 5.2 & 3.9 \\
\hline QMF19840 & Upper Site & & & & & & 6.4 & & 5.3 & 7.0 & 5.8 & 4.8 & 6.4 & 5.3 & 4.1 \\
\hline QMF19884 & Upper Site & & & 7.0 & 5.8 & 5.0 & & & & & & & & & \\
\hline QMF19927 & Upper Site & & & & & & & & & 7.1 & 5.5 & 4.9 & & & \\
\hline QMF19946 & Upper Site & & & & & & 7.3 & 6.4 & 5.5 & & & & & & \\
\hline QMF20280 & Upper Site & & & 6.6 & 5.6 & 5.4 & & & & & & & & & \\
\hline QMF20296 & Upper Site & & & & & & 7.4 & 6.4 & 5.7 & 7.8 & 6.4 & 5.4 & 6.5 & 5.4 & 4.1 \\
\hline QMF58656 & Upper Site & 7.2 & 4.9 & 6.6 & 5.8 & 5.2 & 7.0 & 6.3 & 5.5 & 7.1 & 6.2 & 5.5 & 7.3 & 5.7 & 4.6 \\
\hline QMF19577 & $\begin{array}{l}\text { Wayne's Wok } \\
\text { Site }\end{array}$ & 7.5 & 4.5 & 6.8 & 5.7 & 5.5 & 7.4 & 6.3 & 5.6 & 7.9 & 6.1 & 5.6 & & & \\
\hline QMF19821 & $\begin{array}{l}\text { Wayne's Wok } \\
\text { Site }\end{array}$ & & & 6.4 & 5.8 & 5.3 & 6.6 & 6.2 & 5.6 & 7.2 & 6.3 & 5.6 & 7.3 & 6.0 & 4.8 \\
\hline QMF19920 & $\begin{array}{l}\text { Wayne's Wok } \\
\text { Site }\end{array}$ & & & 6.3 & & & 6.6 & & 5.2 & & & & & & \\
\hline QMF19935 & $\begin{array}{l}\text { Wayne's Wok } \\
\text { Site }\end{array}$ & & & 6.3 & 5.2 & 4.9 & 6.8 & 5.8 & 4.9 & & & & & & \\
\hline QMF24192 & $\begin{array}{l}\text { Wayne's Wok } \\
\text { Site }\end{array}$ & & & & & & 7.0 & 6.2 & 5.4 & 7.2 & 6.1 & 5.3 & 7.3 & 5.3 & \\
\hline QMF31461 & $\begin{array}{l}\text { Wayne's Wok } \\
\text { Site }\end{array}$ & 7.5 & 5.1 & 6.4 & 5.6 & 5.3 & 6.4 & 6.2 & 5.4 & 7.6 & 6.5 & 5.6 & 7.7 & 6.1 & 4.7 \\
\hline QMF31461 & $\begin{array}{l}\text { Wayne's Wok } \\
\text { Site }\end{array}$ & & & 6.3 & 5.8 & 5.6 & 7.0 & 6.4 & 5.5 & 7.7 & 6.6 & 5.7 & 7.8 & 6.1 & 4.5 \\
\hline QMF36412 & $\begin{array}{l}\text { Wayne's Wok } \\
\text { Site }\end{array}$ & 7.4 & 4.6 & 6.3 & 5.5 & 5.4 & 6.9 & 6.3 & 5.3 & 7.1 & & & & & \\
\hline UCMP88212 & $\begin{array}{l}\text { Kutjamarpu } \\
\text { Local Fauna, } \\
\text { South Australia }\end{array}$ & & & & & & 7.5 & 6.1 & 5.7 & 7.5 & 6.2 & 5.9 & 8.6 & 5.9 & 4.7 \\
\hline
\end{tabular}

The following specimens are referred based on casts of the original specimen: Basal Conglomerate, Leaf Locality, Wipajiri Formation, Tirari Desert, Lake Eyre Basin, South Australia: UCMP 88204, right dentary with $\mathrm{p} 3, \mathrm{~m} 1-\mathrm{m} 4$; UCMP 88212, left maxilla with M2-M3.

Emended species diagnosis. Ganawamaya acris differs from all other species of Ganawamaya in having the following unique combination of features: masseteric process of the maxilla with small rounded eminence; well-developed sulcus on the anterior extremity of the zygomatic arch; distinct process on the ectotympanic; large zygomatic epitympanic sinus with thin medial wall; large mastoid foramen on mastoid/squamosal suture; well-developed anterior cingulum on $\mathrm{M} 1$; less well-defined posthypocristid on $\mathrm{m} 1$ and $\mathrm{m} 2$ and no posthypocristid on $\mathrm{m} 4$; more prominent paraconid on $\mathrm{m} 1$; large and sinuous i1 with dorsal and ventral enamel flanges; no marked convexities on the lateral margins of the interloph valley of lower molars; no hypoconulid on lower molars; poorly developed anterior cingulum on $\mathrm{M} 1$; stylar cusp $\mathrm{C}$ less prominent and connected to postparacrista on M1; and larger molar size; no additional cuspid on the posterior end of the p3 below the occlusal margin.

\section{Description}

Cranial morphology described here is based on QM F31461 (Figures 1, 2). This cranium has been transected through the splanchnocranium suggesting that either the anterior portion was 


\section{BUtLER ET AL.: REVISION OF OLIGO-MIOCENE KANGAROOS}

TABLE 3. Measurements ( $\mathrm{mm}$; rounded to one decimal place) of the lower dentition of the type and referred material of Ganawamaya aediculis. Abbreviations are the same as Table 1.

\begin{tabular}{|c|c|c|c|c|c|c|c|c|c|c|c|c|c|c|c|}
\hline Specimen & Locality & p3L & p3w & m1L & m1AW & m1PW & $\mathrm{m} 2 \mathrm{~L}$ & m2AW & m2PW & m3L & m3AW & m3PW & m4L & m4AW & m4PW \\
\hline QMF30076 & $\begin{array}{l}\text { Gillespie's } \\
\text { Gully Site }\end{array}$ & 5.9 & 3.4 & 6.3 & 3.6 & 4.1 & 6.7 & 4.4 & 4.8 & 6.9 & 4.8 & 4.8 & 7.3 & 4.8 & 3.8 \\
\hline QMF30298 & LSO Site & 5.9 & 3.7 & 5.8 & 3.4 & 3.9 & & & & 6.5 & 4.2 & 4.0 & 7.0 & 4.1 & 3.9 \\
\hline QMF31463 & LSO Site & 6.2 & 3.6 & & & & & & & & & & & & \\
\hline QMF16843 & $\begin{array}{l}\text { White Hunter } \\
\text { Site }\end{array}$ & 6.4 & 3.9 & 5.4 & 3.8 & 4.2 & 5.9 & 4.2 & 4.3 & 6.0 & 4.4 & 4.5 & 6.7 & 4.2 & 3.9 \\
\hline QMF19584 & $\begin{array}{l}\text { White Hunter } \\
\text { Site }\end{array}$ & 6.1 & 2.6 & 6.0 & 3.3 & 3.8 & & & & & & & & & \\
\hline QMF19605 & $\begin{array}{l}\text { White Hunter } \\
\text { Site }\end{array}$ & & & & & & & & & & & & 6.4 & 4.1 & 4.0 \\
\hline QMF19876 & $\begin{array}{l}\text { White Hunter } \\
\text { Site }\end{array}$ & & & & & & 6.7 & 4.4 & 4.6 & 6.4 & 4.5 & 4.8 & 7.2 & 4.6 & 4.4 \\
\hline QMF19878 & $\begin{array}{l}\text { White Hunter } \\
\text { Site }\end{array}$ & 6.0 & 3.4 & 5.7 & 3.4 & 3.9 & & & & & & & & & \\
\hline QMF19993 & $\begin{array}{l}\text { White Hunter } \\
\text { Site }\end{array}$ & & & & & & & & & 5.8 & 4.2 & 4.2 & - & 3.8 & \\
\hline QMF19994 & $\begin{array}{l}\text { White Hunter } \\
\text { Site }\end{array}$ & & & & & & & & & & & & & & \\
\hline QMF20146 & $\begin{array}{l}\text { White Hunter } \\
\text { Site }\end{array}$ & & & & & & & & & 6.6 & 4.3 & 4.3 & & & \\
\hline QMF31182 & $\begin{array}{l}\text { White Hunter } \\
\text { Site }\end{array}$ & 5.9 & 3.7 & 5.3 & 3.1 & 3.7 & 5.6 & 3.8 & 3.9 & 5.8 & 4.0 & 4.0 & - & 3.8 & - \\
\hline QMF58660 & $\begin{array}{l}\text { White Hunter } \\
\text { Site }\end{array}$ & 6.6 & 3.6 & 5.9 & 3.3 & 3.8 & 6.3 & 4.2 & 4.3 & 6.6 & 4.5 & 4.3 & 7.0 & 4.4 & 4.2 \\
\hline
\end{tabular}

TABLE 4. Measurements ( $\mathrm{mm}$; rounded to one decimal place) of the upper dentition of the type and referred material of Ganawamaya aediculis. Abbreviations are the same as Table 2.

\begin{tabular}{|c|c|c|c|c|c|c|c|c|c|c|c|c|c|c|c|}
\hline Specimen & Locality & P3L & P3W & M1L & M1AW & M1PW & M2L & M2AW & M2PW & M3L & M3AW & M3PW & M4L & M4AW & M4PW \\
\hline QMF58658 & LSO Site & 6.9 & 4.3 & 5.6 & 5.3 & 4.5 & & & & & & & & & \\
\hline QMF58658 & LSO Site & 6.8 & 4.0 & 5.5 & 5.5 & 4.6 & 6.3 & 5.6 & 4.6 & 6.7 & 5.9 & 4.6 & 6.6 & 4.9 & 4.0 \\
\hline QMF20633 & $\begin{array}{l}\text { White Hunter } \\
\text { Site }\end{array}$ & & & & & & 5.9 & 4.9 & 4.3 & 6.1 & 4.8 & 4.3 & 6.4 & 4.7 & 3.4 \\
\hline QMF23354 & $\begin{array}{l}\text { White Hunter } \\
\text { Site }\end{array}$ & & & 5.5 & 5.0 & 4.5 & 6.1 & 5.3 & 4.6 & & & & & & \\
\hline QMF57791 & $\begin{array}{l}\text { White Hunter } \\
\text { Site }\end{array}$ & 6.8 & 4.6 & 6.7 & 5.6 & 4.8 & 6.9 & 5.8 & 4.9 & & & & & & \\
\hline
\end{tabular}

TABLE 5. Measurements ( $\mathrm{mm}$; rounded to one decimal place) of the lower dentition of the type and referred material of Ganawamaya gillespieae comb. nov. Abbreviations are the same as Table 1.

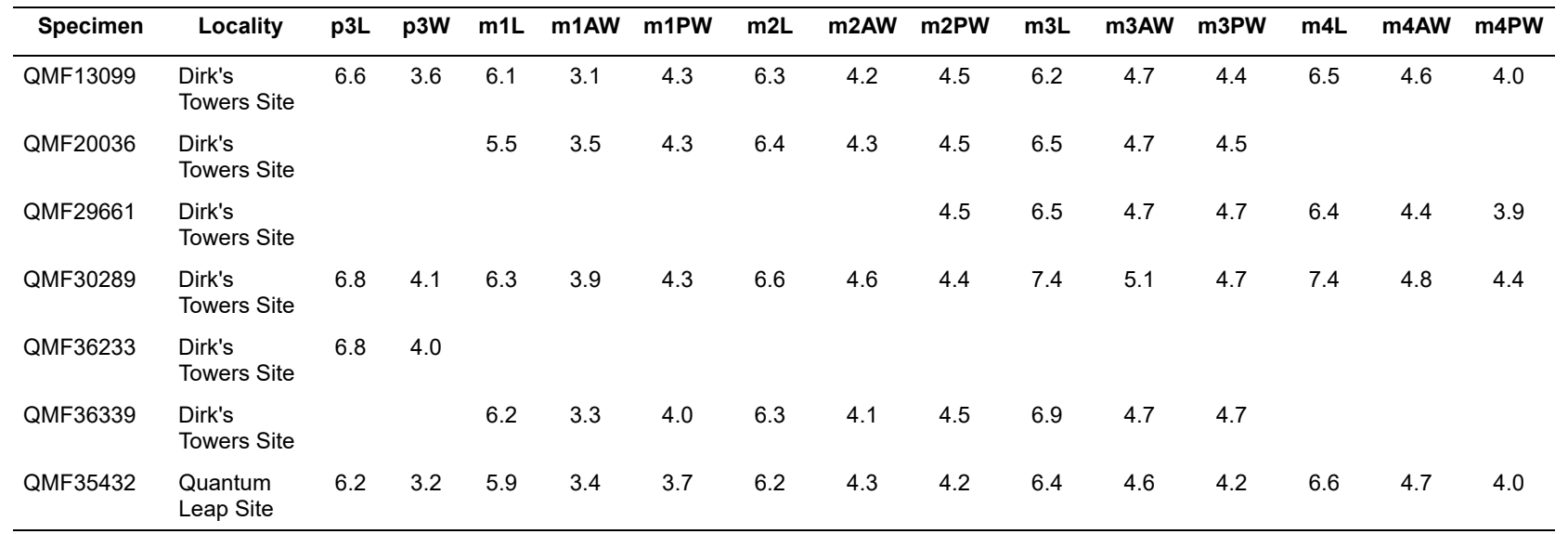


TABLE 6. Measurements (mm; rounded to one decimal place) of the upper dentition of the type and referred material of Ganawamaya gillespieae comb. nov. Abbreviations are the same as Table 2.

\begin{tabular}{|c|c|c|c|c|c|c|c|c|c|c|c|c|c|c|c|}
\hline Specimen & Locality & P3L & P3W & M1L & M1AW & M1PW & M2L & M2AW & M2PW & M3L & M3AW & M3PW & M4L & M4AW & M4PW \\
\hline QMF13100 & $\begin{array}{l}\text { Dirk's Towers } \\
\text { Site }\end{array}$ & & & & & & 6.7 & 5.8 & 4.7 & 6.9 & 5.8 & 4.8 & 6.5 & 5.6 & 4.3 \\
\hline QMF16912 & $\begin{array}{l}\text { Dirk's Towers } \\
\text { Site }\end{array}$ & & & 6.4 & 5.3 & 5.1 & 7.0 & 5.7 & 5.1 & & & & & & \\
\hline QMF24178 & $\begin{array}{l}\text { Dirk's Towers } \\
\text { Site }\end{array}$ & & & 6.1 & 6.1 & 5.2 & 6.6 & 5.7 & 5.0 & & & & 6.9 & 5.7 & 4.3 \\
\hline QMF24180 & $\begin{array}{l}\text { Dirk's Towers } \\
\text { Site }\end{array}$ & & & & & & 7.0 & 5.8 & 4.9 & 7.0 & 6.0 & 4.7 & & & \\
\hline QMF24185 & $\begin{array}{l}\text { Dirk's Towers } \\
\text { Site }\end{array}$ & 6.9 & 4.3 & 6.4 & 5.5 & 4.9 & & & & & & & & & \\
\hline QMF24479 & $\begin{array}{l}\text { Dirk's Towers } \\
\text { Site }\end{array}$ & & & & & & & & & 7.6 & 6.2 & 5.1 & & & \\
\hline QMF35432 & $\begin{array}{l}\text { Quantum } \\
\text { Leap Site }\end{array}$ & 6.9 & 4.2 & 5.9 & 5.2 & 4.5 & 6.9 & 5.8 & 4.8 & 6.9 & 5.6 & 4.6 & 7.0 & 5.1 & 4.1 \\
\hline QMF35432 & $\begin{array}{l}\text { Quantum } \\
\text { Leap Site }\end{array}$ & 6.7 & 4.3 & 6.0 & 5.5 & 4.6 & 6.2 & 5.7 & 4.7 & 6.8 & 5.6 & 4.8 & 6.7 & 5.3 & 4.1 \\
\hline
\end{tabular}

TABLE 7. Measurements ( $\mathrm{mm}$; rounded to one decimal place) of the upper and lower dentition of the type and referred material of Ganawamaya couperi comb. nov. Abbreviations are the same as Tables 1 and 2.

\begin{tabular}{|c|c|c|c|c|c|c|c|c|c|c|c|c|c|c|c|}
\hline Specimen & Locality & p3L & p3W & m1L & m1AW & m1PW & $\mathrm{m} 2 \mathrm{~L}$ & m2AW & $\mathrm{m} 2 \mathrm{PW}$ & m3L & m3AW & m3PW & $\mathrm{m} 4 \mathrm{~L}$ & m4AW & m4PW \\
\hline QMF30401 & $\begin{array}{l}\text { White } \\
\text { Hunter Site }\end{array}$ & 4.9 & 3.1 & 5.1 & 3.0 & 3.4 & 5.1 & 3.5 & 3.9 & 5.4 & 3.9 & 4.1 & 5.6 & 3.7 & 3.6 \\
\hline UCMP57334 & $\begin{array}{l}\text { Ngapakaldi } \\
\text { Local } \\
\text { Fauna }\end{array}$ & 5.4 & 3.2 & 4.6 & 2.9 & 3.3 & 4.7 & 3.1 & 3.3 & 4.6 & 3.1 & 3.2 & & & \\
\hline UCMP10600 & $\begin{array}{l}\text { Ngapakaldi } \\
\text { Local } \\
\text { Fauna }\end{array}$ & 4.9 & 3.2 & 4.7 & 3.2 & 3.2 & & & & 4.8 & 3.6 & 3.4 & & & \\
\hline Specimen & Locality & P3L & P3W & M1L & M1AW & M1PW & M2L & M2AW & M2PW & M3L & M3AW & M3PW & M4L & M4AW & M4PW \\
\hline UCMP57340 & $\begin{array}{l}\text { Ngapakaldi } \\
\text { Local } \\
\text { Fauna }\end{array}$ & 5.3 & 3.3 & 5.2 & 4.6 & 4.1 & 4.7 & 3.4 & 4.1 & 5.0 & 4.4 & 3.9 & 5.1 & 4.0 & 3.0 \\
\hline UCMP57337 & $\begin{array}{l}\text { Ngapakaldi } \\
\text { Local } \\
\text { Fauna }\end{array}$ & 4.5 & 3.0 & 4.0 & 2.8 & 2.8 & 4.4 & 3.1 & 3.0 & & & & & & \\
\hline
\end{tabular}

inadvertently separated in the field at the time of collection or was destroyed during the fossilization process. No specimens examined appear to represent the anterior portion of this cranium.

Maxilla and Palatine. No distinct masseteric process is evident. However, there is a small eminence in place of this process. The maxillopalatine fenestrae are not well preserved. However, the anterior margin is bordered by the maxilla from a point level with the anterior end of $\mathrm{M} 2$, and the posterior margin is bordered by the palatine from a point level with the anterior end of M3. The suborbital shelf of the maxilla is flat, narrow and anteriorly tapered. The infraorbital canal is situated in the anterior portion of the suborbital shelf. The infraorbital foramen, positioned dorsal to the anterior end of $\mathrm{M} 1$, is elliptical in shape. The sphenopalatine foramen is positioned posterior to the infraorbital canal on the anterior end of the palatine. Both the sphenopalatine foramina are oval in shape. A subrounded maxillary foramen is located posterior to the maxillojugal suture. The sphenorbital fissure is large (approximately $6 \mathrm{~mm}$ wide). The foramen rotundum is located posterolateral to the sphenorbital fissure from which it is separated by a thin wall.

Lacrimal. Only the most lateral potion of the lacrimal is preserved. Two small lacrimal foramina occur on the anterior margin of the orbit.

Frontal, parietal, and interparietal. The dorsal anterior portion of the frontal is not preserved. In dorsal view, however, part of a deep sulcus is evident along the posterior portion of the metopic suture. An ethmoidal foramen is positioned at the posteroventral corner of the frontal along the frontal-orbitosphenoid suture. A well-developed sagittal 

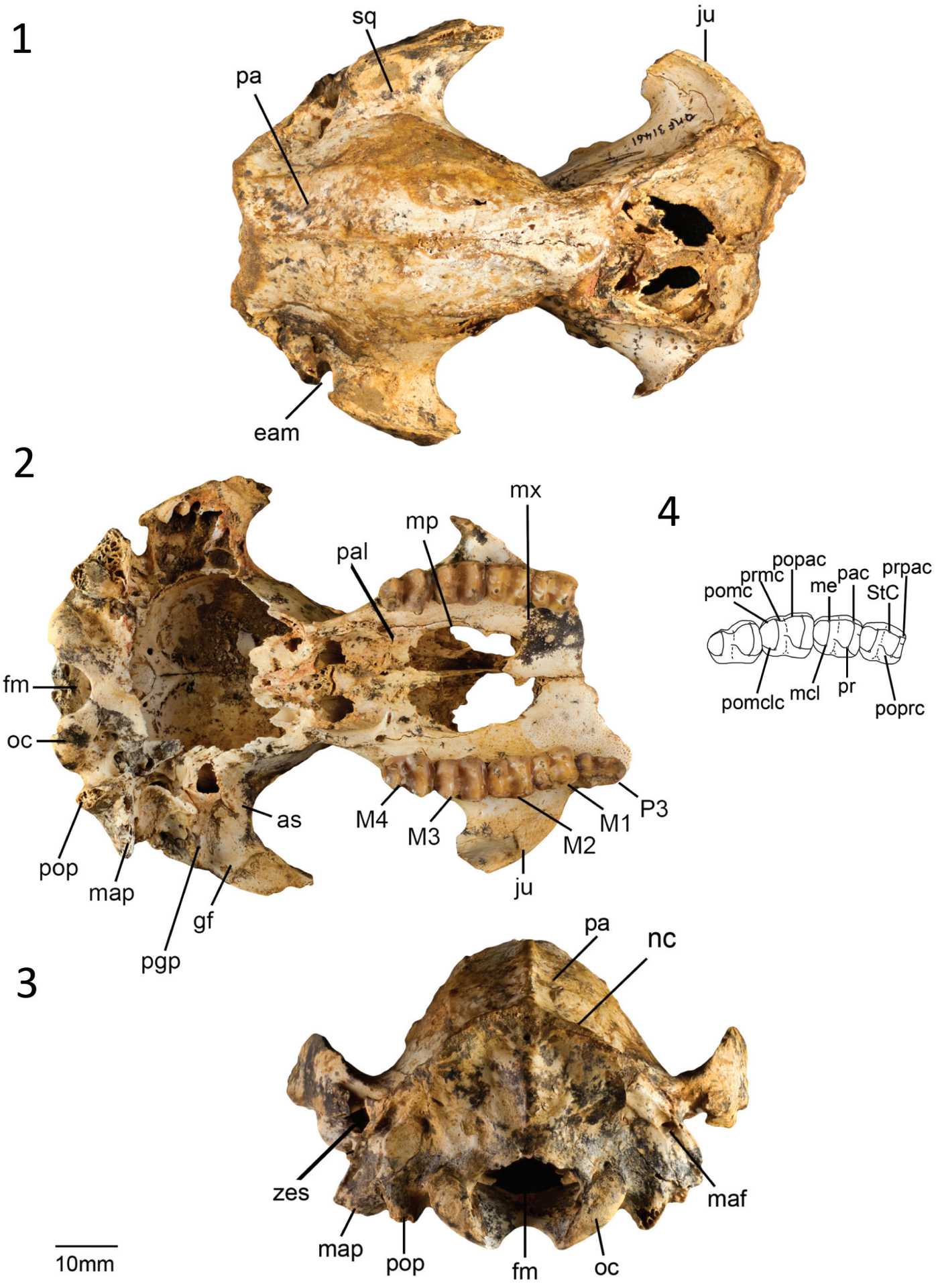

FIGURE 1. Ganawamaya acris partial cranium (QM F31461) in dorsal view (1); ventral view (2); posterior view (3); and line drawing of dentition in occlusal view (4). Abbreviations: as, alisphenoid; eam, exit of auditory meatus; fm, foramen magnum; gf, glenoid fossa; ju, jugal; M1-M4, upper first to fourth molar; maf, mastoid foramen on the mastoid-squamosal suture; map, mastoid process; mcl, metaconule; me, metacone; mp, maxillopalatine fenestra; mx, maxilla; nc, nuchal crest; oc, occipital; P3, upper third premolar; pa, parietal; pac, paracone; pal, palatine; pgp, postglenoid process; pop, paroccipital process; pomc, postmetacrista; pomclc, postmetaconule crista; popac, postparacrista; poprc, postprotocrista; pr, protocone; prpac, preparacrista; sq, squamosal; StC, stylar cusp C; zes, zygomatic epitympanic sinus. 

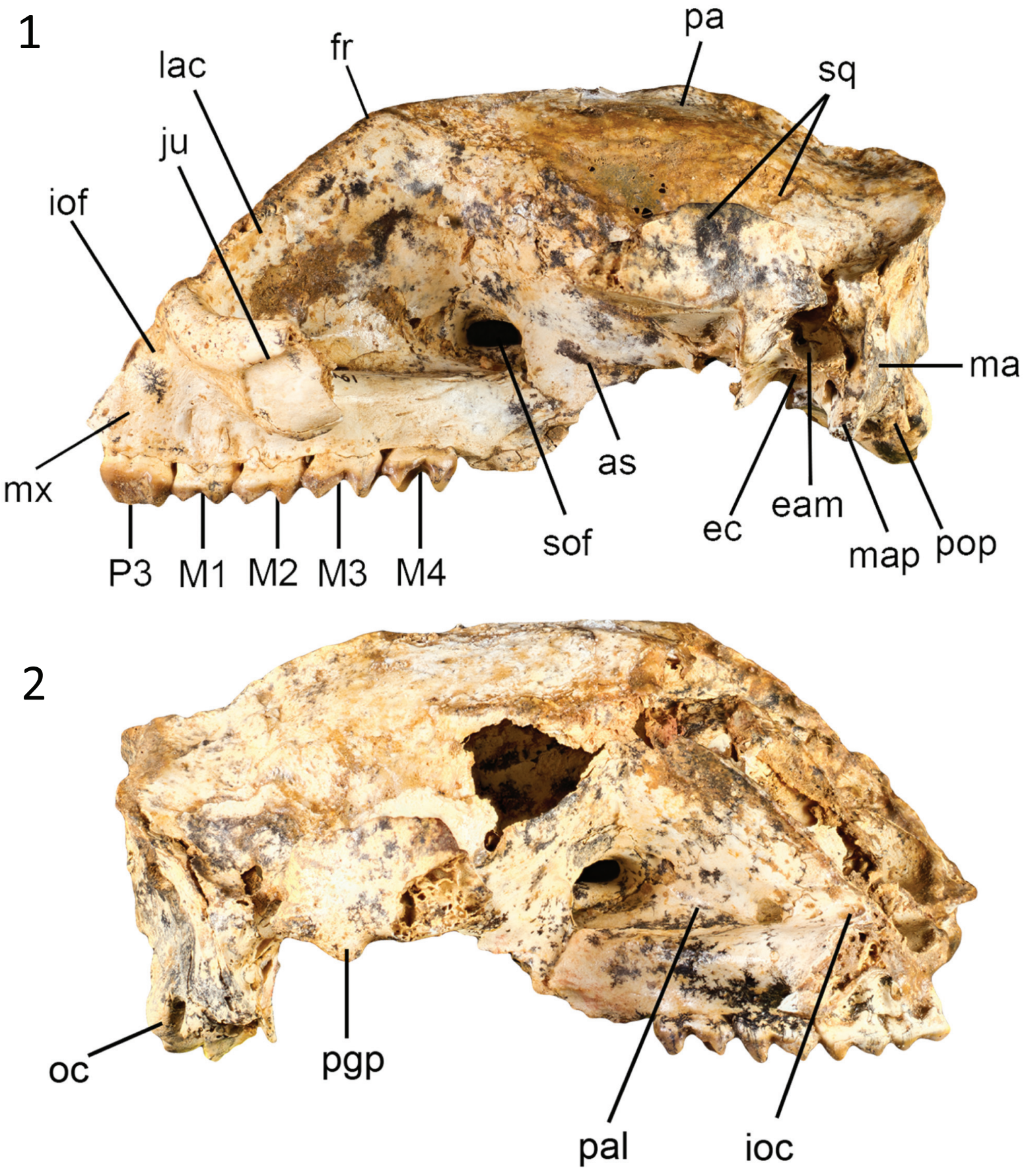

\section{$10 \mathrm{~mm}$}

FIGURE 2. Ganawamaya acris partial cranium (QM F31461) in left lateral view (1) and right lateral view (2). Abbreviations: as, alisphenoid; eam, exit of auditory meatus; ec, ectotympanic; fr, frontal; ioc, infraorbital canal; iof, infraorbital foramen; ju, jugal; lac, lacrimal; M1-M4, upper first to fourth molar; ma, mastoid; map, mastoid process; mx, maxilla; oc, occipital; P3, upper third premolar; pa, parietal; pal, palatine; pgp, postglenoid process; pop, paroccipital process; sof, sphenorbital fissure; sq, squamosal. 
crest is evident along the parietal-parietal suture. The parietals curve gently to form a well-developed nuchal crest. A wedge between the anterior wings of the parietals is formed by the frontals. The anterior wings of the parietals terminate dorsally where post-orbital constriction of the cranium occurs. A frontal-squamosal contact is evident posterior to postorbital constriction of the cranium. There is no contact between the alisphenoid and the parietals. No interparietal-parietal suture is present, suggesting that these bones have completely fused.

Zygomatic arch. The majority of the zygomatic arch is not preserved. The jugal extends anteriorly to the ventral portion of the lacrimal. There is a distinct, well-developed sulcus on the anterior extremity of the zygomatic arch. This sulcus appears to be related to the attachment of the superficial masseter muscle (Warburton, 2009). As in other balbarids, the zygomatic arch transitions smoothly into the facial region as opposed to being separated by a sulcus. The glenoid fossa is generally flat and merges smoothly into the ventral surface of the jugal. A prominent postglenoid process is present.

Neurocranium. The neurocranium is slightly domed. The frontal and parietals form most of the roof of the neurocranium. The ventral walls of the neurocranium are formed laterally by the dorsal wing of the squamosal. The ventral portion of the neurocranium is not preserved.

Basicranium. Small foramina are evident on the occipital condyle with short canals that open posteriorly into the foramen magnum. A hypoglossal foramen is situated medial to these foramina. The paroccipital and mastoid processes are partly broken. However, both appear to project below the level of the occipital condyle. The mastoid process appears more massive than the paroccipital process. A large mastoid foramen occurs on the mastoid-squamosal suture. The occipital condyles are small. The posterior lacerate foramen is only partially preserved but it appears to have been large.

The tympanic wing of the alisphenoid is flat. The external auditory meatus is bordered ventrally by the ectotympanic and dorsally by the squamosal. The ectotympanic has a straight posterior border, concave lateral border, and convex anterior and medial border. The ventral wall of the postglenoid process is contributed to by the ectotympanic. A distinct process is evident on the anteromedialmost corner of the ectotympanic. The zygomatic epitympanic sinus is large with a thin mesial wall. The basioccipital is not preserved.

Upper dentition. The upper dentition for Ganawamaya acris is described in Cooke (1992) except for the dP3, which is preserved in QM F19686. In occlusal view, the dP3 is trapezoidal in outline with a longer buccal margin compared to the lingual one. The paracone and metacone are subequal in height and taller than the protocone and metaconule. The protocone is large and taller than the metaconule. The paracone and protocone are not connected by a protoloph. A weak crest extends lingually from the paracone to meet the preparacrista. The postprotocrista extends posteriorly from the protocone to meet a short, very poorly developed premetaconule crista. A small stylar cusp $C(\mathrm{StC})$ is present buccal to the paracone. A well-developed stylar cusp A (StA) is evident anterobuccal to the paracone. A poorly developed preparacrista extends from the paracone to the base of the StA. A well-defined postparacrista extends posteriorly into the interloph valley where it meets a poorly developed premetacrista. A postmetacrista extends posteriorly from the metacone but it is unclear where it terminates because part of the back of the tooth is obscured by a small piece of unprocessed limestone matrix.

Lower dentition. The lower dentition for Ganawamaya acris is described in Cooke (1992) except for p2 and dp3 which are preserved in QM F30870 and QM F19596.

The p2 is a short, tear-shaped tooth in occlusal view with steeply sloping buccal and lingual faces. Two prominent cuspids are evident on the tooth each with faint associated transcristids. The main crest departs in a posterior direction from the anteriormost cuspid posteriorly and terminates at the posterior end of the tooth. In buccal view the occlusal surface appears slightly convex.

The dp3 is triangular in occlusal outline and tapers anteriorly. Anteriorly, it abuts with the posterior end of $\mathrm{p} 2$. The protoconid is centrally positioned on the trigonid and is the tallest cusp on the tooth. A paracristid descends anteriorly from the protoconid to contact a well-developed paraconid. In QM F19596, a small cusp is present anterolingual to the protoconid and is connected to the paracristid by a short crest. A distinct protostylid is present buccal to the protoconid. The metaconid is well developed. The protoconid, paraconid, and metaconid are laterally compressed. A postmetacristid descends posteriorly into the interlophid valley where it meets a preentocristid. The cristid obliqua extends anterolingually from the hypoconid to the interlophid valley. The hypolophid is formed buccally by the posthypocristid and lingually by a buccal crest from the entoconid. The posthypocristid continues along the posterior flank of the hypol- 
ophid and meets the postentocristid at the posterolingual end of the tooth, encircling a small hypocingulid (a cingulid around the posterior base of the hypolophid). The postentocristid is well developed and continues vertically down the entoconid.

Additional morphological variation observed compared to the description by Cooke (1992) in the lower dentition includes the following: a protostylid is present on $\mathrm{m} 1$ in all juvenile specimens that have unworn molars (e.g., QM F19899, 57790, 57789); complex enamel ridges on the i1 of some juvenile specimens such as QM F19899 and QM F16842 (the holotype of Gan. ornata); the paracristid is straight in worn specimens (e.g., holotype of Gan. acris QM F16840 and 57790) but sinuous in juvenile and unworn specimens (e.g., QM F19899 and 57789); five cuspids are present on the occlusal surface of p3 on specimens such as QM F16842, 19899 and 57790, but in the holotype, QM F16840, the fifth cuspid appears to be obscured by wear. A malformation of the bone is evident on the anterior ventral border of the dentary of $\mathrm{QM}$ F57789, and was previously noted in an unpublished thesis by Cooke (1996).

Remarks. A remnant protostylid is evident in unworn juvenile specimens of Balbaroo (e.g., $B$. fangaroo and $B$. nalima) but is absent in worn adult specimens (Black et al., 2014). In the description of Gan. acris by Cooke (1992), Ganawamaya is distinguished from species of Nambaroo by the lack of a protostylid on $\mathrm{m} 1$. The holotype of Gan. acris is however significantly worn and has a distinct wear facet where the protostylid was most likely present. Juvenile specimens, such as those attributed to 'Nambaroo sp. 4' by Cooke (1997a) and the holotype of Gan. ornata Cooke, 1992, and some unworn adult specimens (Figure 3), retain features such as complex enamel ridges on molars, a sinuous paracristid, and a protostylid on the $\mathrm{m} 1$. The holotype of Gan. ornata is missing $\mathrm{m} 1$, and therefore lacks sufficient diagnostic morphological features to separate it from Gan. acris. Other previously unpublished Ganawamaya specimens identified from Wayne's Wok, the type locality for Gan. ornata, are also consistent with Gan. acris. The dp3 and p3 of QM F2003 from the type locality of Gan. acris (RSO Site) is also identical to the holotype of Gan. ornata and specimens of Gan. acris. We therefore propose that specimens attributed to undescribed Ganawamaya and Nambaroo species (Ganawamaya sp. 4, Nambaroo sp. 2, Nambaroo sp. 4, Nambaroo sp. 5 and Nambaroo sp. 6) from Faunal Zone B by Cooke (1997a), in addition to the holotype of Gan. ornata (QM F16842), be referred to Gan. acris. One specimen, QM F58649, is from Faunal Zone C, unlike the majority of Gan. acris specimens, which suggests that the species spanned the early to middle Miocene.

Age and distribution. The holotype of Gan. acris, QM F16840, is from RSO Site, Riversleigh WHA, northwestern Queensland. The RSO Site is interpreted as to be part of Riversleigh's Faunal Zone B (Archer et al., 1989, 1997; Travouillon et al., 2006, 2011; Arena et al., 2015) with radiometric dates by Woodhead et al. (2016) supporting an early Miocene age for RSO Site $(16.55 \pm 0.29 \mathrm{Ma})$. The RSO Site is interpreted by Arena et al. (2015) to belong to interval B3 within Faunal Zone B. Other referred specimens are from sites also considered to be part of interval B3 of Faunal Zone B: Camel Sputum Site, Inabeyance Site, Judith's Horizontalis Site, Neville's Garden Site, Upper Site and Wayne's Wok Site (Arena et al., 2015). Several referred specimens from Boid Site and Creaser's Ramparts Site, are interpreted as Faunal Zone B, intervals B2 or B3 (Arena et al., 2015). Radiometric dates reported by Woodhead et al. (2016) for Camel Sputum Site $(17.75 \pm 0.78 \mathrm{Ma})$ and Neville's Garden Site $(17.85 \pm 0.13 \mathrm{Ma})$ support the interpretation that these are early Miocene in age. The Price Is Right Site has been interpreted to represent Faunal Zone B (Travouillon et al., 2006, 2011). Arena et al. (2015) found that its biostratigraphy was inconclusive, and it was as likely to be in either interval B2, B3, or C1. One specimen, QM F58649, is from Gag Site, which is interpreted to represent intervals $\mathrm{C} 1$ or $\mathrm{C} 2$ of Faunal Zone $\mathrm{C}$, and thus middle Miocene in age (Archer et al., 1989, 1997; Travouillon et al., 2006, 2011; Arena et al., 2015). One specimen from the Wipajiri Formation, South Australia, is attributed to Gan. acris in our study. The Wipajiri Formation appears to be early or middle Miocene in age based on biocorrelation with Riversleigh deposits (Archer et al., 1997; TravouilIon et al., 2006; Black et al., 2012).

\section{Ganawamaya aediculis Cooke, 1992 Figure 4}

Holotype. QM F16843, right dentary with p3, m1m4 from White Hunter Site, Riversleigh WHA, northwestern Queensland, Australia (Cooke, 1992).

Referred specimens. Gillespie's Gully Site: QM F30076, right dentary with i1, p3, m1-m4. LSO Site: QM F58658, right maxilla with P3, M1-M4; QM F30298, right dentary with p3, m1-m4; QM F31463, left dentary with p3. White Hunter Site: 
1
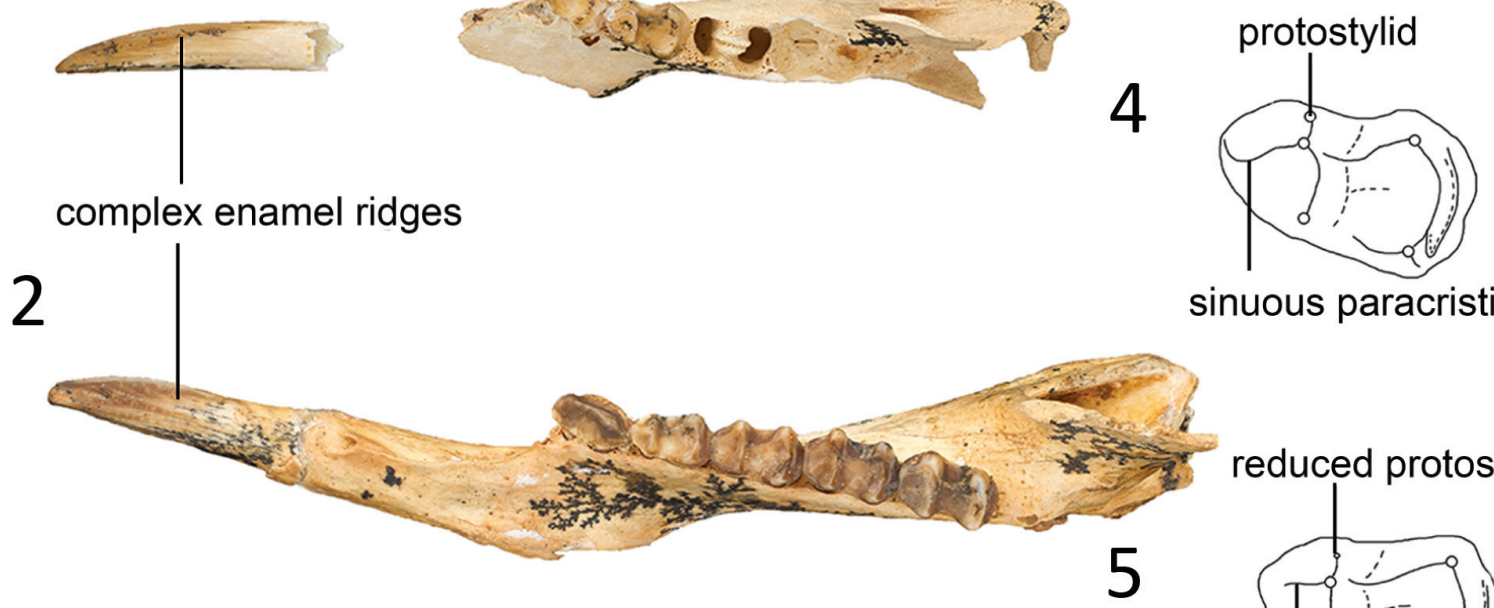

sinuous paracristid

3

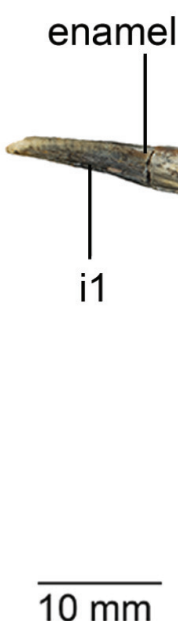

slight (worn) paracristid

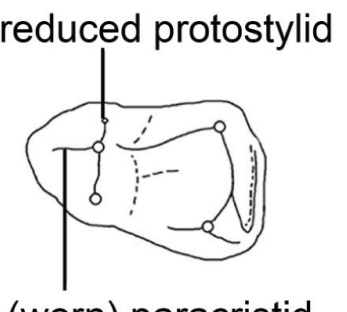

$10 \mathrm{~mm}$

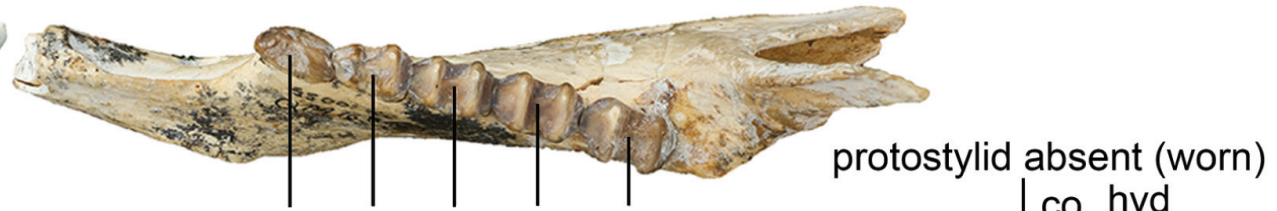

p3 $\quad \mathrm{m} 1 \quad \mathrm{~m} 2 \mathrm{~m} 3 \mathrm{~m} 4$

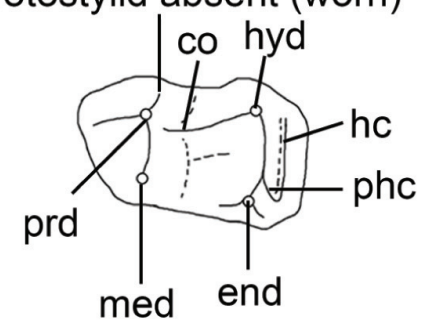

FIGURE 3. Occlusal view of lower dentary and line drawing of first molar for juvenile (1), adult (2), worn adult (3) specimens of a single species from Faunal Zone B; and line drawings for juvenile m1 (4), adult m1 (5), and worn adult m1 (6). The specimens were previously attributed to 1, Nambaroo sp. 4; 2, Nambaroo sp. 2 by Cooke (1997c) and 3, Ganawamaya acris Cooke (1992). Abbreviations: co, cristid obliqua; end, entoconid; hc, hypocingulid; hyd, hypoconid; $\mathrm{i} 1$, lower incisor; p3, third premolar; m1-m4, lower molars one to four; med, metaconid; phc, posthypocristid, prd, protoconid.

QM F58660, left dentary with p3, m1-m4; QM F58661, isolated m2-m3; QM F58662, isolated p3; QM F19584, left dentary with $\mathrm{p3}, \mathrm{m1}$, m3 in crypt; QM F19605, right dentary with m4; QM F19876, left dentary with m2-m4; QM F19878, left dentary with dp3, unerupted p3, m1; QM F19993, right dentary with m3, broken m4; QM F19994, left dentary with $\mathrm{m} 3$ in crypt; QM F20146, right isolated broken m2, m3; QM F20633, Left maxilla with m2-m4; QM F23354, left maxilla with M1-M2, broken M3; QM
F31182, left dentary with $\mathrm{p} 3, \mathrm{~m} 1-\mathrm{m} 3$, broken $\mathrm{m} 4$; QM F57791, left maxilla with P3, M1-M2.

Emended species diagnosis. Ganawamaya aediculis differs from all other species of Ganawamaya in having the following unique combination of features: long and sinuous i1 with dorsal and ventral flanges; additional cuspid on posterior end of $\mathrm{p} 3$ below the occlusal margin; linear occlusal edge on p3; inclined ridge from the anteriormost cuspid on p3; prominent hypocristid on $\mathrm{m} 1$ and $\mathrm{m} 2$; reduced 

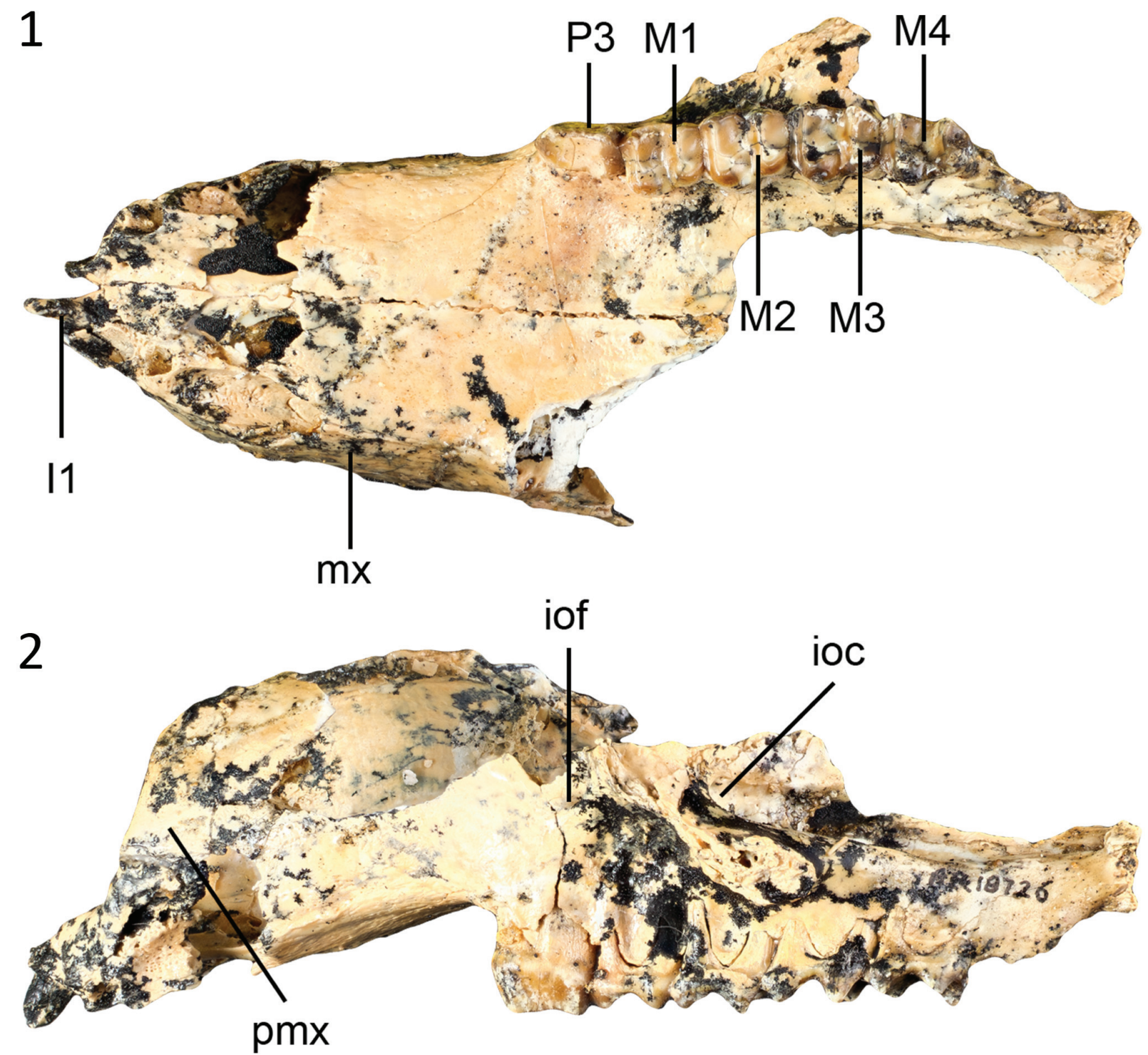

\section{$10 \mathrm{~mm}$}

FIGURE 4. Ganawamaya aediculis partial cranium (QM F58658) in ventral view (1) and left lateral view (2). Abbreviations: 11, first upper incisor; ioc, infraorbital canal; iof, infraorbital foramen; M1-M4, upper first to fourth molar; mx, maxilla; P3, upper third premolar; pmx, premaxilla.

paraconid on $\mathrm{m} 1$; no hypoconulid; no marked convexities on the lateral margins of the interloph valley of the lower molars; $\mathrm{m} 1$ anterior cingulid not extending from paracristid right across to buccal surface of the tooth; poorly developed anterior cingulum of M1; poorly developed anterior cingulum on M1; stylar cusp C on M1 reduced and connected to the postparacrista.

\section{Description}

Description follows Cooke (1992) but we note the following additional features.

Premaxilla. In lateral view, the maxillary-premaxillary suture extends ventrally to the posterior margin of the canine alveolus.

Maxilla and palatine. The infraorbital canal is tube-like and positioned at the anterior extremity of the suborbital shelf. The sphenopalatine foramen is 
oval in shape, anteriorly positioned on the palatine, posterior to the infraorbital canal.

Upper dentition. Description of the upper dentition of Gan. aediculis is based on QM F58658 and 20633. In ventral view (Figure 4) the canine alveolus is larger than each of the three incisor alveoli. The I1 is preserved, lightly recurved and anteroventrally directed. The size of the incisor alveoli may indicate that $\mathrm{I} 2$ is the largest incisor, followed by II and then I3. The left and right I1 alveoli are separated by a wide diastema. In occlusal view, 11 is long, elongate and laterally compressed. 11 is slightly recurved in lateral view. No I2, 13 or $\mathrm{C} 1$ are preserved, however their presence is indicated by alveoli.

The P3 is flexed anterobuccally such that is not in line with the molar row. The tooth is roughly rectangular in occlusal outline but is tapered anteriorly. Five cuspules are visible with the posteriormost cusp being the largest. Each cuspule has an associated transcrista. A prominent posterior lingual cuspule is present from which a well-developed lingual cingulum extends. In lateral view, the occlusal margin of the P3 is slightly concave.

In occlusal view, the M1 is roughly rectangular in outline. The protoloph and metaloph are roughly equal in height, however, the metaloph is narrower than the protoloph. The paracone is shorter but more massive than the protocone. A short, welldeveloped preparacrista extends from the paracone connecting to a well-developed anterior cingulum at the anterior end of the tooth. The anterior cingulum is bordered lingually by a faint forelink, representing a remnant preprotocrista. No precingulum is present. On the face of the paracone and lingual to the preprotocrista, a shallow concavity is present. The postparacrista is prominent and extends towards the interloph valley from the paracone. The postparacrista on M1 extends posteriorly to meet a small but distinct cusp. This cusp is interpreted to represent stylar cusp C in N. gillespieae by Kear et al. (2007). A poorly developed postprotocrista extends posteriorly to the interloph valley where it forms a midlink. The metacone is slightly taller than the metaconule. A premetacrista extends anteriorly to meet the postparacrista in the interloph valley. A prominent postmetacrista extends from the metacone to meet the postmetaconule crista. Both the neometaconule and postlink are absent.

The M2 is similar in morphology to M1 except as follows: it is slightly larger; the preparacrista is more buccally positioned; the anterior cingulum is wider; a precingulum is present lingual to the very faint forelink and borders the anterolingual margin of the tooth; the postparacrista is straighter anteriorly but meets the premetacrista more lingually in the interloph valley; the premetacrista is less developed; StC is present as a distinct cusp on the postparacrista only on QM F20633 where it is, however, poorly defined.

The M3 is similar in morphology to the M2 except as follows: StC is absent; the premetacrista, postprotocrista, and midlink are reduced.

The M4 is similar in morphology to the M3 except as follows: the metaloph is markedly narrower than the protoloph; the postparacrista and premetacrista are reduced; the forelink is more lingually situated.

Lower dentition. The description in Cooke (1992) is sufficient except for as follows: The protostylid on the $\mathrm{m} 1$ is present on unworn adult specimens e.g., QM F31181; and there are five cuspids on p3.

Remarks. Cooke 1992 described the holotype of Gan. aediculis (QM F16843) as having six cuspids on p3 with five associated transcristids. However, upon further inspection we clarify that like in other Ganawamaya species, only five cuspids and four transcristids appear to be present on the occlusal surface (Figure 5). However, an additional in Gan. aediculis, previously interpreted a sixth cuspid at the posterior of the p3 on the holotype, is present below the occlusal margin. The presence of a posterior cuspid on the $\mathrm{p} 3$ bellow the occlusal margin may be a distinguishing feature of Gan. aediculis (Figure 5). We propose that all Ganamwaya have five cuspids along the occlusal row of the p3 while Gan. aediculis has an additional posterior cuspid below the occlusal row. On a number of specimens attributed here to Gan. aediculis, the presence of this cuspid cannot be confirmed as the posterior end of the p3 has been obscured and worn by a slightly overlapping $\mathrm{m} 1$, making it difficult to determine whether this additional cusp is diagnostic of all Gan. aediculis. All specimens referable to species of Ganawamaya (and some previously referred to Nambaroo) from Faunal Zone A, also exhibit variation in apparent cuspid morphology that can be attributed to differences in inter-proximal dental wear similar to that of specimens reassigned to Gan. acris. These variations include the presence, or apparent absence, of the protostylid on $\mathrm{m} 1$, the shape of the paracristid on $\mathrm{m} 1$ and the complexity of enamel ridges on i1. However, specimens from Faunal Zone $A$ assemblages differ from those in Faunal Zone B in having a better defined posthypocristid on $\mathrm{m} 1$ and $\mathrm{m} 2$. Specimens previously attributed to 'N. sp. 8' (Cooke, 1996, 1997a) 


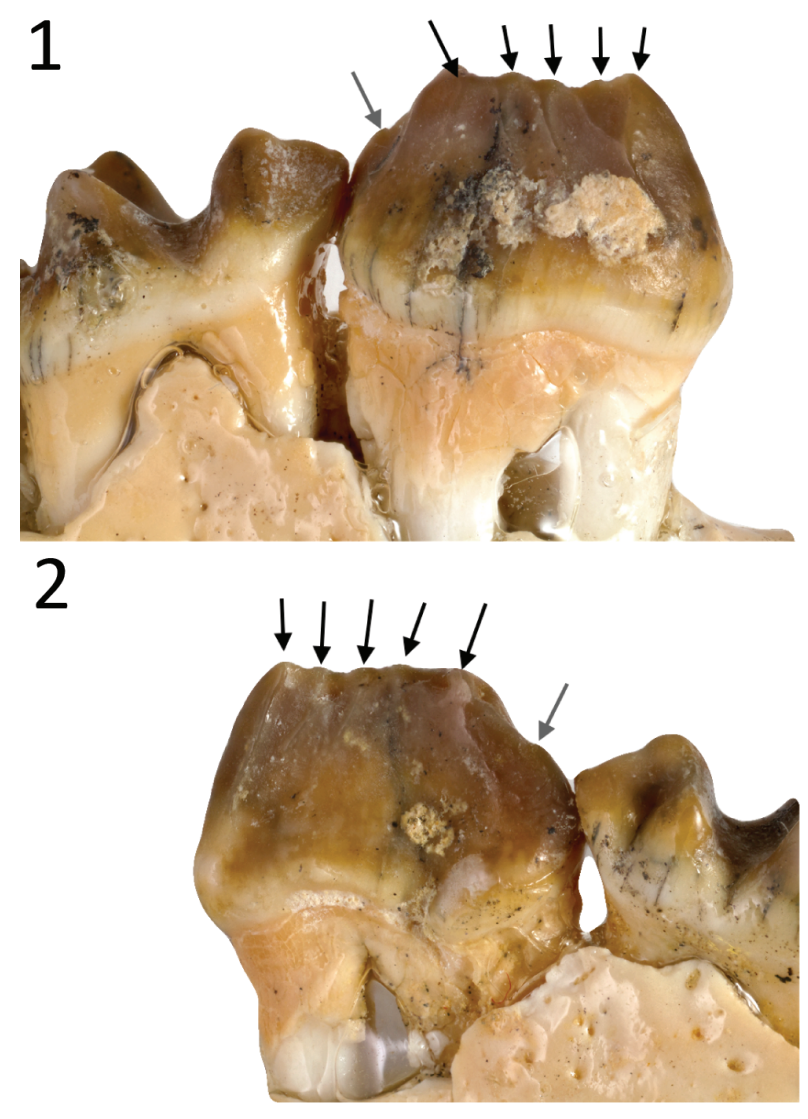

FIGURE 5. Lower third premolar of Ganawamaya aediculis holotype (QM F16843) in buccal view (1) and lingual view (2). Black arrows indicate each cuspid along the occlusal surface of the p3. Grey arrows indicate the additional sixth cuspid present below the occlusal margin.

are referred here to Gan. aediculis because they lack features that would warrant separation as a distinct taxon.

Age and distribution. The holotype of Gan. aediculis is from White Hunter Site, Riversleigh WHA, northwestern Queensland. The White Hunter Site is interpreted to be part of Faunal Zone A, which is interpreted to be late Oligocene in age (Archer et al., 1989, 1997; Myers and Archer 1997; TravouilIon et al., 2006, 2011; Arena et al., 2015). Several other referred specimens are also from sites considered to belong to Faunal Zone A: Gillespie's Gully and LSO Site (Travouillon et al., 2006, 2011).

Ganawamaya gillespieae comb. nov.

v*2007 Nambaroo gillespieae; Kear, Cooke, Archer, and Flannery, p. 1147, figs. 1-10.

Holotype. QM F35432, cranium, left dentary and postcranial material from Quantum Leap Site, Riversleigh WHA, northwestern Queensland, Australia (Kear et al., 2007).
Referred specimens. Dirk's Tower Site: QM F13099, right dentary with p3, m1-m4; QM F13100, left maxilla with M2-M4; QM F16912, right maxilla with M1-M2; QM F20036, left dentary with m1-m3; QM F24178, right maxilla with M1-M2, M4; QM F24180, right maxilla with M2-M3; QM F24185, left maxilla with P3 and M1; QM F24479, left maxilla with broken M2, M3; QM F29661, right dentary with m2-m4; QM F30289, left dentary with p3, m1-m4; QM F36233, left dentary with i1, p3; QM F36339, left dentary with i1, dp2, unerupted p3, m1-m3.

Emended species diagnosis. Ganawamaya gillespieae comb nov. differs from all other species of Ganawamaya in having the following unique combination of features: no distinct masseteric process; poorly-developed sulcus on anterior extremity of zygomatic arch; a large zygomatic epitympanic sinus with a thick mesial wall; a small mastoid foramen on the mastoid/squamosal suture; prominent hypocristid on $\mathrm{m} 1$ and $\mathrm{m} 2$; reduced paraconidon $\mathrm{m} 1$; long and sinuous $\mathrm{i} 1$ with dorsal and ventral flanges; no hypoconulid; no marked convexities on lateral margins of interlophid valley of lower molars; poorly developed anterior cingulum of $\mathrm{M} 1$; stylar cusp $\mathrm{C}$ on $\mathrm{M} 1$ reduced and connected to postparacrista; no additional cuspid on the posterior of p3 below the occlusal margin; $\mathrm{m} 1$ anterior cingulid extends from the paracristid right across to buccal surface of tooth; curved occlusal edge on $\mathrm{p} 3$; no inclined ridge from the anteriormost cuspid on $\mathrm{p} 3$.

\section{Description}

The lower dentition resembles that described by Kear et al. (2007) other than as follows: The p2 (preserved in QM F36339) is a very short but broad tooth with steeply sloping buccal and lingual faces. Two prominent cuspids are evident along the blade of the tooth, each with associated transcristae. In buccal view the occlusal surface is slightly convex.

Remarks. Specimens here referred to species of Ganawamaya (and some previously referred to Nambaroo) from Quantum Leap and Dirk's Tower also exhibit cusp morphology variation that can be attributed to differences in dental wear similar to that of specimens reassigned to Gan. acris and Gan. aediculis. These variations include the presence, or apparent absence, of the protostylid on $\mathrm{m} 1$, the shape of the paracristid on $\mathrm{m} 1$ and the complexity of enamel ridges on i1. Both QM F13099 and 20036 for example have no protostylid but are otherwise similar to the holotype of Gan. gillespieae comb. nov. A second specimen referred 
1
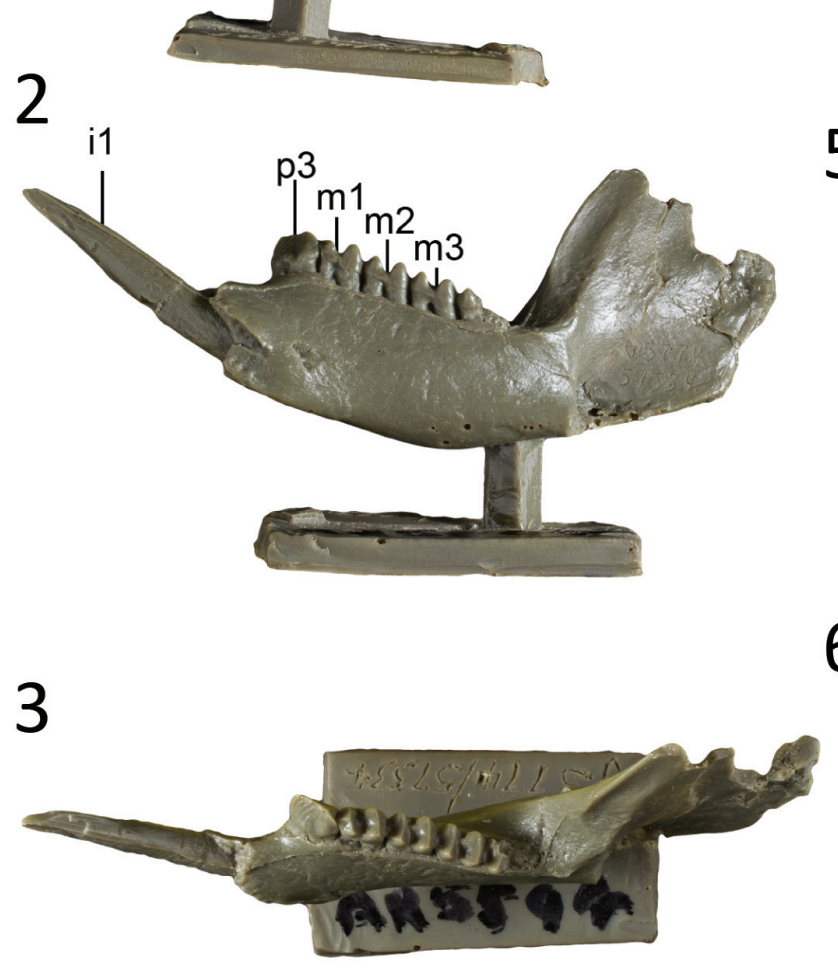

4

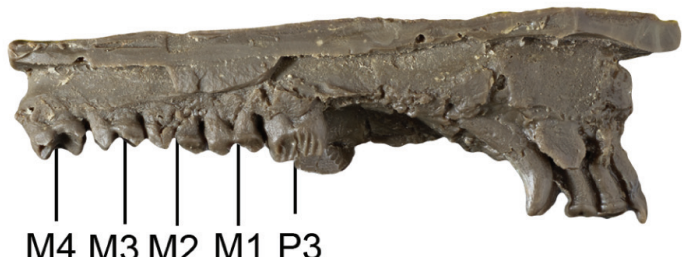

M4 M3 M2 M1 P3

5

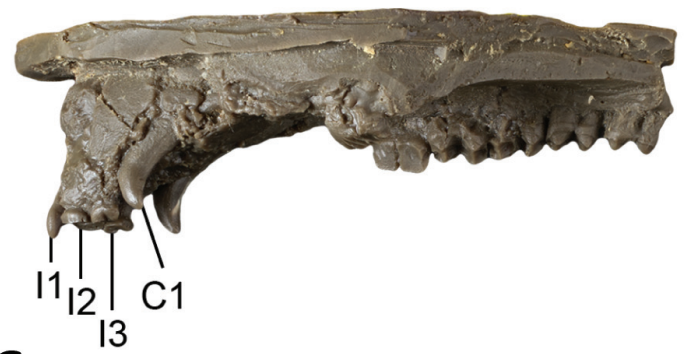

6

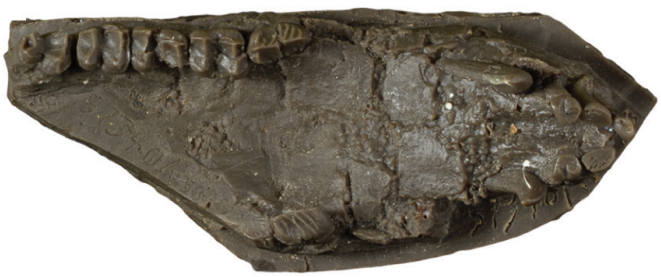

$10 \mathrm{~mm}$

FIGURE 6. Cast of lower dentition of Ganawamaya couperi comb. nov. (UCMP 57334) (1-3) and cast of upper dentition of Gan. couperi comb. nov. (UCMP 57340) (4-6) from the Ngapakaldi Local Fauna, South Australia. Right lateral view (1 and 4), left lateral view (2 and 5), and occlusal view (3 and 6). Abbreviations: C, canine, I1, first upper incisor; $\mathrm{i1}$, first lower incisor, M1-M4, upper first to fourth molar; m1-m3, lower first to third molar, P3, upper third premolar; p3, lower third premolar.

to $N$. gillespieae from Wayne's Wok Site (AR 12829) by Kear et al. (2007) could not be located for the present study. This specimen is therefore not included in the revised specimen list of Gan. aediculis.

Age and distribution. The holotype of Ganawamaya gillespieae comb. nov. is from Quantum Leap Site, Riversleigh WHA, northwestern Queensland. The Quantum Site was initially inter- preted to be part of Faunal Zone A (Travouillon et al., 2006, 2011). However, recent studies indicate that it is part of intervals B2 or B3 of Faunal Zone B (Travouillon et al., 2010, 2013; Arena et al., 2015). Other referred specimens from Dirk's Tower Site are interpreted to represent part of interval B1 of Faunal Zone B by Arena et al. (2015).

Ganawamaya couperi comb. nov. Figure 6 
v*1997 Nambaroo couperi; Cooke, p. 270, figs. 1, 2. Holotype. QM F30401, right dentary with p3 and m1-m4 from White Hunter Site, Riversleigh WHA, northwestern Queensland, Australia (Cooke, 1997b).

Referred specimens. The following specimens are referred based on casts of the original specimens. Ngapakaldi Local Fauna, South Australia: UCMP 57340, left maxilla with P3, M1-M4; UCMP 57337 right $\mathrm{M} 1-\mathrm{M} 2$ and right $\mathrm{p} 3, \mathrm{~m} 1-\mathrm{m} 3$; UCMP 57334, right dentary with p3, m1-m3.

Emended species diagnosis. Ganawamaya couperi comb. nov. differs from all other species of Ganawamaya in having the following combination of features: i1 long and narrow with no ventral flange; a hypoconulid present posterior to the entoconid on the buccal side of the $\mathrm{m} 1$; prominent posthypocristid on the $\mathrm{m} 1-\mathrm{m} 4$; marked convexities on the lateral margins of $\mathrm{m} 1-\mathrm{m} 4$; anterior cingulum on $\mathrm{M} 1$ is well developed; stylar cusp $\mathrm{C}$ is a prominent blade-like convexity buccal to the postparacrista; generally smaller molar size; no additional cuspid on the posterior end of the p3 below the occlusal margin; a poorly developed posterolingual cusp on the P3.

\section{Description}

Upper dentition. Description of the upper dentition of Gan. couperi comb. nov. is based on casts of UCMP 57340 (Figure 6) and 57337. In occlusal view, $I 1$ is large, elongate, and laterally compressed. In lateral view, I1 is slightly recurved, with a low but distinct posterobuccal cusp present. The crown of 11 sits much higher than that of 12 and 13 . In occlusal view, 12 is oval in shape but much longer than it is wide. The crown is completely flat from wear. 13 is shorter but wider than 12 . 13 is distinctly bilobed buccally, with the anterior lobe being larger than the posterior lob. Lingually, the crown has been flattened by wear.

The canines sit directly posterior to the incisors with no intervening diastemata. They are tall and reach a height equal to that of the crowns of 12-3. They are recurved and are slightly laterally inclined. A large diastema separates C1 from P3.

In occlusal view, the occlusal margin of $P 3$ is anterobuccally flexed and is out of alignment with M1. The P3 is blade-like, elliptical in shape, and tapered anteriorly. Six cuspules, each with associated lingual and buccal transcristae, are present along the occlusal margin. The posteriormost lingual and buccal transcristae are well developed as lateral blades, with a poorly developed posterolingual cusp.
The M1 is bilophodont, low crowned and roughly rectangular in outline. The metaloph is narrower than the protoloph. However, both are subequal in height. The paracone is shorter but more massive than the protocone. A short, well-developed preparacrista extends from the paracone to the anterior end of the tooth where it meets a reduced anterior cingulum. The anterior cingulum is bordered lingually by the forelink (remnant of the preprotocrista). No precingulum is present. A shallow concavity is present on the anterior face of the paracone lingual to the preparacrista. The postparacrista extends from the paracone posteriorly towards the interloph valley on UCMP 57340. The postparacrista is less developed on UCMP 57337. A prominent blade-like convexity is evident buccal to the postparacrista which is interpreted as stylar cusp C. The postprotocrista is weakly developed but extends posteriorly to the interloph valley where it forms a midlink. The metacone is taller than the metaconule. A prominent premetacrista extends into the interloph valley where it meets the postparacrista. A well-developed postmetacrista extends posteriorly from the metacone to meet the postmetaconule crista. The neometaconule and postlink are absent.

The $\mathrm{M} 2$ is similar in morphology to the M1 except as follows: it is larger; its protocone is taller; a long precingulum borders the anterior flank of the tooth from the forelink to the lingual side of the tooth; the premetacrista is less well developed; the postprotocrista and midlink are reduced on UCMP 57337.

The M3 is similar in morphology to the M2 except as follows: the preparacrista is more buccally situated; the postparacrista, premetacrista, postprotocrista, and midlink are reduced.

The M4 is similar in morphology to M3 except as follows: the metaloph is markedly shorter than the protoloph; the postparacrista is reduced; StC is absent; the postprotocrista and midlink are reduced; the forelink is more lingually situated, equalling the size of the anterior cingulum and precingulum.

Lower dentition. The description of Ganawamaya couperi comb. nov. is as stated by Cooke (1997b) except as follows: the i1, which is preserved in UCMP 57334, is long and narrow and rises to the level of the molar row. A dorsal enamel flange is present but there is no ventral flange.

The protostylid of the $\mathrm{m} 1$ is tall in UCMP 10600, a juvenile specimen, and is also present although more worn on the holotype and UCMP 57337 . The portion of the missing protostylid is rep- 
resented by a flat wear facet on UCMP 57334 , which represents an even older individual.

Remarks. Flannery and Rich (1986) diagnosed species of the genus Nambaroo as exhibiting the following features: well-developed lophs and lophids, $\mathrm{m} 1$ with a markedly compressed trigonid, a protostylid, posthypocristid on $\mathrm{m} 1$, and absence of a well-developed posterior cingulid on the lower molars. Our study demonstrates, in particular, that the protostylid is present in species of Ganawamaya as well as Nambaroo. Ganawamaya couperi comb. nov. differs from species of Nambaroo in having a rectilinear rather than a third premolar with a plagiaulacoid form, a less developed preprotocrista and a postprotocrista that extends into the interloph valley on M1. These features are present in the specimen previously attributed by Cooke (1997b) to N. couperi (QMF30401) and for this reason we contend that Gan. couperi comb.nov. is a species of Ganawamaya rather than Nambaroo. It is currently unclear whether the protostylid is lost due to wear in other species of Nambaroo. Large upper canines are also preserved in UCMP 57340. Although canine alveoli have been described for Nambaroo (Kear et al. 2007) and Ganawamaya in our study, this specimen is the first to be described in which the canines are preserved.

Age and distribution. The holotype is from White Hunter Site, Riversleigh WHA, northwestern Queensland, Australia. This site is part of Riversleigh's Depositional Phase 1 and contains species interpreted to represent Faunal Zone A assemblages which have been interpreted to be late Oligocene in age (Archer et al., 1989, 1997; Myers and Archer 1997; Travouillon et al., 2006, 2011; Arena et al., 2015). The referred specimens are from the Ngapakaldi Quarry of the Etadunna Formation is interpreted to be late Oligocene (24.6 Ma) in age (Woodburne et al., 1993).

Genus NAMBAROO Flannery and Rich, 1986

Type Species. Nambaroo tarrinyeri Flannery and Rich, 1986, by original description.

Emended generic diagnosis. Species of Nambaroo differ from all other balbarids in having the following combination of features: a short buccally flexed p3 with six to eight cuspids; a more plagiaulacoid p3 form; a poorly developed hypocingulid on the $\mathrm{m} 1$; a pronounced lingual cingulum on $\mathrm{P} 3$; possession of a neometaconule and postlink; a welldeveloped postprotocrista that does not extend into the interloph valley on M1.

Remarks. Nambaroo was first described by Flannery and Rich (1986) to accommodate three species characterised as differing from other balbarids
(Ganawamaya was not described at the time) by having a protostylid on $\mathrm{m} 1$, lacking a well-developed posterior cingulid on lower molars, and possessing a posthypocristid on the m1. Species of Nambaroo differ from Balbaroo in having noticeably smaller molars, a poorly developed midlink, and in lacking a well-developed hypocingulid on all lower molars. As previously discussed, our study demonstrates that the protostylid, a defining character in the generic diagnosis of Nambaroo (Flannery and Rich, 1986) is present in species of Ganawamaya as well as Nambaroo. However, Nambaroo species do differ from Ganawamaya species in having a more plagiaulacoid molar form as opposed to rectilinear, a more developed preprotocrista and postprotocrista, and possession of a postlink and neometaconule.

\section{MORPHOMETRIC AND PHYLOGENETIC ANALYSES}

\section{Coefficients of Variation}

Coefficients of variation for lower molars range from 3.7 to 14.2 for the revised Ganawamaya aediculis list of specimens (Appendix 2), 1.1 to 9.2 for Gan. gillespieae comb. nov. (Appendix 3) and 3.5 to 9.8 for Gan. acris (Appendix 4). For the upper dentition, coefficients of variation range from 0.1 to 11.4 for Gan. aediculis, 0.8 to 6.4 for Gan. gillespieae comb. nov. and from 3.9 to 8.9 for Gan. acris. The sample size for Gan. couperi comb. nov. was too small for statistical analysis. With the exception of variation in the length of P3 (0.8) and upper molars of Gan. gillespieae comb. nov., CVs are generally consistent with those for the extant macropodid species Thylogale thetis (4.98-11.16) and T. stigmatica (3.54-12.5); see Travouillon et al. (2014). While these results indicate that the range of dental measurements for Ganawamaya specimens are consistent with, or less diverse, than that evident in Thylogale species, we acknowledge that these results should be taken with caution as the expected variation in this study is based solely on two extant taxa. We propose that further study of intraspecific variation in the dentition of modern macropodids should be completed in the future.

\section{Bivariate Plots and Statistical Analysis}

Bivariate plots for lower dentition using the revised taxonomic classifications from this study are presented in Figure 7. The lower dentition of Ganawamaya acris, Gan. gillespieae comb. nov. and Gan. aediculis cannot be distinguished using bivariate plots. Ganawamaya couperi comb. nov. 

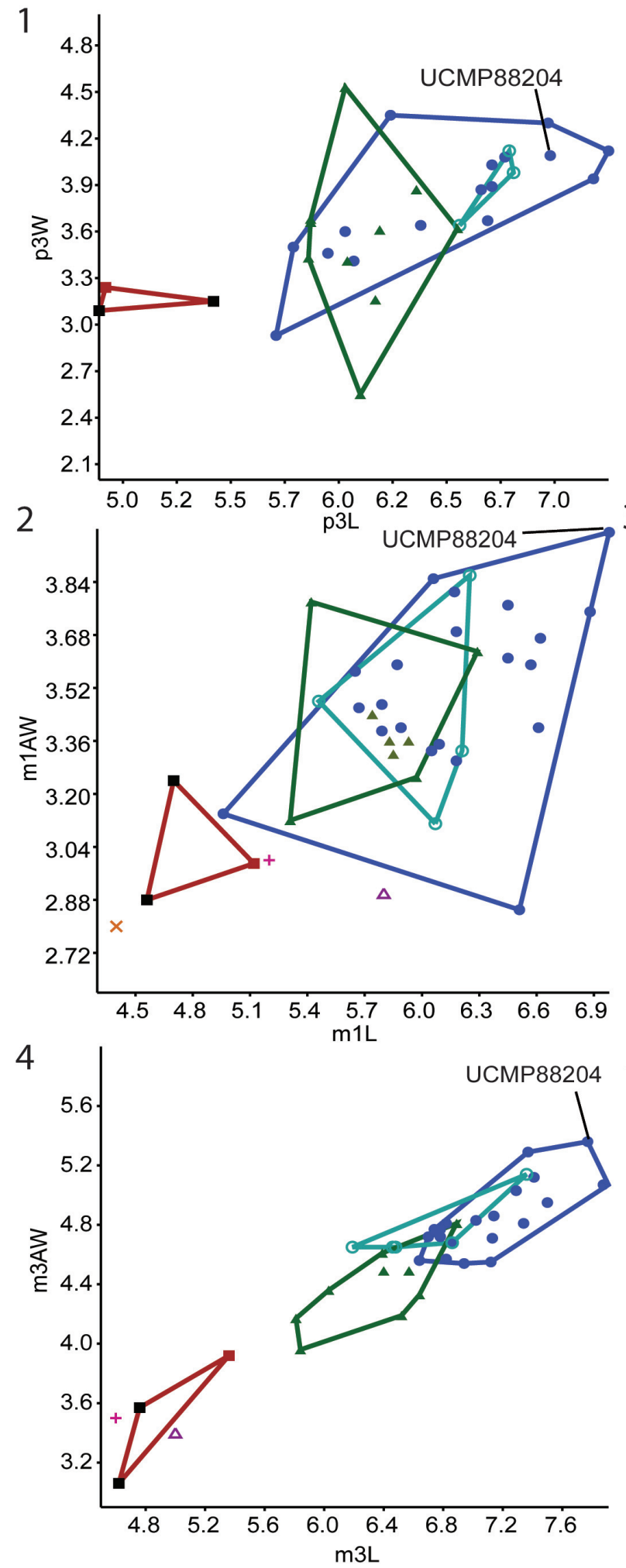

- Ganawamaya acris

- Gan. aediculis

- Gan. couperi comb. nov. from Riversleigh

- Gan. couperi comb. nov. from NLF

$\bigcirc$ Gan. gillespieae comb. nov.

+ Nambaroo tarrinyeri

$\triangle N$. saltavus

$\times N$. novus

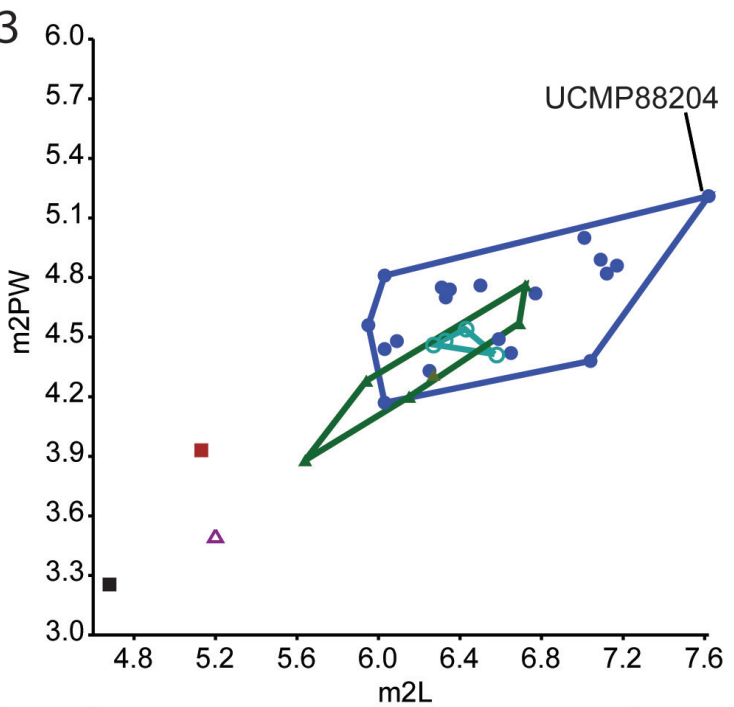

5

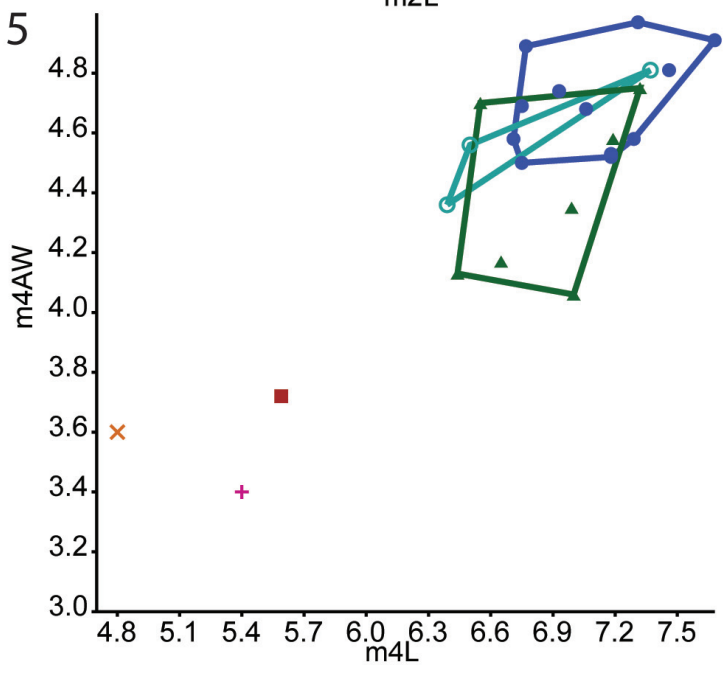

FIGURE 7. Bivariate plots of lower teeth: the third premolar (1) and the first to fourth molars (2-5) for specimens of Ganawamaya acris, Gan. couperi comb. nov., Gan. aediculis, Gan. gillespieae comb. nov., Nambaroo tarrinyeri, N. novus and $N$. saltavus from the Riversleigh World Heritage Area and the Ngapakaldi Local Fauna (NLF). Black squares represent specimens of Gan. couperi comb. nov. from NLF. Abbreviations: L, length; AW, anterior width; PW, posterior width; M1-M4, upper first to four premolar, P3, upper third premolar. 
can be distinguished from other Ganawamaya species at Riversleigh in having a shorter premolar and smaller molars. Specimens of Gan. couperi comb. nov. from South Australia (Ngapakaldi Local Fauna) are similar in molar size to the holotype from Riversleigh. Species of Nambaroo (N. tarrinyeri, $N$. novus and $N$. saltavus) cannot be distinguished from species of Ganawamaya based on molar size. The Gan. acris specimen from Leaf Locality (UCMP 88204) clusters with larger Gan. acris specimens from Riversleigh. These results also reflect those for the upper dentition (Figure 8). The results of Kruskal-Wallis tests (Appendix 5) indicate that dental measurements for each species differ significantly $(p<0.05)$ for lower premolar length and width, lower first molar length and anterior width, lower second molar posterior width, lower third molar length and widths, lower fourth molar anterior width, upper third premolar length and width and upper first, second and third molar length and widths. Mann-Whitney $U$ tests (Appendix 6 ) suggest that Gan, couperi comb. nov. is generally significant smaller than other Ganawamaya species $(p<0.05)$. Ganawamaya gillespieae comb. nov. is generally similar to Gan. acris in size but is significantly smaller $(p<0.05)$ in terms of third lower and upper molar posterior width, first upper molar posterior width, and second upper molar anterior and posterior widths (Appendix 6). Ganawamaya aediculis differs from other species significantly in terms of lower third premolar length, lower first and second molar posterior width, and lower third premolar length and width $(p<0.05$; Appendix 6).

\section{Principal Component Analysis (PCA)}

In the PCA of log transformed lower tooth measurements (Appendix 7), PC (Principal Component) 1 accounts for $62.7 \%$ of variance while PC2 accounts for $10.0 \%$ (Figure 9.1). The length of the premolar, length of the molars and the anterior, and posterior, widths of the $\mathrm{m} 3$ appear to have the most significant effect on PC1 (Appendix 7). PC2 is driven primarily by length and width of the lower third premolar. There is some overlap between Ganawamaya acris and Gan. aediculis. Ganawamaya acris and Gan. gillespieae comb. nov. overlap entirely. However, Gan. couperi comb. nov. falls outside the size range of other Ganawamaya species. In the PCA of log transformed upper tooth measurements (Appendix 8), PC1 accounts for $63.8 \%$ of the variance while PC2 accounts for $17.7 \%$ (Figure 9.2). Loadings for PC1 are highest for the length and width of the upper first and sec- ond molars as well as the length of the P3 (Appendix 8). The length and width of the upper fourth and third molars also have high loadings. Loadings for PC2 are highest for the length and width of the upper third and fourth molars. While there is some separation of Gan. acris (PC1: -0.4-2.56) and Gan. aediculis (PC1: -1.8-0.5) specimens in terms of principal components, both can be distinguished from Gan. couperi comb. nov., which has lower PC2 values (Figure 9.2). There is significant overlap between Gan. acris and Gan. gillespieae comb. nov. Sample sizes for Nambaroo species (N. tarrinyeri, $N$. novus, and $N$. saltavus) were not sufficient to include in the PCA.

\section{Phylogenetic Analysis}

Our analysis resulted in 1580 most parsimonious trees (tree length $=578$, consistency index $=$ 0.36 , retention index $=0.79$ ). The trees are summarised in a strict consensus tree in Figure 10. Hypsiprymnodontidae is unresolved at the base of the macropodiform clade. However, Propleopinae is recovered as a distinct group and as a sister taxon to Balbaridae but with low support. Within Balbaridae, Nambaroo saltavus and N. tarrinyeri are recovered at the base of the balbarid clade. Ganawamaya species form a distinct clade to the exclusion of Nambaroo species from South Australia ( $N$. saltavus and $N$. tarrinyeri) with moderate support (Bootstrap $=79$ ). Ganawamaya aediculis and Gan. gillespieae comb. nov. cluster together to the exclusion of Gan. acris and Gan. couperi comb. nov. with low support (Bootstrap $=61$ ). Ganawamaya forms a sister clade to Balbaroo and Wururoo. Macropodidae is recovered as a clade distinct from Hypsiprymnodontidae and Balbaridae with high support (Bootstrap $=85$ ). Our matrix includes those characters uniting Balbaridae as a family in Kear and Cooke (2001), and the strict consensus tree supports its placement as a distinct group.

Within Macropodidae, extant species of Potoroinae (Potorous tridactylus, Bettongia penicillata, and Aepyprymnus rufescens) are recovered as a monophyletic clade but with low support from bootstrap analysis. Specimens previously referred as fossil potoroines do not form a clade with the extant species and instead appear to be an outgroup to all other macropodids. This suggests that these species are most likely not potoroines but stem macropodids. However, missing data for fossil specimens may affect the positioning of these species within the phylogenetic tree. Species of Ganguroo and Wabularoo are unresolved at the base of the clade that includes lagostrophines, 

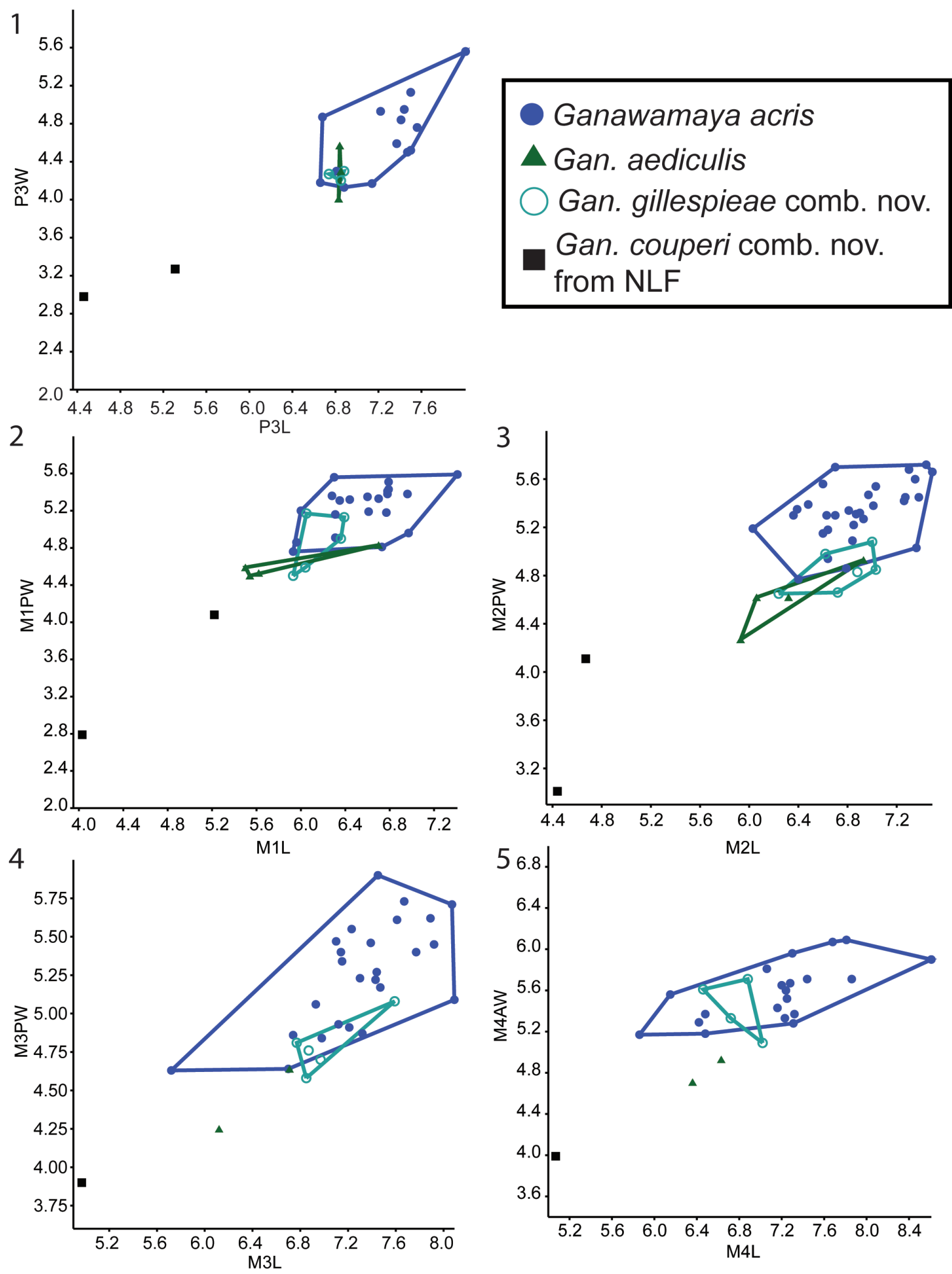

FIGURE 8. Bivariate plots of upper teeth: the third premolar (1) and the first to fourth molars (2-5) for specimens of Ganawamaya acris, Gan. aediculis, Gan. gillespieae comb. nov. and Gan. couperi comb. nov. from the Riversleigh World Heritage Area and the Ngapakaldi Local Fauna (NLF). Black squares represent specimens from NLF. Abbreviations: L, length; AW, anterior width; PW, posterior width; M1-M4, upper first to four premolar; P3, upper third premolar. 


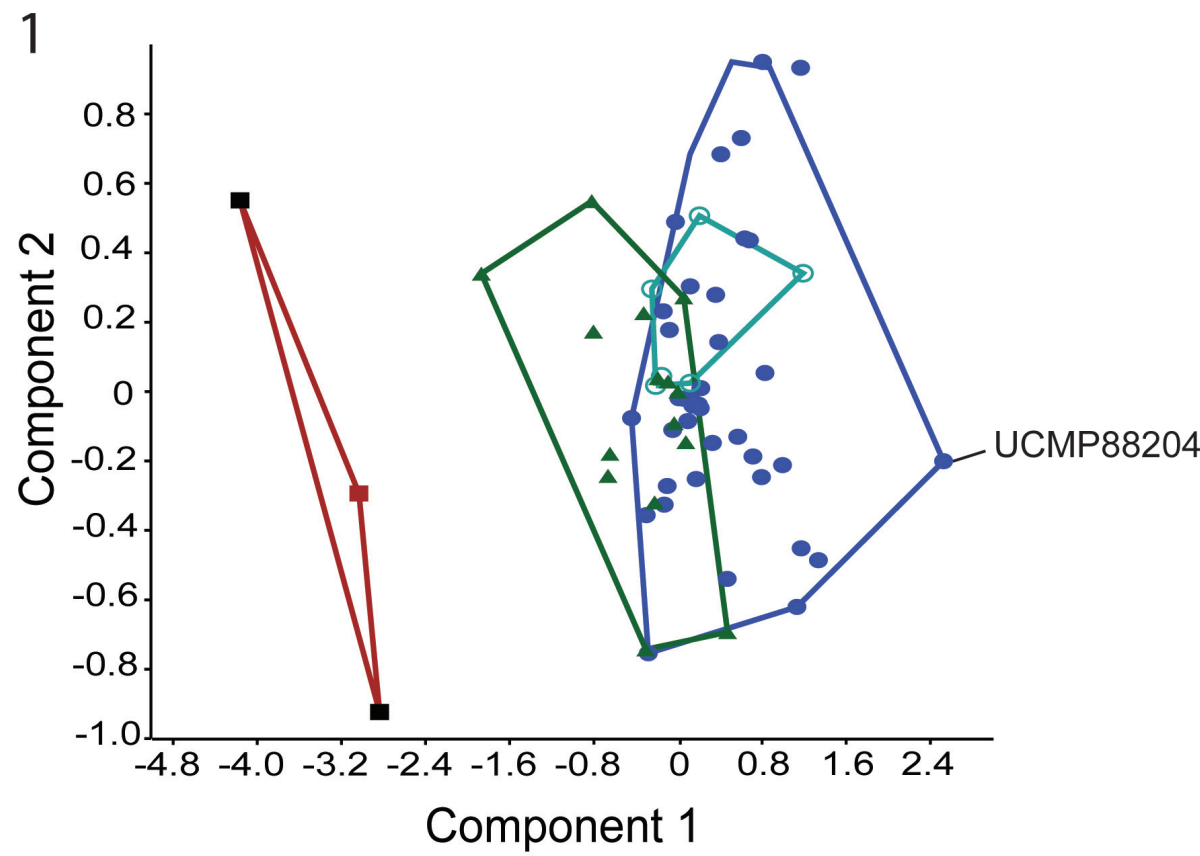

2

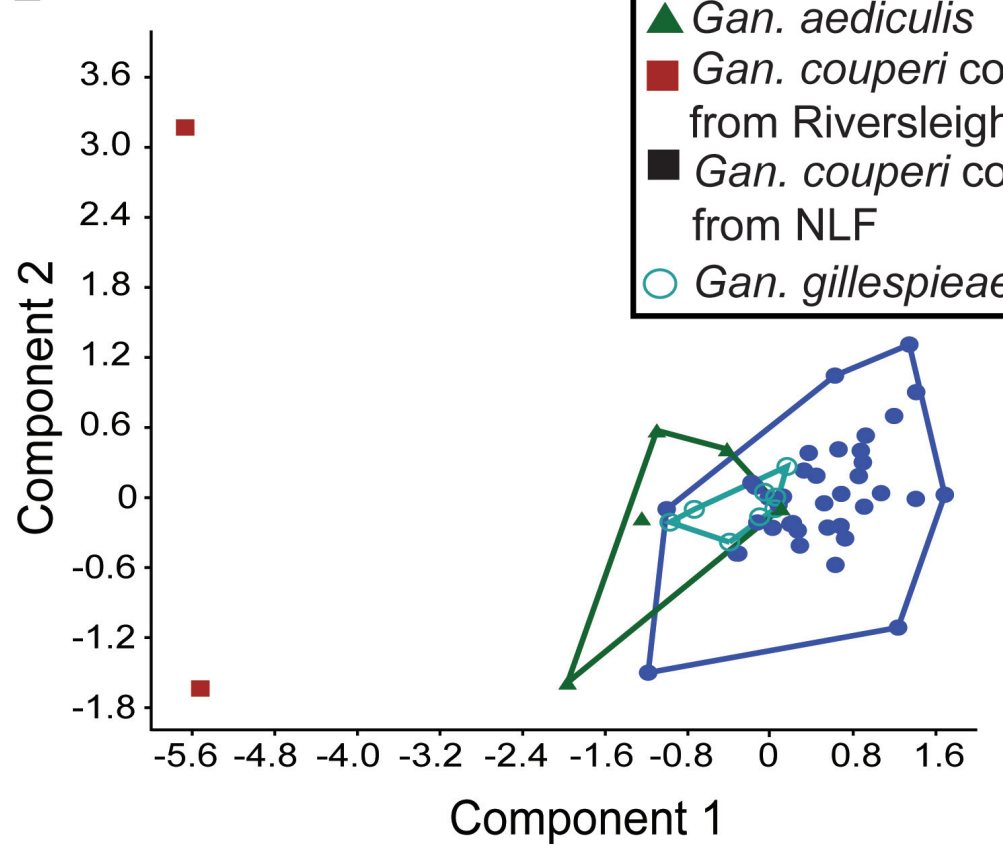

FIGURE 9. Principal Component Analysis with convex hulls of log transformed measurements for upper (1) and lower (2) tooth measurements for Ganawamaya acris, Gan. couperi comb. nov., Gan. gillespieae comb. nov. and Gan. aediculis from the Riversleigh World Heritage Area and the Ngapakaldi Local Fauna (NLF)".

sthenurines, and macropodines. In analyses of previous iterations of the matrix, the interrelationships of Lagostrophinae, Sthenurinae, and Macropodidae were also unresolved (e.g., Butler et al., 2016). We believe that the inclusion of the genus Cookeroo in Butler et al. (2016) resulted in the col- lapse of these clades because the genus shares a number of characters with specimens from each of the three clades. As such we did not include Cookeroo in this analysis. This also indicates that macropodiform phylogeny requires significant further study and, as suggested by Butler et al. 


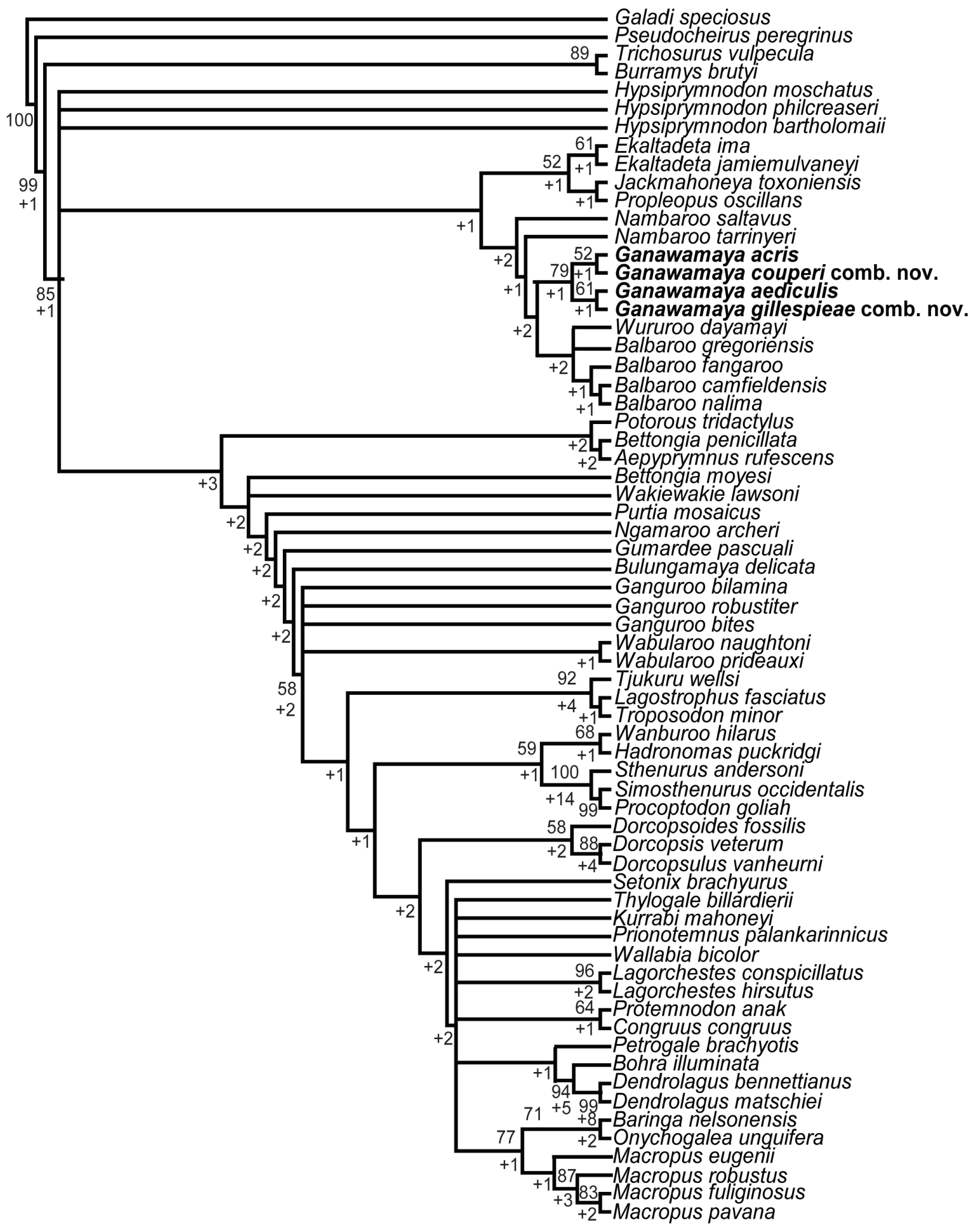

FIGURE 10. Strict consensus of 1580 most parsimonious trees (tree length $=578$, consistency index $=0.36$, retention index $=0.79$ ) from parsimony analysis of the matrix containing 66 taxa and 120 characters, assessing the phylogenetic relationship of revised Ganawamaya (highlighted in bold). Numbers above represent bootstrap values while numbers below represent decay indices. Decay indices are prefaced with a plus sign. 
(2016), the inclusion of additional postcranial material, if suitable specimens are recovered, may resolve the issue.

In the present study, Lagostrophinae is recovered as a clade with high support (Bootstrap =92), and as a sister taxon to Sthenurinae and Macropodinae but with low support, supporting the results of Prideaux and Warburton (2010). Sthenurinae (including Wanburoo hilarus and Hadronomas puckridgi) is recovered as a clade with low support (Bootstrap $=59$ ) and as a sister taxon to Macropodinae but with low support. Macropodinae is recovered as a clade with low support. The clade composed of members of the genus Dorcopsoides is recovered as a sister taxon to all other macropodines. The relationships of clades within Macropodinae are unresolved.

\section{DISCUSSION}

Of the features distinguishing Nambaroo (see remarks), which were described by Flannery and Rich (1986), only the protostylid differs from descriptions of Ganawamaya by Cooke (1992). Of the states listed in the descriptions of Gan. couperi comb. nov. (N. couperi in Cooke, 1997b) and Gan. gillespieae comb. nov. (N. gillespieae in Kear et al., 2007), the presence of a protostylid on $\mathrm{m} 1$ appears to be the primary distinguishing feature from Ganawamaya. In our study, however, the lack of a protostylid on $\mathrm{m} 1$ appears to be the result of dental wear and not a diagnostic feature for distinguishing Nambaroo and Ganawamaya. The protostylid is present in juvenile and relatively little-worn teeth but absent in most adult specimens because of wear. Kear et al. (2007) noted that in Gan. gillespieae comb. nov. there is a concavity (wear facet) on the anterobuccal face of the paracone, lingual to the preparacrista on $\mathrm{M} 1$, which received the $\mathrm{m} 1$ protostylid. This wear facet is also present on Gan. aediculis as described in our study, and on the referred specimen of Gan. acris described by Cooke (1992) but was not recognised to be the consequence of occlusion between the protostylid of $\mathrm{m} 1$ and the upper molar. The presence of this wear facet suggests that a protostylid was likely present in juveniles of Ganawamaya/Nambaroo species. However, we interpret that this interaction between the protostylid of the $\mathrm{m} 1$ and upper molar only occurs when the jaw is at rest and does not account for the wearing of the protostylid. For Gan. gillespieae comb. nov., during occlusion, the protostylid on the $\mathrm{m} 1$ slides between blade of the P3 and the P3's posterolateral cusp thus wearing the protostylid slowly. The presence of a protostylid in juveniles but absence in adults is also similar to findings in other balbarid taxa such as Balbaroo fangaroo and $B$. nalima (Black et al., 2014) although the protostylid appears to wear slower in Ganawamaya than in Balbaroo. In species of Balbaroo the P3 posterolateral cusp sits directly in front of the protostylid such that as the jaw moves forward it would be expected that the posterolateral cusp would wear down the protostylid much quicker than in Ganawamaya.

Our phylogenetic analysis also indicates that species of Ganawamaya and species previously attributed to Nambaroo from Riversleigh form a distinct clade to the exclusion of Nambaroo saltavus and $N$. tarrinyeri (Figure 10). Specimens of Ganawamaya from Riversleigh differ from N. tarrinyeri and $N$. saltavus in having a more rectilinear rather than plagiaulacoid-like p3 in addition to a less developed preprotocrista and a postprotocrista that extends into the interloph valley in $\mathrm{M} 1$ and in lacking a postlink and neometaconule on upper molars, although they are similar in molar size to smaller Gan. couperi comb. nov. (Figure 7). These results indicate that Riversleigh species previously attributed to Nambaroo and Ganawamaya are referrable to a single genus, Ganawamaya, and that the assigned species differ from those of $\mathrm{Nam}$ baroo from South Australia. Specimens previously attributed to $N$. couperi and $N$. gillespieae are here referred to Ganawamaya. Thus, the geographic range of Nambaroo is restricted only to South Australia.

The previously proposed 12 species for Ganawamaya (previously Ganawamaya and Nambaroo) at Riversleigh (Cooke, 1996, 1997a) were distinguished on the combination of the complexity of enamel ridges on the $\mathrm{m} 1$, shape of the paracristid, number of cusps on P3 and the presence of a hypoconulid on lower molars (Cooke, 1992, 1996, 1997b). Variation in the complexity of enamel ridges and shape of the paracristid appear to relate to stages of dental wear (see Figure 3). Juvenile or less worn adult specimens have a longer more sinuous paracristid, while adult specimens can have a shorter paracristid resulting from wear of the anterior portion of the paracristid. Complex enamel ridges are generally evident in juvenile specimens, such as that of the holotype of Gan. ornata. The combination of a sinuous versus straight paracristid, and the presence or absence of complex enamel ridges, are therefore evidently not taxonomically informative characters for distinguishing species of Ganawamaya (and previously Nambaroo). 
The results of our phylogenetic analysis are consistent with previous phylogenetic analyses (Kear et al., 2007; Kear and Pledge, 2007; Travouillon et al., 2014) in that Propleopinae (Ekaltadeta, Jackamhoneya, Propleopus) comes out as the sister taxon of Balbaridae, although support for this relationship is weak. Nambaroo saltavus and $N$. tarrinyeri appear to be relatively plesiomorphic members of the balbarid clade, with species of Ganawamaya (including Gan. couperi comb. nov.) forming a distinct clade. Ganawamaya species are recovered as the sister taxon to a group including species of Balbaroo and Wururoo. The interrelationships of Balbaroo species in our analyses are consistent with the results of Black et al. (2014), although there is relatively low bootstrap support for this relationship. Here, an additional phylogenetic character, the presence or absence of an interparietal, was included in the analysis. No interparietal was evident in either of the propleopine or balbarid crania available for study, and the absence of an interparietal appears to be a synapomorphy uniting the two clades in our analysis. If this is the case, Propleopinae could be a subfamily of Balbaridae, rather than Hypsiprymnodontidae. However, it should be noted that an interparietal suture on a balbarid was described and figured by Kear (2003) on a Balbaroo endocranial cast. However, because this specimen and the undescribed but associated fragmentary cranium referred to by Kear (2003) could not be located for our present study, we cannot confirm the existence of this feature in balbarids.

In terms of Riversleigh biostratigraphy, Gan. couperi comb. nov. is known only in Faunal Zone $A$ assemblages. Ganawamaya couperi comb. nov. appears to be more plesiomorphic than Gan. aediculis in that it retains a hypoconulid similar to that seen in species of Nambaroo from the late Oligocene Namba Formation (Flannery and Rich, 1986). However, Gan. couperi comb. nov. groups phologentically with Ganawamaya from Riversleigh as opposed to Nambaroo. Ganawamaya couperi comb. nov. can also be distinguished from other species of Ganawamaya in having marked convexities on the lateral margins of the m1-m4 (Cooke, 1997b) and by its significantly smaller molar size as evident in bivariate plots (Figure 8, 9). Ganawamaya aediculis is only present in Fauna Zone A assemblages at Riversleigh. It has features that appear to be ancestral to those of Gan. acris, such as the presence of a more pronounced posthypocristid on $\mathrm{m} 1$ and a poorly developed anterior cingulid, a strongly developed postprotocrista on M1, a less developed sulcus on the anterior extremity of the zygomatic arch, a distinct process on the ectotympanic, and smaller mastoid foramen on the mastoid/squamosal suture. Additionally, the presence of Gan. aediculis primarily in late Oligocene (Faunal Zone A) deposits suggests that it may be ancestral to Gan. acris, which occurs primarily in Miocene assemblages (Faunal Zone B, intervals $\mathrm{B} 2$ and B3, and Faunal Zone C, interval C1). This relationship was not resolved in phylogenetic analyses (Figure 10), which indicate that Gan. gillespieae comb. nov. and Gan. aediculis cluster together to the exclusion of Gan. acris and Gan. couperi comb. nov. However, we believe that this is because there are no characters distinguishing Gan. gillespieae comb. nov. and Gan. aediculis in the phylogenetic matrix. Despite this, examination of characters not included in the matrix but noted in our species diagnoses suggests that Gan. gillespieae comb. nov. retains an $\mathrm{m} 1$ anterior cingulid which extends from the paracristid right across to the buccal surface of the tooth, a more curved occlusal edge on $\mathrm{p} 3$ and no inclined ridge from the anteriormost cuspid on p3. It is therefore possible that Gan. aediculis, Gan. gillespieae comb. nov., and Gan. acris form a continuous evolutionary lineage and may be chronospecies.

A presence/absence table for Ganawamaya species is provided in Table 8. Specimens from Dirk's Tower are interpreted as belonging to Faunal Zone B by Travouillon et al. (2010) and interval B1 by Arena et al. (2015). Specimens from Quantum Leap Site interpreted as a Faunal Zone B assemblage by Travouillon et al. (2010) and interval B2 or B3 by Arena et al. (2015), are referred to Gan. gillespieae comb. nov. The presence of Gan. gillespieae comb. nov. alone and absence of Gan. acris in Quantum Leap Sites suggest that the deposit may be older than other Faunal Zone B, interval B2 sites. One specimen attributed to Gan. acris in this study is from Gag Site which is interpreted as a Faunal Zone $\mathrm{C}$ assemblage, interval $\mathrm{C} 1$ or $\mathrm{C} 2$ by Arena et al. (2015). This extends the temporal range of Ganawamaya into the middle Miocene. This specimen is currently the only Ganawamaya specimen known from Faunal Zone C. As a result two balbarid species (Gan. acris and Balbaroo nalima) are present in Faunal Zone $C$ assemblages at Riversleigh.

A previous biostratigraphic study has indicated the presence of undescribed species of Nambaroo in the Ngapakaldi Quarry and Leaf Locality deposits (Woodburne et al., 1993). Examination of four specimens from the Ngapakaldi 
TABLE 8. Presence/absence table for species of Ganawamaya throughout Australia. Numbers represent the number of specimens. Abbreviations are: B, Boid Site; CR, Creaser's Ramparts Site; CS, Camel Sputum Site; D, D Site; DT, Dirk's Towers Site; G, Gag Site; GG, Gillespie's Gully Site; LSO, LSO Site; NG, Neville's Garden Site; PIR, Price Is Right Site; RSO, RSO Site; U, Upper Site; WH, White Hunter Site; WW, Wayne's Wok Site.

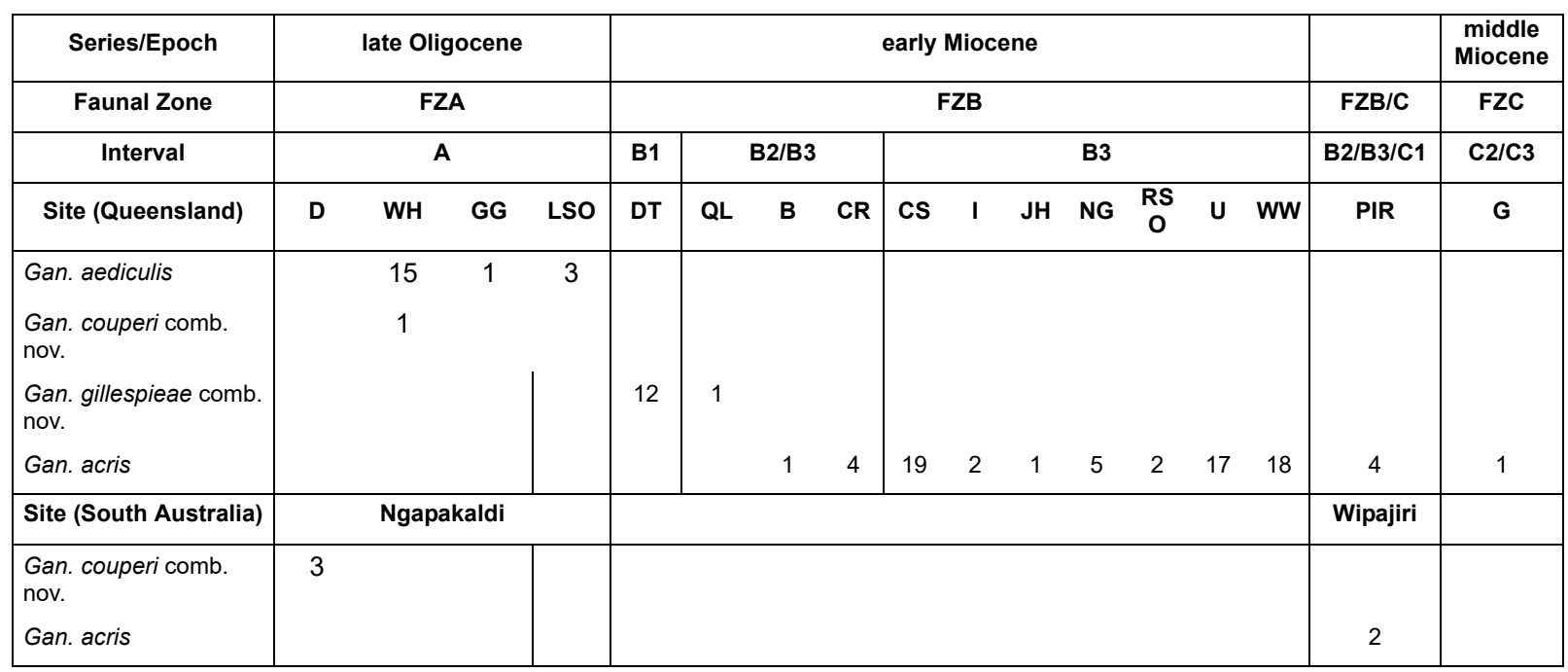

Quarry, South Australia (UCMP 10600, 57340, 57337 and 57334) indicates that these specimens differ from Nambaroo tarrinyeri, $N$. novus, and $N$. saltavus from the Namba Formation, South Australia. Each specimen exhibits morphological features that characterise Gan. couperi comb. nov. including a more rectilinear (rather than plagiaulacoid) p3, less developed preprotocrista, a postprotocrista that extends into the interloph valley, a posthypocristid evident on $\mathrm{m} 4$, and marked convexities on the lateral margins of the $\mathrm{m} 1-\mathrm{m} 4$. The associated upper dentition (UCMP 57340) indicates that in Gan. couperi comb. nov., StC is present buccal to the postparacrista, which is not the case in other Ganawamaya species where StC is connected to the preparacrista. Two specimens from the Leaf Locality, South Australia (UCMP 88212 and 88204), are identified in the present study as Gan. acris. The presence of species of Ganawamaya in South Australia significantly extends the geographic range of this genus, and further supports the correlation between the Leaf Locality of the Wipajiri Formation and early Miocene assemblages (e.g., Faunal Zone B) at Riversleigh (e.g., Archer et al., 1997; Travouillon et al., 2006).

After revising Riversleigh specimens referred to Ganawamaya or previously attributed to Nambaroo, we recognise a total of four species, all referable to Ganawamaya: Gan. acris, Gan. aediculis, Gan. couperi comb. nov., and Gan. gillespieae comb. nov. Postcranial material, QM F35432, from Riversleigh previously referred to $N$. gillespieae (Kear et al., 2007) is now referred to Ganawamaya.
This postcranial material has been interpreted to imply a quadrupedal gait for Nambaroo and other balbarid species (Kear et al., 2007; Black et al., 2014). Alternatively, analysis of macropodiform calcaneal measurements by Janis et al. (2016) indicates that balbarids postcranial material is more consistent with generalized hoppers such as those of the genus Thylogale (pademelons). Further analysis is required in order to resolve the conflicting results for proposed locomotor ability of balbarids at Riversleigh.

Species of Ganawamaya also exhibit lophodont dentitions, consistent with a browsing herbivorous diet, and a mesowear profile of sharp and tall cusps, consistent with mesowear profiles of extant browsing kangaroo species recorded by Butler et al. (2014). Analysis of the relationship between macropodiform craniodental measurements and diet suggests that the diets of balbarids such as Balbaroo species and Gan. aediculis are generally consistent with extant folivorous browsing kangaroos. Species of Nambaroo fall either in the browsing/omnivore category or close to folivorous browsers (Janis et al., 2016). Analyses by Janis et al. (2016) suggest that macropodid species from the same Riversleigh Faunal Zones were also folivorous browsers.

The similar diets of balbarids such as Ganawamaya and macropodid species (Janis et al., 2016) may suggest that extinction of Balbaridae during the middle Miocene, as proposed by Cooke (1997a), was driven by competition between these clades. If macropodids exhibited a 
greater deal of dietary plasticity this may have put balbarids at a selective disadvantage at a time when global cooling (e.g., McGowran and Li, 1994) and changes in environment at Riversleigh from rainforest to open woodland during the mid to late Miocene occurred (Travouillon et al., 2009). Such changes in environment at the time are supported by analyses from Travouillon et al. (2009). However, further study comparing diets of these species using dietary proxies known to reflect diet of kangaroos on ecological time scales such as mesowear analysis (e.g., Butler et al., 2014) or stable isotope analysis (Montanari et al., 2013) are required in order to test these hypotheses further. Recent analyses of trends in macropodiform species diversity and trends in body mass through time (Butler et al., 2017) made use of the revised classifications of Ganawamaya specimens presented in this study. The results suggested that balbarids were less abundant than macropodids during the Late Oligocene and most of the Miocene (Butler et al., 2017).

\section{CONCLUSION}

The revision of Nambaroo and Ganawamaya results in a significant reduction in apparent diversity of late Oligocene to early Miocene balbarids from 12 proposed species down to just four. In addition, the temporal range of Ganawamaya is extended into the middle Miocene of Riversleigh. Recent description, and revision, of balbarids from Riversleigh (e.g., Kear et al., 2007; Bates et al., 2014; Black et al., 2014; Travouillon et al., 2014,
2015; Cooke et al., 2015; Butler et al., 2016) suggest that the current understanding of balbarid and macropodid diversity and their temporal ranges will benefit from continued reassessment of existing, as well as rapidly accumulating new fossils from Oligo-Miocene sites throughout Australia.

\section{ACKNOWLEDGEMENTS}

Thank you to K. Spring, A. Rozefelds, S. Hocknull, and H. Janetzki of the Queensland Museum for access to specimens. Research at Riversleigh is supported by Australian Research Council grants (LP100200486, LP0989969, DE130100467, DP170101420 and DP130100197). We thank R. Day for providing funding to The University of Queensland to create a postdoctoral position for K.J. Travouillon. Thank you to the UNSW Palaeosciences Lab and the UQ PalaeoResearch Group for their support. We thank P. Creaser and the CREATE Fund; the Queensland Parks and Wildlife Service; Riversleigh Society Inc.; Environment Australia; Associated Scientific Limited; Outback at Isa; and private supporters including K. and M. Pettit, E. Clark, M. Beavis, M. Dickson, S. Lavarack, and the Rackham family. Hundreds of volunteers, staff and postgraduate students of the University of New South Wales have provided assistance in the field at Riversleigh. K. Butler was supported by an Australian Postgraduate Award. We thank anonymous reviewers and the editorial crew of Palaeontologia Electronica for helpful comments and advice.

\section{REFERENCES}

Archer, M. 1984. The Australian marsupial radiation, p. 633-808. In Archer, M. and Clayton, G. (eds.), Vertebrate Zoogeography \& Evolution in Australasia. (Animals in Space \& Time). Hesperian Press, Carlisle.

Archer, M., Godthelp, H., Hand, S.J., and Megirian, D. 1989. Fossil mammals of Riversleigh, northwestern Queensland: preliminary overview of biostratigraphy, correlation and environmental change. Australian Zoologist, 25(2):29-65. https://doi.org/10.7882/ AZ.1989.001

Archer, M., Hand, S.J., Godthelp, H., and Creaser, P. 1997. Correlation of the Cainozoic sediments of the Riversleigh World Heritage Fossil Property, Queensland, Australia, p. 131152. In Aguilar, J.P., Legendre, S., and Michaux, J. (eds.), Actes du Congr ès BiochroM'97, Mémoires et Travaux. L'école Pratique des Hautes Etudes, Institut de Montpellier, Montpellier, France.

Arena, D.A., Travouillon, K.J., Beck, R.M.D., Black, K., Gillespie, A.K., Myers, T.J., Archer, M., and Hand, S.J. 2015. Mammalian lineages and the biostratigraphy and biochronology of Cenozoic faunas from the Riversleigh World Heritage Area, Australia. Lethaia, 49:43-60. https://doi.org/10.1111/let.12131

Bates, H., Travouillon, K., Cooke, B., Beck, R., Hand, S., and Archer, M. 2014. Three new Miocene species of musky rat-kangaroos (Hypsiprymnodontidae, Macropodoidea): 
description, phylogenetics and paleoecology. Journal of Vertebrate Paleontology, 34(2):383396. https://doi.org/10.1080/02724634.2013.812098

Black, K., Archer, M., Hand, S., and Godthelp, H. 2012. The rise of Australian marsupials: A synopsis of biostratigraphic, phylogenetic, palaeoecologic and palaeobiogeographic understanding, p. 983-1078. In Talent, J. (ed.), Earth and Life. Springer, Netherlands. https:// doi.org/10.1007/978-90-481-3428-1

Black, K.H., Travouillon, K.J., Den Boer, W., Kear, B.P., Cooke, B.N., and Archer, M. 2014. A new species of the basal "kangaroo" Balbaroo and a re-evaluation of stem macropodiform interrelationships. PLoS ONE, 9(11):e112705. https://doi.org/10.1371/journal.pone.0112705

Butler, K., Louys, J., and Travouillon, K. 2014. Extending dental mesowear analyses to Australian marsupials, with applications to six Plio-Pleistocene kangaroos from southeast Queensland. Palaeogeography, Palaeoclimatology, Palaeoecology, 408:11-25. https:// doi.org/10.1016/j.palaeo.2014.04.024

Butler, K., Travouillon, K., Price, G.J., Archer, M., and Hand, S.J. 2016. Cookeroo, a new genus of fossil kangaroos (Marsupialia, Macropodidae) from the Oligo-Miocene of Riversleigh, northwestern Queensland, Australia. Journal of Vertebrate Paleontology, 36(3):e1083029. https://doi.org/10.1080/02724634.2016.1083029

Butler, K., Travouillon, K.J., Price, G.J., Archer, M., and Hand, S.J. 2017. Species abundance, richness and body size evolution of kangaroos (Marsupialia: Macropodiformes) throughout the Oligo-Miocene of Australia. Palaeogeography, Palaeoclimatology, Palaeoecology, 487:25-36. https://doi.org/10.1016/j.palaeo.2017.08.016

Cooke, B.N. 1992. Primitive macropodids from Riversleigh, north-western Queensland. Alcheringa, 16(3):201-217. https://doi.org/10.1080/03115519208619119

Cooke, B.N. 1996. Researches into fossil kangaroos and kangaroo evolution. Unpublished PhD Thesis, University of New South Wales, Sydney, Australia.

Cooke, B.N. 1997a. Biostratigraphic implications of fossil kangaroos at Riversleigh, northwestern Queensland. Memoirs of the Queensland Museum, 41:295-302.

Cooke, B.N. 1997b. Two new balbarine kangaroos and lower molar evolution within the subfamily. Memoirs of the Queensland Museum, 41:269-280.

Cooke, B.N. 1997c. New Miocene bulungamayine kangaroos (Marsupialia, Potoroidae) from Riversleigh, northwestern Queensland. Memoirs of the Queensland Museum, 41:281-294.

Cooke, B.N. and Kear, B.P. 1999. Evolution and diversity of kangaroos (Macropodoidea: Marsupialia). Australian Mammalogy, 21:1-45.

Cooke, B.N., Travouillon, K.J., Archer, M., and Hand, S. J. 2015. Ganguroo robustiter sp. nov. (Macropodidae, Marsupialia), a middle to early late Miocene basal macropodid from Riversleigh World Heritage Area, Australia. Journal of Vertebrate Paleontology, 35(4): e956879. https://doi.org/10.1080/02724634.2015.956879

Flannery, T., Archer, M., and Plane, M. 1982. Middle Miocene kangaroos (Macropodoidea, Marsupialia) from three localities in northern Australian, with a description of two new subfamilies. BMR Journal of Australian Geology \& Geophysics, 7(4):287-302.

Flannery, T. and Rich, T.H.V. 1986. Macropodoids from the Middle Miocene Namba Formation, South Australia, and the homology of some dental structures in kangaroos. Journal of Paleontology, 60(2):418-447. https://doi.org/10.1017/S0022336000021958

Hammer, Ø., Harper, D.A.T., and Ryan, P.D. 2001. PAST: Paleontological statistics software package for education and data analysis. Palaeontologia Electronica, 4.1.4:1-9. http://palaeo-electronica.org/2001_1/past/issue1_01.htm

Illiger, C. 1811. Prodromus systematis mammalium et avium additis terminis zoographicis utriusque classis, eorumque versione germanica. Sumptibus C. Salfeld, Berlin. https:// doi.org/10.5962/bhl.title.42403

Janis, C.M., Damuth, J., Travouillon, K.J., Figueirido, B., Hand, S.J., and Archer, M. 2016. Palaeoecology of Oligo-Miocene macropodoids determined from craniodental and calcaneal data. Memoirs of Museum Victoria, 73:200-232. https://doi.org/10.24199/j.mmv.2016.74.17

Kear, B.P. 2003. Macropodoid endocranial casts from the early Miocene of Riversleigh, northwestern Queensland. Alcheringa: An Australasian Journal of Palaeontology, 27:295302. https://doi.org/10.1080/03115510308619109

Kear, B.P. and Cooke, B. 2001. A review of macropodoid (Marsupialia) systematics with the inclusion of a new family. Association of Australasian Palaeontologists, 25:83-101.

Kear, B.P., Cooke, B.N., Archer, M., and Flannery, T.F. 2007. Implications of a new species of the Oligo-Miocene kangaroo (Marsupialia: Macropodoidea) Nambaroo, from the Riversleigh 
World Heritage Area, Queensland, Australia. Journal of Paleontology, 81(6):1147-1167. https://doi.org/10.1666/04-218.1

Kear, B.P. and Pledge, N.S. 2007. A new fossil kangaroo from the Oligocene-Miocene Etadunna Formation of Ngama Quarry, Lake Palankarinna, South Australia. Australian Journal of Zoology, 55(6):331-339. https://doi.org/10.1071/zo08002

Kirsch, J.A., Lapointe, F., and Springer, M. 1997. DNA-hybridisation studies of marsupials and their implications for metatherian classification. Australian Journal of Zoology, 45(3):211-280. https://doi.org/10.1071/zo96030

Linnaeus, C. 1758. Systema naturæ per regna tria naturæ, secundum classes, ordines, genera, species, cum characteribus, differentiis, synonymis, locis. Laurentius Salvius, Stockholm. https://doi.org/10.5962/bhl.title.542

McGowran, B. and Li, Q. 1994. The Miocene oscillation in southern Australia. Records of the South Australian Museum, 27:197-212.

Meredith, R.W., Westerman, M., and Springer, M.S. 2009. A phylogeny and timescale for the living genera of kangaroos and kin (Macropodiformes: Marsupialia) based on nuclear DNA sequences. Australian Journal of Zoology, 56(6):395-410. https://doi.org/10.1071/zo08044

Montanari, S., Louys, J., and Price, G.J. 2013. Pliocene paleoenvironments of Southeastern Queensland, Australia inferred from stable isotopes of marsupial tooth enamel. PLoS ONE, 8:e66221. https://doi.org/10.1371/journal.pone.0066221

Myers, T. and Archer, M. 1997. Kuterintja ngama (Marsupialia, Ilariidae): a revised systematic analysis based on material from the late Oligocene of Riversleigh, northwestern Queensland. Memoirs of the Queensland Museum, 41:379-392.

Owen, R. 1866. On the Anatomy of Vertebrates. Longmans, Green, and Co., London. https:// doi.org/10.5962/bhl.title.990

Prideaux, G.J. and Warburton, N.M. 2010. An osteology-based appraisal of the phylogeny and evolution of kangaroos and wallabies (Macropodidae: Marsupialia). Zoological Journal of the Linnean Society, 159(4):954-987. https://doi.org/10.1111/j.1096-3642.2009.00607.x

Schwartz, L.R. and Megirian, D. 2004. A New Species of Nambaroo (Marsupialia; Macropodoidea) from the Miocene Camfield Beds of Northern Australia with observations on the phylogeny of the Balbarinae. Journal of Vertebrate Paleontology, 24(3):668-675. https:// doi.org/10.1671/0272-4634(2004)024[0668:ANSONM]2.0.CO;2

Swofford, D. 2002. PAUP* Phylogeny Analysis Using Parsimony ( ${ }^{*}$ and other methods), version 40b10. Sinauer Association, Sunderland, Massachusetts.

Travouillon, K.J., Archer, M., and Hand, S.J. 2015. Revision of Wabularoo, an early macropodid kangaroo from mid-Cenozoic deposits of the Riversleigh World Heritage Area, Queensland, Australia. Alcheringa, 39:274-286. https://doi.org/10.1080/03115518.2015.994115

Travouillon, K.J., Archer, M., Hand, S.J., and Godthelp, H. 2006. Multivariate analyses of Cenozoic mammalian faunas from Riversleigh, northwestern Queensland. Alcheringa: An Australasian Journal of Palaeontology, 30(supplement 1):323-349. https://doi.org/10.1080/ 03115510608619590

Travouillon, K.J., Cooke, B., Archer, M., and Hand, S.J. 2014. Revision of basal macropodids from the Riversleigh World Heritage Area with descriptions of new material of Ganguroo bilamina Cooke, 1997 and a new species. Palaeontologia Electronica, 17.1.20A:1-34. https:/ /doi.org/10.26879/402 http://palaeo-electronica.org/content/2014/711-riversleigh-basal-macropodoids

Travouillon, K.J., Escarguel, G., Legendre, S., Archer, M., and Hand, S.J. 2011. The use of MSR (Minimum Sample Richness) for sample assemblage comparisons. Paleobiology, 37(4):696709. https://doi.org/10.1666/09050.1

Travouillon, K.J., Gurovich, Y., Archer, M., Hand, S.J., and Muirhead, J. 2013. The genus Galadi: three new bandicoots (Marsupialia, Peramelemorphia) from Riversleigh's Miocene deposits, northwestern Queensland, Australia. Journal of Vertebrate Paleontology, 33(1):153-168. https://doi.org/10.1080/02724634.2012.713416

Travouillon, K.J., Gurovich, Y., Beck, R., and Muirhead, J. 2010. An exceptionally well-preserved short-snouted bandicoot (Marsupialia; Peramelemorphia) from Riversleigh's Oligo-Miocene deposits, northwestern Queensland, Australia. Journal of Vertebrate Paleontology, 30(5):1528-1546. https://doi.org/10.1080/02724634.2010.501463

Warburton, N.M. 2009. Comparative Jaw Muscle Anatomy in Kangaroos, Wallabies, and RatKangaroos (Marsupialia: Macropodoidea). The Anatomical Record: Advances in Integrative Anatomy and Evolutionary Biology, 292(6):875-884. https://doi.org/10.1002/ar.20905 
Woodburne, M.O., Macfadden, B.J., Case, J.A., Springer, M.S., Pledge, N.S., Power, J.D., Woodburne, J.M., and Springer, K.B. 1993. Land mammal biostratigraphy and magnetostratigraphy of the Etadunna Formation (late Oligocene) of South Australia. Journal of Vertebrate Paleontology, 13(4):483-515. https://doi.org/10.1080/02724634.1994.10011527

Woodhead, J., Hand, S.J., Archer, M., Graham, I., Sniderman, K., Arena, D.A., Black, K.H., Godthelp, H., Creaser, P., and Price, E. 2016. Developing a radiometrically-dated chronologic sequence for Neogene biotic change in Australia, from the Riversleigh World Heritage Area of Queensland. Gondwana Research, 29(1):153-167. https://doi.org/10.1016/ j.gr.2014.10.004

Wroe, S., Brammall, J., and Cooke, B.N. 1998. The skull of Ekaltadeta ima (Marsupialia, Hypsiprymnodontidae?): an analysis of some marsupial cranial features and a reinvestigation of propleopine phylogeny, with notes on the inference of carnivory in mammals. Journal of Paleontology, 72(4):738-751. https://doi.org/10.1017/s0022336000040439 


\section{APPENDIX 1.}

Nexus formatted character matrix for taxa included in the phylogenetic analysis using revised species classifications for Ganawamaya and Nambaroo from this study. Outgroup species: Pseudocheirus peregrinus, Trichosurus vulpecula, Galadi speciosus, and Burramys brutyi. ? = missing data.

Revision of Oligo-Miocene kangaroos, Ganawamaya and Nambaroo (Marsupialia: Macropodiformes, Balbaridae)

Kaylene Butler, Kenny J. Travouillon, Gilbert J. Price, Michael Archer, and Suzanne J. Hand

Palaeontologia Electronica

\section{\#NEXUS}

[ File saved by NDE version 0.5.0, Fri Sep 09 10:09:50 2016 ]

\section{BEGIN TAXA;}

DIMENSIONS NTAX=66;

\section{TAXLABELS}

'Galadi speciosus'

'Trichosurus vulpecula'

'Pseudocheirus peregrinus'

'Burramys brutyi'

'Nambaroo tarrinyeri'

'Nambaroo saltavus'

'Wururoo dayamayi'

'Balbaroo gregoriensis'

'Balbaroo fangaroo'

'Balbaroo camfieldensis'

'Balbaroo nalima'

'Hypsiprymnodon moschatus'

'Hypsiprymnodon bartholomaii'

'Hypsiprymnodon philcreaseri'

'Ekaltadeta ima'

'Ekaltadeta jamiemulvaneyi'

'Jackmahoneya toxoniensis'

'Propleopus oscillans'

'Bettongia moyesi'

'Bettongia penicillata'

'Aepyprymnus rufescens'

'Potorous tridactylus'

'Purtia mosaicus'

'Wakiewakie lawsoni'

'Ngamaroo archeri'

'Lagostrophus fasciatus'

'Tjukuru wellsi'

'Troposodon minor'

'Gumardee pascuali'

'Bulungamaya delicata'

'Ganguroo bilamina'

'Ganguroo bites'

'Ganguroo robustiter'

'Wabularoo naughtoni'

'Wabularoo prideauxi'

'Wanburoo hilarus' 
'Hadronomas puckridgi'

'Sthenurus andersoni'

'Simosthenurus occidentalis'

'Procoptodon goliah'

'Dorcopsoides fossilis'

'Dorcopsis veterum'

'Dorcopsulus vanheurni'

'Setonix brachyurus'

'Thylogale billardierii'

'Petrogale brachyotis'

'Bohra illuminata'

'Dendrolagus bennettianus'

'Dendrolagus matschiei'

'Protemnodon anak'

'Congruus congruus'

'Wallabia bicolor'

'Prionotemnus palankarinnicus'

'Kurrabi mahoneyi'

'Lagorchestes conspicillatus'

'Lagorchestes hirsutus'

'Baringa nelsonensis'

'Onychogalea unguifera'

'Macropus eugenii'

'Macropus fuliginosus'

'Macropus pavana'

'Macropus robustus'

'Ganawamaya acris'

'Ganawamaya aediculis'

'Ganawamaya couperi'

'Ganawamaya gillespieae'

;

ENDBLOCK;

BEGIN CHARACTERS;

DIMENSIONS NCHAR=120;

FORMAT DATATYPE=STANDARD MISSING=? GAP=- SYMBOLS="012345"; CHARLABELS

[1] 'Rostrum depth relative to posterior (neurocranial)portion of cranium'

[2] 'Marked cranial foreshortening (brachycephaly)'

[3] 'Level of basicranial plane relative to palatal plane'

[4] 'Splanchnocranium anteroventral deflection'

[5] 'Superficial masseter origin on jugal'

[6] 'Large ectoglenoid process'

[7] 'Postglenoid process'

[8] 'Neurocranium element contact'

[9] 'Ectotympanic proportions'

[10] 'Maximum occiput breadth relative to height'

[11] 'Foramen magnum size relative to occiput size'

[12] 'V-shaped squamosal inflation between occiput and posterior end of zygomatic arch'

[13] 'Relative anteroposterior length of upper incisors'

[14] 'I1 shape'

[15] 'I3 anterobuccal crest'

[16] 'I3 lingual surface'

[17] 'Number of cuspules/ridgelets on P3/p3 anterior to large posterior cusp' 
[18] 'Deep cleft on main crest of P3 and p3 immediately posterior to anterior most cuspule'

[19] 'P3 lingual cingulum'

[20] 'P3 lateral constriction immediately anterior to posterolingual cusp'

[21] 'Upper cheek tooth row shape in transverse plane'

[22] 'Molar progression'

[23] 'Molar morphology'

[24] 'Preprotocrista development'

[25] 'Postprotocrista orientation'

[26] 'Postprotocrista development'

[27] 'Postprotocrista division'

[28] 'Postparacrista development'

[29] 'Postmetacrista/postmetaconulecrista development'

[30] 'Morphology of symphyseal plate of dentary'

[31] 'Buccinator sulcus on dentary'

[32] 'Anterior extent of masseteric canal'

[33] 'Insertion area for middle masseter muscle'

[34] 'Mandibular condyle shape'

[35] 'Position of i1 occlusal surface during incisor occlusion'

[36] 'i1 morphology'

[37] 'Enamel distribution on i1'

[38] 'p3 morphology'

[39] 'Buccal side of p3'

[40] 'Cheek tooth row shape in dorsoventral plane'

[41] 'Molar crown height index'

[42] 'Premetacristid development'

[43] 'Slight postmetacristid'

[44] 'Postprotocristid development'

[45] 'Cristid obliqua form'

[46] 'Paracristid and cristid obliqua division'

[47] 'Development of postentocristid and posthypocristid'

[48] 'Lophid enamel crenulations'

[49] 'Tuber calcanei posteromedial expansion'

[50] 'Relative length of talus articular region on calcaneus'

[51] 'Step of calcaneus-cuboid articulation'

[52] 'Ventromedian facet of cuboid articulation on calcaneus'

[53] 'Relative breadth of calcaneus-talus articulation'

[54] 'Distinctness of medial and lateral talar facetson calcaneus'

[55] 'Shape of lateral talar facet on calcaneus'

[56] 'Medial projection of sustentaculum tali of calcaneus beyond edge of medial talar facet'

[57] 'Shape of sustentaculum tali of calcaneus'

[58] 'Posterior extent of sustentaculum tali'

[59] 'Orientation of talar trochlear crests'

[60] 'Height of medial trochlear crest on talus relativeto lateral crest'

[61] 'Medial malleolar process/fossa on talus'

[62] 'Metatarsal IV length relative to calcaneus length'

[63] 'Metatarsal IV relative breadth'

[64] 'Metatarsal IV distal epiphysis breadth'

[65] 'Metatarsal V relative breadth'

[66] 'Metatarsal V plantar ridge'

[67] 'Relative length of fibular articular facet on tibia'

[68] 'Relative length of anterior tibial crest'

[69] 'Shape of anterior tibial crest'

[70] 'Length of tibia relative to that of femur'

[71] 'Development of greater trochanter crest of femur' 
[72] 'Angle of ilium to ischium'

[73] 'Position of rectus femoris origin on ilium'

[74] 'lliopubic process at junction of ilium and pubis'

[75] 'Relative length of ischium to ilium'

[76] 'Area of supraspinous fossa relative to infraspinousfossa of scapula'

[77] 'Scapula acromion shape'

[78] 'Displacement of acromion relative to glenoid fossa on scapula'

[79] 'Relative size of medial tuberosity to lateral tuberosity on humerus'

[80] 'Development of deltoid tuberosity vs. pectoralcrests on humerus'

[81] 'Relative width of trochlear notch posterior margin on ulna'

[82] 'Olecranon length/shape relative to length of ulna'

[83] 'Radius cross-section depth (mid-length) to width of the diaphysis, measured at the mid-length ofthe diaphysis from between the epiphyseal plates'

[84] 'Basioccipital and basisphenoid'

[85] 'Frontal region'

[86] 'Frontal sinuses'

[87] 'Postorbital constriction of skull'

[88] 'Masseteric process'

[89] 'Cheek region of skull'

[90] 'Alisphenoid contribution to paroccipital process'

[91] 'Mastoid process'

[92] 'Inflated alisphenoid forming auditory bulla'

[93] 'Digastric eminence'

[94] 'Mandibular canal'

[95] 'Posterior mental foramen'

[96] 'i1 occlusal surface'

[97] 'Presence of i2'

[98] p2

[99] C1

[100] p3

[101] 'p3/P3'

[102] ' $\mathrm{m} 4$ length'

[103] P3

[104] 'm1 protoconid'

[105] 'm1 protoconid'

[106] 'Trigonid basin on m1'

[107] 'm1 protostylid'

[108] 'hypocingulid on lower molars'

[109] 'M1 StC'

[110] 'M1 StD'

[111] 'M1 anterolingual cingulum'

[112] 'M1 neometaconule and postlink'

[113] 'Internal carotid foramen'

[114] 'Ventral margin of mandible'

[115] Postentocristid

[116] 'Height of p3/P3'

[117] 'Palatal vacuities'

[118] 'p3 main crest'

[119] 'p3 occlusal outline'

[120] Interparietal

;

STATELABELS

1

shallow 
intermediate

deep,

2

absent

present,

3

'same plane or slightly higher'

'markedly higher',

4

marked

intermediate

minimal,

5

shallow

'deep, with distinct orbital rim',

6

absent

present,

7

absent

small

large,

8

'frontal-squamosal'

'parietal-alisphenoid',

9

small

'thick, wide, rugose, ventrally keeled',

10

'deeper than broad'

'broader than deep',

11

small

large,

12

absent

present,

13

'I2 and/or I3 not reduced relative to I1'

'I2 distinctly shorter than I1 and I3'

'I2 and I3 distinctly shorter than I1',

14

subcylindrical

'slightly broadened'

'markedly broadened',

15

'absent or very small, restricted to anterior end' distinct,

16

'no anterolingual crest or lingual shelf'

'anterolingual crest present, no lingual shelf'

'anterolingual crest and small lingual shelf present', 17

'Transcristae absent' 
'Less than 3'

Three

Four

'between 5 and 10'

'10 or more',

18

absent

present,

19

'absent or very low, fine'

'low, narrow to moderately broad, tapered anteriorly'

'broad, not raised into crest along lingual edge, with or without cuspules'

'broad, raised into low crest along lingual edge'

'raised into high crest along lingual edge',

20

absent

present,

21

straight

'bowed laterally',

22

absent

present,

23

Other

Bunodont

'Bunolophodont '

Lophodont

Bilophodont,

24

'strongly developed, confluent with precingulum'

'small but distinct'

absent,

25

'restricted to lingual side of tooth'

'extends into interloph valley near to tooth midline',

26

'short, thick'

'fine, low'

intermediate

'high, thick, strongly developed',

27

absent

'incipiently or completely divided into two components',

28

present

'absent or very fine and low',

29

'both distinct'

'postmetaconulecrista enlarged, postmetacrista absent or very weak', 30

'shallow, smooth or very slightly rugose'

'deep, rugose'

'deep, very rugose, and anteriorly expanded', 
31

absent

'narrow, shallow'

'narrow, deep'

'broad, deep concavity',

32

'Masseteric canal not developped'

'to below anterior cheek teeth'

'to below posterior cheek teeth'

'posterior to m4 (near vertical)',

33

'small to moderately proportioned'

'broad and concave'

'large, terminates ventrally at distinct ridge',

34

'barrel shaped, not tapered medially'

'oval or circular'

'barrel shaped, tapered medially'

'Oval with anteromedial expansion',

35

'i1 rests on crowns of $\mathrm{I} 2$ and $\mathrm{I} 3$, and posteriorfacet of $\mathrm{I} 1$ '

'i1 rests on palate, bordered by 12 and I3',

36

'procumbent, thin and elongate'

'procumbent blade with thick enamel flanges'

'slightly robust with thin enamel flanges'

'markedly upturned and robust',

37

'principally buccal side'

'buccal enamel layer extended to completely encircle crown '

'separate lingual enamel layer present',

38

'No transcristae'

Plagiaulacoid

Sectorial,

39

'lacks eminence, cingulid, or crest'

'bears posterobuccal eminence'

'bears welldeveloped buccal cingulid or crest',

40

Concave

'flat or very slightly convex'

'markedly convex dorsally',

41

'low $(<0.45)^{\prime}$

'intermediate (0.45-0.75)'

'high (> 0.75)',

42

'well developed, confluent with paracristid'

'moderately developed'

'weakly developed or absent',

43

present

absent, 
44

distinct

'slight or absent',

45

'restricted to buccal side of tooth'

'straight or slightly curved, terminates near tooth midline low on posterior face of protolophid'

'distinctly kinked, terminates near tooth midline low on posterior face of protolophid',

46

absent

present,

47

'postentocristid distinct, meets large posthypocristid'

'both crests fine or absent'

'posthypocristid present, adjacent to distinct central groove',

48

absent

present,

49

absent

present,

50

'long (>0.43)'

'intermediate (0.43-0.35)'

'short (<0.35)',

51

incipient

'markedly stepped or slightly bevelled'

'slightly smoothed, oblique'

smoothed,

52

absent

'continuous with dorsolateralfacet'

'separate, distinct, well-developed'

'reduced, confluent with dorsomedial facet',

53

'intermediate (0.40-0.45)'

'narrow $(<0.40)$ '

'broad (>0.45)',

54

'confluent, smoothly continuousanteriorly'

'continuous anteriorly, but facetcontours distinct'

'distinct, separate facets',

55

'untapered or marginally tapered medially'

'slightly or moderately tapered medially'

'markedly tapered medially',

56

'absent or very slight'

marked,

57

'straight (anteroventrally oriented) or veryslightly curved'

rounded

square,

58 
'roughly in line with fibular facet'

intermediate

'significantly posteriorly placed from fibular facet',

59

'oblique (anterolaterally oriented)'

'anteroposteriorly oriented',

60

'subequal in height (trochleagroove shallow)'

'medial crest slightly higher'

'medial crest distinctly higher, with trochleargroove deep',

61

'fossa intermediate, no distinct process'

'fossa intermediate, process small, slightly mediallyextended'

'fossa broad/shallow, process largeand medially extended'

'fossa narrow/deep, process small, slightly medially extended',

62

'intermediate (1.5-2.4)'

'long (> 2.4) '

'short $(<1.5)$ ',

63

'narrow $(<0.12)$ '

'intermediate $(0.12-0.16)$ '

'broad (> 0.16)',

64

'narrow relative to ligament attachments'

'distinctly broad relative to shaft width, minimum development of ligament attachments',

65

'intermediate (0.07-0.13)'

'narrow $(<0.07)$ '

'wide (>0.13)'

'highly to extremely reduced',

66

'small, posteriorly restricted'

absent

'elongate, well developed',

67

'short (< 0.62)'

'long $(>0.62)$ ',

68

'intermediate (0.20-0.26)'

'long $(>0.26)^{\prime}$

'short $(<0.20)$ ',

69

'stepped-in distally'

'not stepped distally, curves smoothly intodiaphysis',

70

'intermediate (1.10-1.45)'

'short (<1.10)'

'long (> 1.45)',

71

'distally flared or intermediate'

'distally narrowed' 
'distally flared and markedly broadened',

72

'slight angle'

'aligned in same plane'

'large angle',

73

'distinctly separate from acetabular rim'

intermediate

'adjacent to acetabular rim',

74

'very small, pointed'

'long, well-developed, square in outline'

'short, broad'

'very large',

75

'long (>0.7)'

'short $(<0.7)$ ',

76

'roughly equal'

'supraspinous fossa roughly half area'

'supraspinous fossa roughly one-third area'

'supraspinous fossa much smaller than infraspinous fossa',

77

'anterodorsally curved'

straight,

78

'caudal to the cranial margin ofthe glenoid fossa'

'cranially displaced',

79

'slightly smaller'

'distinctly smaller'

subequal,

80

'deltoid insertion poorly developed'

'intermediate, small deltoid tuberosity connected by oblique ridge'

'large deltoid tuberosity separated from pectoral crest by sulcus',

81

wide

narrow,

82

'long, deep'

intermediate

reduced,

83

'intermediate (1.3-1.5)'

'shallow $(<1.3)$ '

'deep (1.5-2.0)'

'very deep (> 2.0)',

84

coplanar

angled,

85

'Not flat'

Flat,

86

42 
'Not markedly inflated'

'Markedly inflated',

87

Absent

'Slight constriction'

'Marked constriction',

88

'Not extending below alveolar margin'

'Extending below alveolar margin',

89

'Smooth transition of zygoma to cheek'

'With sulcus anterior to zygoma',

90

'Does not contribute'

'contribute to anterior face',

91

'Small (<paroccipital process)'

'Hypertrophied (>paroccipital process)',

92

Uninflated

'Lightly inflated'

'Highly inflated',

93

Undisctinct

Distinct,

94

'Single mandibular canal'

'Mandibular canal confluent with masseteric canal'

'Mandibular canal length reduced, foramina overlap'

'Mandibular canal lost, single mandibular foramen',

95

Present

Absent,

96

'Reaching to level of molar occlusal plane'

'Below molar occlusal plane',

97

Present

Absent,

98

'persists after p3 eruption'

'displaced by p3 eruption',

99

'Present and large'

'Present and small'

Absent,

100

'Buccally flexed'

'Aligned with molar row',

101

'Very short (P3L/M1 <1)'

'Short (P3L/M1 <1-1.299)'

'Medium (P3L/M1 1.3-1.599)'

'Long (P3L/M1 1.6-1.99)' 
'Very long (P3L/M1 >2)',

102

'Smaller than $\mathrm{m}^{3}$

'Subequal to $\mathrm{m} 3$ '

'Larger than $\mathrm{m} 3$ ',

103

'Lacking posterolingual cusp or ridge'

'With posterolingual cusp or ridge',

104

Central

Buccal,

105

'Dominates trigonid'

'Subequal to metaconid',

106

'Not developed'

'Narrow transversely'

'Broad transversely',

107

Absent

'Present as enamel ridge'

'Present as cuspid',

108

'Hypocingulid present between low posthypocristid and entoconid'

'Hypocingulid present posterior to posthypocristid'

Absent,

109

Present

'Reduced to stylar crest'

Absent,

110

Present

'Reduced to stylar crest'

Absent,

111

Absent

Present,

112

Absent

Present,

113

'Anterior to basioccipital/basisphenoid suture'

'Close to or posterior to basioccipital/basisphenoid suture',

114

'Convex (anterior of mandible steeply inclined)'

'Straight (anterior of mandible shallowly inclined)',

115

absent

'Present and connects to posthypocristid'

'Present. connected to hypocingulid',

116

'Extends above the level of $\mathrm{m} 1 / \mathrm{M} 1$ '

'Levels with $\mathrm{m} 1 / \mathrm{M} 1$ ',

117 
Present

Absent,

118

'Straight '

Curved

'L-shaped',

119

'Short and wide'

'Short and narrow'

'Long and narrow'

'Long and wide',

120

absent

present,

MATRIX

'Galadi speciosus'

$000000210100 ? ? ? ? 001000000000000000 ? ? ? 001$ ?21110-0?? ?????????? ?????????? ?????????? ???0001010 $01001000010201000000000000000 ?$ 00010011010000000000002000000000000000000201000011 0020100000022022010100001000020030002100010010011002000010120000110001 'Pseudocheirus peregrinus' $\quad 00010011010000000110000000000000000000000001100002$ 0020000000022022010100001000020030001000010001001100000020000000111001

'Burramys brutyi' ?????????? ??????4000 $0010000000000 ? ? 0010000010000 ? ? ? ? ? ? ? ? ? ? ? ?$ ?????????? ?????????? ???????00? ??000000?0 $200000002200 ? 0100031$

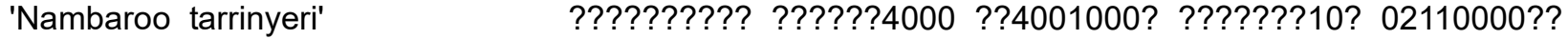
?????????? ?????????? ?????????? ?????????? ?????????? 0110002(01)22 01??20?00?

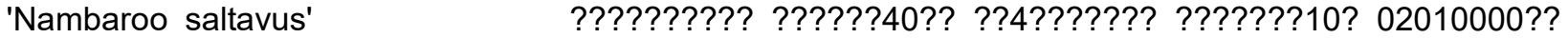
?????????? ?????????? ?????????? ?????????? ?????????? 1??0102(01)?? ????(12)0?00?

'Wururoo dayamayi' ?????????? ??????30?? ?04??????0 11?????100 $02111010 ? ?$ ?????????? ?????????? ?????????? ?????????? ??0?0??1?1 21?00111?? ???020?03?

'Balbaroo gregoriensis' ?????????? ?????????? ??4??????? ?????????? 02111010?? ?????????? ?????????? ?????????? ?????????? ?????????? ???00101?? ????2?????

'Balbaroo fangaroo' $0001001000000000400000411100001100 ? 1020101111010 ? ?$ ?????????? ??????????????????? ???0011000 $1001000101211011(01) 1120110210130$ 'Balbaroo camfieldensis' ?????????? ????????? ?04??????? 110??????1 02111010?? ?????????? ?????????? ?????????? ?????????? ??011????? ?1111101?? ???12?????

'Balbaroo nalima' $00010020000000 ? ? 400000411100001200 ? 102010(01) 11101001$ 22220000?? ?????????? 0????????? 0??0011000 1001001101 211112(012)112 0111210130 'Hypsiprymnodon moschatus' $\quad 00000000000000004000001000000001000001010201000000$ 0000000000000000000000000000000000100000010110011020000020220000100031

'Hypsiprymnodon bartholomaii' 0000000100 00????4000 001000000? ???????1?? 0????????? ?????????? ?????????? ?????????? ???????000 01???????0 300?????22 001?100030

'Hypsiprymnodon philcreaseri' ????????? ??????4000 $0010000000010 ? ? 00101$ ?????????? ?????????? ?????????? ???????00? ??011001?0 300000202200 ?010?03? $000000100000 ? ? ? ? 40000020000000010 ? 00010101010000 ? ?$ ?????????? ?????????? ?????????? ???001200? 10011000?0 30000020220010100030 'Ekaltadeta jamiemulvaneyi' ????????? ??????40?? ?02??????? 01?????101 $01010000 ? ?$ ?????????? ?????????? ?????????? ?????????? ??0?1??0?0 3??00020?? ???010?03? 'Jackmahoneya toxoniensis' ?????????? ??????4000 ?020100000 0100???101 ?????????? ?????????? ?????????? ?????????? ??0?10?1?0 $300000200210 ? 010 ? 03 ?$ 'Propleopus oscillans' ?????????? ??????4000 002000000001 ???00101 ?????????? ?????????? ?????????? ???????01? ??0?100110 $200000202210 ? 010 ? 03 ?$ 'Bettongia moyesi' $10010001 ? ? ? ? 1000500010100000000 ? 0 ? 00020000000000 ? ?$ ?????????? ?????????? ?????????? ????10100? ????100111 $400112000210 ?+110021$ 
'Bettongia penicillata' $\quad 100100100000100050001010000000010000020000000000011101000000$ 000011020000011100000030100000020310111130011200221010110021

'Aepyprymnus rufescens' $\quad 10010020000010004000102000000011000002000000000001$ 1121000001110011020000011200000030110001110310111130011200220010111021

'Potorous tridactylus' $\quad 000100000000100041001010000000010001020000000000011101000000$ 001001020000011000010030100000010110111120011200220010110121

'Purtia mosaicus' ????????? ??????50?? ?03??????0 0??????200 00000000?? ????????? ????????? ?????????? ?????????? ?????0?1?1 3??11200?? ???011?02?

'Wakiewakie lawsoni' ?????????? ??????50?? ?02??????? 010????20000000000?? ?????????? ?????????? ?????????? ?????????? ??010??1?1 40?11200?? ???011?02?

'Ngamaroo archeri' ?????????? ??????50?? ?03?????0 010????200 0100000000 21?10001?? ?010??0000 ????????00 0????????? ??011??1?1 3??11200?? ???011?12?

'Lagostrophus fasciatus' 00000021000000002010104012000133110012011201101001 $110100210100100212001001110001001 ? 100111020311112111111202221110010211$

'Tjukuru wellsi' ????????? ??????10?? ?04??????1 32??????01 12111010?? ?????????? ?????????? ?????????? ?????????? ??0?0??1?1 11?11202?? ???001?21?

'Troposodon minor' ?????????? ???0?02010 $0040120001321100120112112010 ? ?$ ?????????? ?????????? ?????????? ???????11? ??031111?1 111112012211 ?001?21?

'Gumardee pascuali'

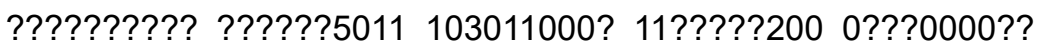
?????????? ?????????? ?????????? ?????????? ??0?0??1?1 301112 ? 00211 ?011012?

'Bulungamaya delicata'

?????????? ??????4000 $00301100001201 ? 0020101000000 ? ?$ ?????????? ?????????? ?????????? ???????00? ??010001?1 210112000211 ?011?13?

'Ganguroo bilamina' $000100110000000040100041110000120100020101111010 ? ?$ ?????????? ?????????? ?????????? ???1101000 111101011121111202011111010131

'Ganguroo bites' ?????????? ??????40?? ?04?????? 1201???201 01111010?? ?????????? ?????????? ?????????? ?????????? ??010??1?1 3??11202?? ???001?12?

'Ganguroo robustiter' $000100110000000040100041110000120100020101111010 ? ?$ ?????????? ?????????0 ??0??11010 02?1100000 110101?111 31111202011111010131

'Wabularoo naughtoni' ????????? ??????4000 $004111(01) 000$ 2??????201 $01111010 ? ?$ ?????????? ?????????? ?????????? ?????????? ??1?0??1?1 2??1120202 11?101?13?

'Wabularoo prideauxi' ????????? ?????????? ?????????? ????????? ??010??1?1 211112020 ? 11?101113?

'Wanburoo hilarus' ????????? ??00014020 00421100002201 210211 $01111010 ? ?$ ?????????? ?????????? ?????????? ????????0? ??0201?111 211112021211 ?101013?

'Hadronomas puckridgi' 1201000111101102001 ? ?013?210?? 12?101000? ?0121111?1 11111202111011010131 'Sthenurus andersoni' 200201211100120130401042110002230203222112111111011201002212 $00113102122013 ? ? ? 1121221000111000300112121111202221010010131$

'Simosthenurus occidentalis' 21120121110010013040104211100223020322211211111101 122100221200113100122213031112122100111 ? 000300112121111202221010010131

'Procoptodon goliah' $\quad 211201211100100130401042111002230203222112111101011201002212$ 001131001222130311 ?2 1221012111000300112102111202221110110101

'Dorcopsoides fossilis' 0000001100 00?110(34)001 $0042110000110 ? 1122011211101001$ $1201110101101002 ? 00201011$ ????0 010????0?? 1?0?1??1?1 $211112010110 ? 101012 ?$

'Dorcopsis veterum' $\quad 000000110000011030010042110000110110020111111010011202110001$ 101002000000111210100101001111000311111142111202121011010121

'Dorcopsulus vanheurni' $0000001100100110(34) 0010042110000110110020111111010$ ?? ???21???01 1?????0000 01111210100101101111000211111122111202221011010121

'Setonix brachyurus' $\quad 000000210000021030101042120000120111020112111010011202100001$ 121000000001021210000111001111021311112131111202221011010121

'Thylogale billardierii' 000000210000021020101042120000130111020112111010011202100000 101000000001011110110111101111000111112111111202221011010021

'Petrogale brachyotis' $\quad 000000210111021220101042120000130112020112111010012202100001$ $1010000000010102101101011011110103(01) 111211$ ?11120222 1011010021 
'Bohra illuminata' $\quad 100000210111011220101042110000130112021112111010103322100001$ 201020000? ?112??10?1 0??1101111 00021??121 $2111120222101 ? 01113 ?$

'Dendrolagus bennettianus' 10000021011101121120104211000012011202110211101010 $33222100002220200101012202102001101001110002(01) 1111131111202221011011131$

'Dendrolagus matschiei' 10000021011101122120104211000012011202110211101010 3322200000222020110101220210210110011111000211111131111202221010011131

'Protemnodon anak' $1000002101100210(23) 030104212000013011102012211101001$ $1222000201221120010210021210120111 ? 011110 ? 0 ? 1111213211120122101101002 ?$

'Congruus congruus' $10000021011002102030104212000 ?$ ?????????? 2????????? ?????????? ?????????? ?????????? ???0101011 00??????21 121?????22 101??11?1?

'Wallabia bicolor' $\quad 000000210000021020301042120000130311020122111010021212001201$ 301002000211011210120121101111000311112112111202221011010021

'Prionotemnus palankarinnicus' ????0????? ???2102010 $1042130100130 ? 110 ? 0112111010 ? ?$ ?????????? ?????????? ?????????? ????????1? ??021??1?1 111112012210 10101001?

'Kurrabi mahoneyi' ?????????? ??????2010 $1042130110130 ?$ ?10?01 22111010?? ????????? ?????????? ?????????? ???????11? ??0?1111?1 $321112022210 ? 101$ ?12?

'Lagorchestes conspicillatus' $\quad 0000002100 \quad 0002102010104212000013011102012211101002$ 1212001001 -100121200 $110112101100210011110202(01) 1111111111202221011010101$

'Lagorchestes hirsutus' $\quad 00000021000002102010104212000013011102012211101001$ $12120010013100121200110112100100210011110202(01) 1111111111202221011010101$ 'Baringa nelsonensis' ?0??1????? ??22??2000 $1042130110132 ? 110 ? 0222111010 ? ?$ ????????? ?????????? ?????????? ?????????? ??0?1111?1 0??1120212 10?101?01?

'Onychogalea unguifera' 00001021000022101000104213000013231002022211201002 1212001201300012120210011110110021101111020311111102111202221011010011 'Macropus eugenii' $\quad 000000210000021010101042130110130111020222112010011212000101$ 300002000210011110110021001111010311112102111202221011010011

'Macropus fuliginosus' $\quad 00000021000002101000114113011013011102022211202002$ 1212000201100012120210011110110121001111010311112102111202221011011011

'Macropus pavana' ????????? ??????1000 $1141130110130 ? ? ? ? ? ? 222112020 ? ?$ ?????????? ????????? ?????????? ?????????? ??0?1??1?? $021112022210 ?$ ?:01?011

'Macropus robustus' 00000021000002101010114213011013011102022211202002 1212000201301012120211011111110121001111010311112102111202221011011011 'Ganawamaya acris' ??0?001000 00????(23)010 $0041110000110 ? ? 1020102111010 ? ?$ ?????????? ?????????? ?????????? ??????2000 100100?1?0 111000(02)122 10?0210100

'Ganawamaya aediculis' ?????????? ???0??4010 0041110000 11?????201 $02111010 ? ?$ ?????????? ?????????? ?????????? ????????0? ??010??100 111000(02)102 00?021010?

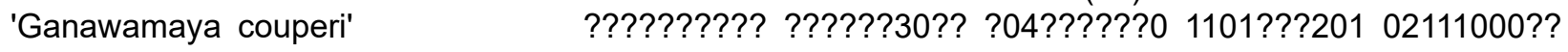

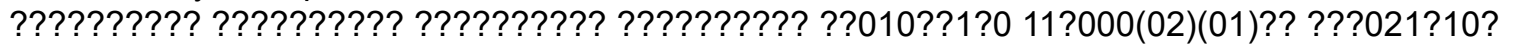
'Ganawamaya gillespieae' $000100100000 ? ? ? ?(34) 01000411100001101 ? 102010211101001$ $2222010000002000 ? ? 1 ? 000110000 ? 0 ? ? 00120001001000100111000(02) 1020010210100$ ;

ENDBLOCK;

BEGIN ASSUMPTIONS;

OPTIONS DEFTYPE=UNORD POLYTCOUNT=MINSTEPS;

ENDBLOCK;

BEGIN NOTES;

[Taxon comments]

[Character comments]

[Character state comments] 
[Attribute comments]

[Taxon pictures]

[Character pictures]

[Character state pictures]

[Attribute pictures]

ENDBLOCK;

\section{BEGIN PAUP;}

Outgroup 'Galadi speciosus' 'Trichosurus vulpecula' 'Pseudocheirus peregrinus' 'Burramys brutyi'; set maxtrees $=100000$ tcompress=yes torder=left showtaxnum=no taxlabels=full; set root=outgroup outroot=monophyl criterion=parsimony;

BEGIN ASSUMPTIONS;

OPTIONS DEFTYPE=UNORD POLYTCOUNT=MINSTEPS;

TYPESET *mytypes = IRREV.UP: 2338 116;

\section{ENDBLOCK;}




\section{APPENDIX 2.}

Univariate statistics for teeth of Ganawamaya aediculis. Rounded to one decimal place. Measurements are in $\mathrm{mm}$. Abbreviations: $\mathrm{N}$, number of specimens; Min, minimum measurement; Max, maximum measurement; L, tooth length; AW, anterior width; PW, posterior width; $P$, upper premolar; $\mathrm{p}$, lower premolar; M, upper molar; $\mathrm{m}$, lower molar.

\begin{tabular}{lcccccccc}
\hline & N & Min & Max & Mean & SE & VA & SD & CV \\
\hline p3L & 10 & 5.9 & 6.6 & 6.1 & 0.1 & 0.1 & 0.2 & 3.7 \\
p3W & 10 & 2.6 & 4.5 & 3.6 & 0.2 & 0.3 & 0.5 & 14.2 \\
m1L & 8 & 5.3 & 6.3 & 5.8 & 0.1 & 0.1 & 0.3 & 5.4 \\
m1AW & 8 & 3.1 & 3.8 & 3.4 & 0.1 & 0.0 & 0.2 & 6.2 \\
m1PW & 8 & 3.7 & 4.2 & 3.9 & 0.1 & 0.0 & 0.2 & 4.2 \\
m2L & 6 & 5.6 & 6.7 & 6.2 & 0.2 & 0.2 & 0.4 & 6.8 \\
m2AW & 6 & 3.8 & 4.4 & 4.2 & 0.1 & 0.1 & 0.2 & 5.8 \\
m2PW & 6 & 3.9 & 4.8 & 4.3 & 0.1 & 0.1 & 0.3 & 7.0 \\
m3L & 9 & 5.8 & 6.9 & 6.3 & 0.1 & 0.1 & 0.4 & 5.9 \\
m3AW & 9 & 4.0 & 4.8 & 4.4 & 0.1 & 0.1 & 0.3 & 5.8 \\
m3PW & 9 & 4.0 & 4.8 & 4.3 & 0.1 & 0.1 & 0.3 & 6.9 \\
m4L & 7 & 6.4 & 7.3 & 6.9 & 0.1 & 0.1 & 0.3 & 4.9 \\
m4AW & 9 & 3.8 & 4.8 & 4.3 & 0.1 & 0.1 & 0.4 & 8.4 \\
m4PW & 7 & 3.8 & 4.4 & 4.0 & 0.1 & 0.0 & 0.2 & 5.2 \\
P3L & 3 & 6.8 & 6.9 & 6.8 & 0.0 & 0.0 & 0.0 & 0.1 \\
P3W & 3 & 4.0 & 4.6 & 4.3 & 0.2 & 0.1 & 0.3 & 6.5 \\
M1L & 4 & 5.5 & 6.7 & 5.8 & 0.3 & 0.3 & 0.6 & 9.9 \\
M1AW & 4 & 5.0 & 5.6 & 5.3 & 0.1 & 0.1 & 0.3 & 4.8 \\
M1PW & 4 & 4.5 & 4.8 & 4.6 & 0.1 & 0.0 & 0.1 & 3.2 \\
M2L & 4 & 5.9 & 6.9 & 6.3 & 0.2 & 0.2 & 0.4 & 7.0 \\
M2AW & 4 & 4.9 & 5.8 & 5.4 & 0.2 & 0.2 & 0.4 & 7.7 \\
M2PW & 4 & 4.3 & 4.9 & 4.6 & 0.1 & 0.1 & 0.3 & 5.9 \\
M3L & 2 & 6.1 & 6.7 & 6.4 & 0.3 & 0.2 & 0.4 & 6.5 \\
M3AW & 2 & 4.8 & 5.9 & 5.3 & 0.6 & 0.6 & 0.8 & 14.7 \\
M3PW & 2 & 4.3 & 4.6 & 4.4 & 0.2 & 0.1 & 0.3 & 6.2 \\
M4L & 2 & 6.4 & 6.6 & 6.5 & 0.1 & 0.0 & 0.2 & 2.9 \\
M4AW & 2 & 4.7 & 4.9 & 4.8 & 0.1 & 0.0 & 0.2 & 3.2 \\
\hline & 3.4 & 4.0 & 3.7 & 0.3 & 0.2 & 0.4 & 11.4 \\
\hline MPW & 2 & & & & & & &
\end{tabular}


APPENDIX 3.

Univariate statistics for teeth of Ganawamaya gillespieae comb. nov. Rounded to one decimal place. Measurements are in $\mathrm{mm}$. Abbreviations are the same as Appendix 2.

\begin{tabular}{|c|c|c|c|c|c|c|c|c|}
\hline & $\mathbf{N}$ & Min & Max & Mean & SE & VA & SD & CV \\
\hline p3L & 3 & 6.6 & 6.8 & 6.7 & 0.1 & 0.0 & 0.1 & 2.1 \\
\hline p3W & 3 & 3.6 & 4.1 & 3.9 & 0.1 & 0.1 & 0.2 & 6.3 \\
\hline $\mathrm{m} 1 \mathrm{~L}$ & 4 & 5.5 & 6.3 & 6.0 & 0.2 & 0.1 & 0.4 & 6.1 \\
\hline m1AW & 4 & 3.1 & 3.9 & 3.4 & 0.2 & 0.1 & 0.3 & 9.2 \\
\hline m1PW & 4 & 4.0 & 4.3 & 4.2 & 0.1 & 0.0 & 0.2 & 3.9 \\
\hline $\mathrm{m} 2 \mathrm{~L}$ & 4 & 6.3 & 6.6 & 6.4 & 0.1 & 0.0 & 0.1 & 2.1 \\
\hline m2AW & 4 & 4.1 & 4.6 & 4.3 & 0.1 & 0.0 & 0.2 & 5.1 \\
\hline $\mathrm{m} 2 \mathrm{PW}$ & 5 & 4.4 & 4.5 & 4.5 & 0.0 & 0.0 & 0.1 & 1.1 \\
\hline $\mathrm{m} 3 \mathrm{~L}$ & 5 & 6.2 & 7.4 & 6.7 & 0.2 & 0.2 & 0.5 & 6.8 \\
\hline m3AW & 5 & 4.7 & 5.1 & 4.8 & 0.1 & 0.0 & 0.2 & 4.5 \\
\hline m3PW & 5 & 4.4 & 4.7 & 4.6 & 0.1 & 0.0 & 0.1 & 2.7 \\
\hline $\mathrm{m} 4 \mathrm{~L}$ & 3 & 6.4 & 7.4 & 6.8 & 0.3 & 0.3 & 0.5 & 7.9 \\
\hline m4AW & 3 & 4.4 & 4.8 & 4.6 & 0.1 & 0.1 & 0.2 & 4.9 \\
\hline m4PW & 3 & 3.9 & 4.4 & 4.1 & 0.1 & 0.1 & 0.2 & 5.7 \\
\hline P3L & 3 & 6.7 & 6.9 & 6.8 & 0.0 & 0.0 & 0.1 & 1.1 \\
\hline P3W & 3 & 4.2 & 4.3 & 4.3 & 0.0 & 0.0 & 0.1 & 1.2 \\
\hline M1L & 5 & 5.9 & 6.4 & 6.2 & 0.1 & 0.0 & 0.2 & 3.4 \\
\hline M1AW & 5 & 5.2 & 6.1 & 5.5 & 0.2 & 0.1 & 0.4 & 6.4 \\
\hline M1PW & 5 & 4.5 & 5.2 & 4.9 & 0.1 & 0.1 & 0.3 & 6.3 \\
\hline M2L & 6 & 6.2 & 7.0 & 6.7 & 0.1 & 0.1 & 0.3 & 4.4 \\
\hline M2AW & 6 & 5.7 & 5.8 & 5.7 & 0.0 & 0.0 & 0.0 & 0.8 \\
\hline M2PW & 6 & 4.7 & 5.1 & 4.8 & 0.1 & 0.0 & 0.2 & 3.5 \\
\hline M3L & 5 & 6.8 & 7.6 & 7.0 & 0.1 & 0.1 & 0.3 & 4.7 \\
\hline M3AW & 5 & 5.6 & 6.2 & 5.8 & 0.1 & 0.1 & 0.2 & 4.2 \\
\hline M3PW & 5 & 4.6 & 5.1 & 4.8 & 0.1 & 0.0 & 0.2 & 3.9 \\
\hline M4L & 4 & 6.5 & 7.0 & 6.8 & 0.1 & 0.1 & 0.2 & 3.5 \\
\hline M4AW & 4 & 5.1 & 5.7 & 5.4 & 0.1 & 0.1 & 0.3 & 5.2 \\
\hline M4PW & 4 & 4.1 & 4.3 & 4.2 & 0.1 & 0.0 & 0.1 & 3.0 \\
\hline
\end{tabular}




\section{APPENDIX 4.}

Univariate statistics for teeth of Ganawamaya acris. Rounded to one decimal place. Measurements are in $\mathrm{mm}$. Abbreviations are the same as Appendix 2.

\begin{tabular}{|c|c|c|c|c|c|c|c|c|}
\hline & $\mathbf{N}$ & Min & Max & Mean & SE & VA & SE & $\mathrm{CV}$ \\
\hline p3L & 20 & 5.7 & 7.3 & 6.5 & 0.1 & 0.2 & 0.5 & 7.0 \\
\hline p3W & 16 & 2.9 & 4.4 & 3.8 & 0.1 & 0.1 & 0.4 & 9.8 \\
\hline $\mathrm{m} 1 \mathrm{~L}$ & 22 & 5.0 & 7.0 & 6.2 & 0.1 & 0.2 & 0.5 & 7.6 \\
\hline m1AW & 21 & 2.9 & 4.0 & 3.5 & 0.1 & 0.1 & 0.3 & 7.4 \\
\hline m1PW & 21 & 3.8 & 4.7 & 4.2 & 0.1 & 0.1 & 0.2 & 5.8 \\
\hline $\mathrm{m} 2 \mathrm{~L}$ & 19 & 6.0 & 7.6 & 6.6 & 0.1 & 0.2 & 0.5 & 7.4 \\
\hline m2AW & 19 & 4.0 & 5.1 & 4.4 & 0.1 & 0.1 & 0.2 & 5.5 \\
\hline $\mathrm{m} 2 \mathrm{PW}$ & 19 & 4.2 & 5.2 & 4.7 & 0.1 & 0.1 & 0.3 & 5.5 \\
\hline $\mathrm{m} 3 \mathrm{~L}$ & 21 & 6.6 & 7.9 & 7.1 & 0.1 & 0.1 & 0.4 & 5.1 \\
\hline m3AW & 21 & 4.5 & 5.4 & 4.8 & 0.1 & 0.1 & 0.2 & 4.8 \\
\hline m3PW & 21 & 4.5 & 5.2 & 4.8 & 0.0 & 0.0 & 0.2 & 4.5 \\
\hline $\mathrm{m} 4 \mathrm{~L}$ & 12 & 6.7 & 7.7 & 7.1 & 0.1 & 0.1 & 0.3 & 4.4 \\
\hline m4AW & 12 & 4.5 & 5.0 & 4.7 & 0.0 & 0.0 & 0.2 & 3.5 \\
\hline $\mathrm{m} 4 \mathrm{PW}$ & 11 & 4.0 & 4.6 & 4.3 & 0.1 & 0.0 & 0.2 & 4.4 \\
\hline P3L & 14 & 6.7 & 8.0 & 7.3 & 0.1 & 0.1 & 0.4 & 5.3 \\
\hline P3W & 14 & 4.1 & 5.6 & 4.7 & 0.1 & 0.2 & 0.4 & 8.8 \\
\hline M1L & 23 & 5.9 & 7.4 & 6.6 & 0.1 & 0.1 & 0.4 & 5.5 \\
\hline M1AW & 22 & 5.2 & 6.1 & 5.7 & 0.0 & 0.0 & 0.2 & 3.9 \\
\hline M1PW & 23 & 4.8 & 5.6 & 5.2 & 0.1 & 0.1 & 0.2 & 4.6 \\
\hline M2L & 30 & 6.0 & 7.5 & 6.9 & 0.1 & 0.1 & 0.4 & 5.4 \\
\hline M2AW & 28 & 5.5 & 7.0 & 6.2 & 0.1 & 0.1 & 0.3 & 5.0 \\
\hline M2PW & 30 & 4.8 & 5.7 & 5.3 & 0.0 & 0.1 & 0.2 & 4.5 \\
\hline M3L & 27 & 5.7 & 8.1 & 7.3 & 0.1 & 0.3 & 0.5 & 6.9 \\
\hline M3AW & 25 & 5.5 & 6.7 & 6.1 & 0.1 & 0.1 & 0.3 & 5.6 \\
\hline M3PW & 25 & 4.6 & 5.9 & 5.3 & 0.1 & 0.1 & 0.3 & 6.6 \\
\hline M4L & 20 & 5.9 & 8.6 & 7.2 & 0.1 & 0.4 & 0.6 & 8.9 \\
\hline M4AW & 20 & 5.2 & 6.1 & 5.6 & 0.1 & 0.1 & 0.3 & 5.1 \\
\hline M4PW & 18 & 3.7 & 4.8 & 4.3 & 0.1 & 0.1 & 0.3 & 7.6 \\
\hline
\end{tabular}




\section{APPENDIX 5.}

Results of Kruskal-Wallis test comparing each of the four Ganawamaya species for each dental measurement. Bold indicates statistical significance. $\mathrm{H}=$ test statistic for Kruskal-Wallis test.

\begin{tabular}{|c|c|c|}
\hline Measurement & $P$ value & $H\left(X^{2}\right)$ \\
\hline p3L & $1.87 \times 10^{-03}$ & 14.92 \\
\hline p3W & 0.03 & 8.60 \\
\hline $\mathrm{m} 1 \mathrm{~L}$ & $7.79 \times 10^{-03}$ & 11.83 \\
\hline m1AW & 0.05 & 7.76 \\
\hline m1PW & $5.73 \times 10^{-04}$ & 17.43 \\
\hline $\mathrm{m} 2 \mathrm{~L}$ & 0.06 & 7.24 \\
\hline m2AW & 0.09 & 6.24 \\
\hline $\mathrm{m} 2 \mathrm{PW}$ & 0.01 & 10.28 \\
\hline $\mathrm{m} 3 \mathrm{~L}$ & $8.74 \times 10^{-05}$ & 21.38 \\
\hline m3AW & $1.63 \times 10^{-04}$ & 20.06 \\
\hline m3PW & $2.18 \times 10^{-04}$ & 19.47 \\
\hline $\mathrm{m} 4 \mathrm{~L}$ & 0.32 & 2.27 \\
\hline m4AW & 0.03 & 3.89 \\
\hline m4PW & 0.31 & 2.35 \\
\hline P3L & 0.03 & 8.62 \\
\hline P3W & 0.04 & 8.22 \\
\hline M1L & $5.19 \times 10^{-03}$ & 12.74 \\
\hline M1AW & 0.01 & 10.55 \\
\hline M1PW & $4.62 \times 10^{-03}$ & 17.88 \\
\hline M2L & 0.02 & 9.77 \\
\hline M2AW & $2.65 \times 10^{-04}$ & 19.06 \\
\hline M2PW & $4.02 \times 10^{-05}$ & 23 \\
\hline M3L & 0.04 & 6.33 \\
\hline M3AW & 0.07 & 5.29 \\
\hline M3PW & $3.78 \times 10^{-03}$ & 11.15 \\
\hline M4L & 0.09 & 4.78 \\
\hline M4AW & 0.05 & 5.89 \\
\hline M4PW & 0.07 & 5.31 \\
\hline
\end{tabular}




\section{APPENDIX 6.}

Results of Mann-Whitney $U$ tests for each molar comparing measurements for each species. Rounded to two decimal places. $P$ values lower than 0.01 are listed as ' $<0.01$ '. Bold numbers represent species which differ significantly $(p<0.05)$.

\begin{tabular}{|c|c|c|c|c|}
\hline & G. acris & $\begin{array}{l}\text { G. gillespieae } \\
\text { comb. nov. }\end{array}$ & G. aediculis & $\begin{array}{l}\text { G. couperi } \\
\text { comb. nov. }\end{array}$ \\
\hline \multicolumn{5}{|l|}{ p3 length } \\
\hline G. acris & & 0.32 & 0.02 & 0.01 \\
\hline G. gillespieae comb. nov. & 0.32 & & 0.01 & 0.08 \\
\hline G. aediculis & 0.02 & 0.01 & & 0.01 \\
\hline G. couperi comb. nov. & 0.01 & 0.08 & 0.01 & \\
\hline \multicolumn{5}{|l|}{ p3 width } \\
\hline G. acris & & 0.61 & 0.13 & 0.02 \\
\hline G. gillespieae comb. nov. & 0.61 & & 0.15 & 0.08 \\
\hline G. aediculis & 0.13 & 0.15 & & 0.08 \\
\hline G. couperi comb. nov. & 0.02 & 0.08 & 0.08 & \\
\hline \multicolumn{5}{|l|}{ m1 length } \\
\hline G. acris & & 0.59 & 0.03 & 0.01 \\
\hline G. gillespieae comb. nov. & 0.59 & & 0.27 & 0.05 \\
\hline G. aediculis & 0.03 & 0.27 & & 0.02 \\
\hline G. couperi comb. nov. & 0.01 & 0.05 & 0.02 & \\
\hline \multicolumn{5}{|l|}{ m1 anterior width } \\
\hline G. acris & & 0.60 & 0.18 & 0.02 \\
\hline G. gillespieae comb. nov. & 0.60 & & 0.93 & 0.11 \\
\hline G. aediculis & 0.18 & 0.93 & & 0.03 \\
\hline G. couperi comb. nov. & 0.02 & 0.11 & 0.03 & \\
\hline \multicolumn{5}{|l|}{ m1 posterior width } \\
\hline G. acris & & 0.88 & $<0.01$ & 0.01 \\
\hline G. gillespieae comb. nov. & 0.88 & & 0.02 & 0.05 \\
\hline G. aediculis & $<0.01$ & 0.02 & & 0.02 \\
\hline G. couperi comb. nov. & 0.01 & 0.05 & 0.02 & \\
\hline \multicolumn{5}{|l|}{ m2 length } \\
\hline G. acris & & 0.68 & 0.17 & 0.03 \\
\hline G. gillespieae comb. nov. & 0.68 & & 0.52 & 0.11 \\
\hline G. aediculis & 0.17 & 0.52 & & 0.07 \\
\hline G. couperi comb. nov. & 0.03 & 0.11 & 0.07 & \\
\hline \multicolumn{5}{|l|}{ m2 anterior width } \\
\hline G. acris & & 0.66 & 0.32 & 0.03 \\
\hline G. gillespieae comb. nov. & 0.66 & & 0.83 & 0.11 \\
\hline G. aediculis & 0.32 & 0.83 & & 0.07 \\
\hline G. couperi comb. nov. & 0.03 & 0.11 & 0.07 & \\
\hline \multicolumn{5}{|l|}{ m2 posterior width } \\
\hline G. acris & & 0.17 & 0.04 & 0.03 \\
\hline G. gillespieae comb. nov. & 0.17 & & 0.41 & 0.08 \\
\hline G. aediculis & 0.04 & 0.41 & & 0.13 \\
\hline G. couperi comb. nov. & 0.03 & 0.08 & 0.13 & \\
\hline
\end{tabular}


BUtLER ET AL.: REVISION OF OLIGO-MIOCENE KANGAROOS

\begin{tabular}{|c|c|c|c|c|}
\hline & G. acris & $\begin{array}{l}\text { G. gillespieae } \\
\text { comb. nov. }\end{array}$ & G. aediculis & $\begin{array}{l}\text { G. couperi } \\
\text { comb. nov. }\end{array}$ \\
\hline \multicolumn{5}{|l|}{ m3 length } \\
\hline G. acris & & 0.07 & $<0.01$ & 0.01 \\
\hline G. gillespieae comb. nov. & 0.07 & & 0.35 & 0.04 \\
\hline G. aediculis & $<0.01$ & 0.35 & & 0.02 \\
\hline G. couperi comb. nov. & 0.01 & 0.04 & 0.02 & \\
\hline \multicolumn{5}{|l|}{ m3 anterior width } \\
\hline G. acris & & 0.28 & $<0.01$ & 0.01 \\
\hline G. gillespieae comb. nov. & 0.28 & & 0.02 & 0.03 \\
\hline G. aediculis & $<0.01$ & 0.02 & & 0.02 \\
\hline G. couperi comb. nov. & 0.01 & 0.03 & 0.02 & \\
\hline \multicolumn{5}{|l|}{ m3 posterior width } \\
\hline G. acris & & 0.05 & $<0.01$ & 0.01 \\
\hline G. gillespieae comb. nov. & 0.05 & & 0.14 & 0.04 \\
\hline G. aediculis & $<0.01$ & 0.14 & & 0.04 \\
\hline G. couperi comb. nov. & 0.01 & 0.04 & 0.04 & \\
\hline \multicolumn{5}{|l|}{ m4 length } \\
\hline G. acris & & 0.28 & 0.25 & \\
\hline G. gillespieae comb. nov. & 0.28 & & 0.65 & \\
\hline G. aediculis & 0.25 & 0.65 & & \\
\hline \multicolumn{5}{|l|}{ m4 anterior width } \\
\hline G. acris & & 0.39 & 0.01 & \\
\hline G. gillespieae comb. nov. & 0.39 & & 0.20 & \\
\hline G. aediculis & 0.01 & 0.20 & & \\
\hline \multicolumn{5}{|l|}{ m4 posterior width } \\
\hline G. acris & & 0.19 & 0.25 & \\
\hline G. gillespieae comb. nov. & 0.19 & & 0.93 & \\
\hline G. aediculis & 0.25 & 0.93 & & \\
\hline \multicolumn{5}{|l|}{ P3 length } \\
\hline G. acris & & 0.13 & 0.15 & 0.03 \\
\hline G. gillespieae comb. nov. & 0.13 & & 0.82 & 0.15 \\
\hline G. aediculis & 0.15 & 0.82 & & 0.15 \\
\hline G. couperi comb. nov. & 0.03 & 0.15 & 0.15 & \\
\hline \multicolumn{5}{|l|}{ P3 width } \\
\hline G. acris & & 0.17 & 0.17 & 0.03 \\
\hline G. gillespieae comb. nov. & 0.17 & & 0.82 & 0.15 \\
\hline G. aediculis & 0.17 & 0.82 & & 0.15 \\
\hline G. couperi comb. nov. & 0.03 & 0.15 & 0.15 & \\
\hline \multicolumn{5}{|l|}{ M1 length } \\
\hline G. acris & & 0.05 & 0.02 & 0.02 \\
\hline G. gillespieae comb. nov. & 0.05 & & 0.27 & 0.08 \\
\hline G. aediculis & 0.02 & 0.27 & & 0.11 \\
\hline G. couperi comb. nov. & 0.02 & 0.08 & 0.11 & \\
\hline \multicolumn{5}{|l|}{ M1 anterior width } \\
\hline G. acris & & 0.18 & 0.03 & 0.02 \\
\hline
\end{tabular}




\begin{tabular}{|c|c|c|c|c|}
\hline & G. acris & $\begin{array}{l}\text { G. gillespieae } \\
\text { comb. nov. }\end{array}$ & G. aediculis & $\begin{array}{l}\text { G. couperi } \\
\text { comb. nov. }\end{array}$ \\
\hline G. gillespieae comb. nov. & 0.18 & & 0.90 & 0.08 \\
\hline G. aediculis & 0.03 & 0.90 & & 0.11 \\
\hline G. couperi comb. nov. & 0.02 & 0.08 & 0.11 & \\
\hline \multicolumn{5}{|l|}{ M1 posterior width } \\
\hline G. acris & & 0.01 & $<0.01$ & 0.02 \\
\hline G. gillespieae comb. nov. & 0.01 & & 0.27 & 0.08 \\
\hline G. aediculis & $<0.01$ & 0.27 & & 0.11 \\
\hline G. couperi comb. nov. & 0.02 & 0.08 & 0.11 & \\
\hline \multicolumn{5}{|l|}{ M2 length } \\
\hline G. acris & & 0.64 & 0.04 & 0.02 \\
\hline G. gillespieae comb. nov. & 0.64 & & 0.17 & 0.07 \\
\hline G. aediculis & 0.04 & 0.17 & & 0.11 \\
\hline G. couperi comb. nov. & 0.02 & 0.07 & 0.11 & \\
\hline \multicolumn{5}{|l|}{ M2 anterior width } \\
\hline G. acris & & $<0.01$ & $<0.01$ & 0.02 \\
\hline G. gillespieae comb. nov. & $<0.01$ & & 0.24 & 0.07 \\
\hline G. aediculis & $<0.01$ & 0.24 & & 0.11 \\
\hline G. couperi comb. nov. & 0.02 & 0.07 & 0.11 & \\
\hline \multicolumn{5}{|l|}{ M2 posterior width } \\
\hline G. acris & & $<0.01$ & $<0.01$ & 0.02 \\
\hline G. gillespieae comb. nov. & $<0.01$ & & 0.11 & 0.07 \\
\hline G. aediculis & $<0.01$ & 0.11 & & 0.10 \\
\hline G. couperi comb. nov. & 0.02 & 0.07 & 0.10 & \\
\hline \multicolumn{5}{|l|}{ M3 length } \\
\hline G. acris & & 0.12 & 0.05 & \\
\hline G. gillespieae & 0.12 & & 0.08 & \\
\hline G. aediculis & 0.05 & 0.08 & & \\
\hline \multicolumn{5}{|l|}{ M3 anterior width } \\
\hline G. acris & & 0.11 & 0.09 & \\
\hline G. gillespieae comb. nov. & 0.11 & & 0.56 & \\
\hline G. aediculis & 0.09 & 0.56 & & \\
\hline \multicolumn{5}{|l|}{ M3 posterior width } \\
\hline G. acris & & 0.01 & 0.03 & \\
\hline G. gillespieae comb. nov. & 0.01 & & 0.18 & \\
\hline G. aediculis & 0.03 & 0.18 & & \\
\hline \multicolumn{5}{|l|}{ M4 length } \\
\hline G. acris & & 0.10 & 0.15 & \\
\hline G. gillespieae comb. nov. & 0.10 & & 0.25 & \\
\hline G. aediculis & 0.15 & 0.25 & & \\
\hline \multicolumn{5}{|l|}{ M4 anterior width } \\
\hline G. acris & & 0.44 & 0.03 & \\
\hline G. gillespieae comb. nov. & 0.44 & & 0.11 & \\
\hline G. aediculis & 0.03 & 0.11 & & \\
\hline
\end{tabular}

M4 posterior width

G. acris

0.20

0.07 
BUTLER ET AL.: REVISION OF OLIGO-MIOCENE KANGAROOS

\begin{tabular}{lcccc}
\hline & G. acris & $\begin{array}{c}\text { G. gillespieae } \\
\text { comb. nov. }\end{array}$ & G. aediculis & $\begin{array}{c}\text { G. couperi } \\
\text { comb. nov. }\end{array}$ \\
\hline $\begin{array}{l}\text { G. gillespieae comb. nov. } \\
\text { G. aediculis }\end{array}$ & 0.20 & & 0.11 \\
\\
\hline
\end{tabular}




\section{APPENDIX 7.}

Summary statistics of principal component analysis of lower tooth measurements for Ganawamaya acris, G. aediculis, G. gillespieae comb. nov. and G. couperi comb. nov. (rounded to one decimal place).

\begin{tabular}{cccccccccccccccccc}
\hline $\mathbf{P C}$ & $\begin{array}{c}\text { Eigen } \\
\text { value }\end{array}$ & $\begin{array}{c}\text { varianc } \\
\mathbf{e}\end{array}$ & & $\mathbf{P C}$ & $\mathbf{P C}$ & $\mathbf{P C}$ & $\mathbf{P C}$ & $\mathbf{P C}$ & $\mathbf{P C}$ & $\mathbf{P C}$ & $\mathbf{P C}$ & $\mathbf{P C}$ & $\mathbf{P C}$ & $\mathbf{P C}$ & $\mathbf{P C}$ & $\mathbf{P C}$ & $\mathbf{P C}$ \\
& & & $\mathbf{1}$ & $\mathbf{2}$ & $\mathbf{3}$ & $\mathbf{4}$ & $\mathbf{5}$ & $\mathbf{6}$ & $\mathbf{7}$ & $\mathbf{8}$ & $\mathbf{9}$ & $\mathbf{1 0}$ & $\mathbf{1 1}$ & $\mathbf{1 2}$ & $\mathbf{1 3}$ & $\mathbf{1 4}$ \\
\hline 1 & 1.0 & 62.7 & $\mathrm{p} 3 \mathrm{~L}$ & 0.3 & 0.7 & 0.0 & 0.1 & 0.0 & -0.6 & 0.0 & -0.2 & 0.0 & -0.1 & 0.0 & 0.0 & -0.2 & 0.0 \\
2 & 0.2 & 10.0 & $\mathrm{p} 3 \mathrm{~W}$ & 0.2 & 0.5 & 0.2 & -0.1 & 0.3 & 0.6 & -0.3 & 0.2 & -0.1 & 0.0 & 0.1 & 0.1 & 0.0 & -0.1 \\
3 & 0.1 & 6.5 & $\mathrm{~m} 1 \mathrm{~L}$ & 0.3 & 0.0 & 0.1 & -0.5 & -0.8 & 0.1 & -0.2 & 0.1 & 0.0 & -0.1 & 0.1 & 0.1 & -0.1 & 0.0 \\
4 & 0.1 & 6.2 & $\mathrm{~m} 1 \mathrm{AW}$ & 0.1 & 0.1 & 0.1 & -0.1 & 0.1 & 0.2 & 0.8 & -0.1 & -0.4 & 0.0 & 0.0 & 0.3 & -0.2 & 0.2 \\
5 & 0.1 & 4.8 & $\mathrm{~m} 1 \mathrm{PW}$ & 0.2 & 0.2 & 0.1 & -0.2 & 0.0 & 0.1 & 0.3 & 0.0 & 0.3 & 0.3 & -0.3 & -0.5 & 0.4 & -0.1 \\
6 & 0.0 & 2.7 & $\mathrm{~m} 2 \mathrm{~L}$ & 0.3 & -0.4 & 0.4 & -0.2 & 0.3 & -0.2 & -0.3 & -0.1 & -0.4 & 0.4 & -0.1 & -0.1 & -0.2 & -0.0 \\
7 & 0.0 & 1.7 & $\mathrm{~m} 2 \mathrm{AW}$ & 0.2 & -0.2 & 0.2 & -0.1 & 0.2 & -0.2 & 0.1 & 0.0 & 0.0 & -0.5 & 0.3 & 0.2 & 0.4 & -0.5 \\
8 & 0.0 & 1.5 & $\mathrm{~m} 2 \mathrm{PW}$ & 0.2 & -0.2 & 0.1 & -0.1 & 0.3 & -0.1 & 0.0 & 0.2 & 0.6 & -0.3 & -0.2 & 0.2 & -0.2 & 0.4 \\
9 & 0.0 & 1.0 & $\mathrm{~m} 3 \mathrm{~L}$ & 0.5 & -0.1 & -0.4 & 0.3 & 0.0 & 0.2 & -0.1 & -0.3 & -0.2 & -0.3 & -0.4 & 0.0 & 0.1 & -0.0 \\
10 & 0.0 & 0.8 & $\mathrm{~m} 3 \mathrm{AW}$ & 0.3 & -0.1 & -0.2 & 0.1 & 0.1 & 0.0 & 0.1 & 0.2 & -0.1 & 0.0 & 0.6 & -0.4 & 0.1 & 0.5 \\
11 & 0.0 & 0.7 & $\mathrm{~m} 3 \mathrm{PW}$ & 0.3 & 0.0 & -0.3 & 0.1 & 0.1 & 0.0 & 0.1 & 0.1 & 0.3 & 0.5 & 0.2 & 0.3 & -0.2 & -0.4 \\
12 & 0.0 & 0.6 & $\mathrm{~m} 4 \mathrm{~L}$ & 0.1 & -0.1 & 0.5 & 0.5 & -0.2 & 0.2 & 0.1 & -0.4 & 0.3 & 0.0 & 0.2 & -0.2 & -0.2 & -0.1 \\
13 & 0.01 & 0.4 & $\mathrm{~m} 4 \mathrm{AW}$ & 0.1 & -0.0 & 0.2 & 0.4 & -0.2 & -0.2 & 0.2 & 0.7 & -0.2 & -0.1 & -0.2 & -0.1 & -0.1 & -0.1 \\
14 & 0.00 & 0.3 & $\mathrm{~m} 4 \mathrm{PW}$ & 0.1 & 0.0 & 0.2 & 0.29 & -0.1 & -0.1 & -0.1 & 0.0 & 0.0 & 0.3 & 0.0 & 0.5 & 0.6 & 0.3 \\
\hline
\end{tabular}




\section{APPENDIX 8.}

Summary statistics of principal component analysis of upper tooth measurements for Ganawamaya acris, G. aediculis and G. gillespieae comb. nov. (rounded to two decimal places).

\begin{tabular}{|c|c|c|c|c|c|c|c|c|c|c|c|c|c|c|c|c|c|}
\hline \multirow[b]{2}{*}{ PC } & \multirow[b]{2}{*}{$\begin{array}{l}\text { Eigen } \\
\text { value }\end{array}$} & \multirow[b]{2}{*}{$\begin{array}{c}\% \\
\text { variance }\end{array}$} & & \multirow[b]{2}{*}{$\begin{array}{c}\mathrm{PC} \\
1\end{array}$} & \multirow[b]{2}{*}{$\begin{array}{c}\mathrm{PC} \\
2\end{array}$} & \multirow[b]{2}{*}{$\begin{array}{c}\mathrm{PC} \\
3\end{array}$} & \multirow[b]{2}{*}{$\begin{array}{c}\mathrm{PC} \\
4\end{array}$} & \multirow[b]{2}{*}{$\begin{array}{c}\mathrm{PC} \\
5\end{array}$} & \multirow[b]{2}{*}{$\begin{array}{c}\mathrm{PC} \\
6\end{array}$} & \multicolumn{2}{|c|}{ Loadings } & \multirow[b]{2}{*}{$\begin{array}{c}\text { PC } \\
9\end{array}$} & \multirow[b]{2}{*}{$\begin{array}{l}\text { PC } \\
10\end{array}$} & \multirow[b]{2}{*}{$\begin{array}{l}\text { PC } \\
11\end{array}$} & \multirow[b]{2}{*}{$\begin{array}{c}\mathrm{PC} \\
12\end{array}$} & \multirow[b]{2}{*}{$\begin{array}{l}\mathrm{PC} \\
13\end{array}$} & \multirow[b]{2}{*}{$\begin{array}{l}P C \\
14\end{array}$} \\
\hline & & & & & & & & & & $\begin{array}{c}\mathrm{PC} \\
7\end{array}$ & $\begin{array}{c}\mathrm{PC} \\
8\end{array}$ & & & & & & \\
\hline 1 & 1.8 & 63.8 & P3L & 0.3 & -0.3 & 0.2 & 0.1 & -0.1 & -0.5 & -0.1 & 0.3 & 0.1 & -0.2 & 0.3 & 0.3 & 0.1 & -0.4 \\
\hline 2 & 0.5 & 17.7 & P3W & 0.2 & -0.1 & 0.3 & 0.2 & 0.0 & -0.3 & -0.4 & 0.0 & 0.3 & 0.3 & -0.3 & -0.2 & 0.0 & 0.4 \\
\hline 3 & 0.1 & 4.8 & M1L & 0.3 & -0.3 & 0.3 & 0.1 & -0.3 & 0.5 & -0.2 & -0.5 & -0.1 & -0.1 & 0.0 & 0.0 & 0.0 & -0.2 \\
\hline 4 & 0.1 & 3.7 & M1AW & 0.3 & -0.3 & 0.1 & 0.0 & 0.1 & 0.0 & 0.5 & 0.0 & -0.3 & 0.6 & 0.2 & -0.3 & -0.1 & -0.0 \\
\hline 5 & 0.1 & 2.6 & M1PW & 0.3 & -0.3 & 0.1 & 0.0 & 0.1 & 0.3 & 0.3 & 0.3 & 0.0 & -0.6 & -0.2 & 0.0 & -0.2 & 0.4 \\
\hline 6 & 0.1 & 1.9 & M2L & 0.4 & 0.0 & -0.4 & -0.4 & -0.5 & 0.0 & 0.1 & 0.0 & 0.5 & 0.1 & 0.1 & -0.1 & 0.0 & 0.1 \\
\hline 7 & 0.0 & 1.2 & M2AW & 0.4 & 0.0 & -0.4 & -0.1 & 0.3 & -0.3 & -0.1 & -0.4 & -0.2 & -0.2 & -0.3 & 0.0 & -0.3 & -0.2 \\
\hline 8 & 0.0 & 1.1 & M2PW & 0.3 & -0.1 & -0.3 & 0.0 & 0.3 & 0.3 & -0.3 & 0.3 & -0.2 & 0.2 & 0.1 & 0.2 & 0.5 & 0.2 \\
\hline 9 & 0.0 & 1.0 & M3L & 0.3 & 0.4 & -0.1 & 0.5 & -0.5 & -0.1 & 0.2 & 0.1 & -0.4 & 0.0 & -0.2 & 0.0 & 0.1 & 0.1 \\
\hline 10 & 0.0 & 0.7 & M3AW & 0.2 & 0.3 & 0.0 & 0.3 & 0.2 & 0.0 & -0.1 & -0.2 & 0.1 & -0.2 & 0.7 & -0.4 & 0.0 & 0.2 \\
\hline 11 & 0.0 & 0.6 & M3PW & 0.2 & 0.3 & 0.0 & 0.2 & 0.2 & 0.4 & -0.1 & 0.4 & 0.3 & 0.2 & -0.1 & 0.0 & -0.5 & -0.4 \\
\hline 12 & 0.0 & 0.4 & M4L & 0.2 & 0.4 & 0.4 & -0.6 & 0.0 & 0.0 & -0.2 & 0.1 & -0.3 & -0.1 & 0.0 & -0.1 & 0.0 & 0.0 \\
\hline 13 & 0.01 & 0.3 & M4AW & 0.2 & 0.3 & 0.2 & -0.0 & 0.24 & -0.0 & 0.4 & -0.2 & 0.4 & -0.1 & -0.4 & -0.1 & 0.5 & -0.3 \\
\hline 14 & 0.01 & 0.3 & M4PW & 0.2 & 0.2 & 0.1 & 0.0 & 0.11 & -0.0 & 0.2 & -0.3 & 0.1 & 0.2 & 0.2 & 0.7 & -0.2 & 0.3 \\
\hline
\end{tabular}

